\title{
JULIANA PUKa
}

\section{Perfil biomolecular do derrame pleural maligno experimentalmente induzido: frequência de mutações e impacto de terapias-alvo}

Tese apresentada à Faculdade de Medicina da Universidade de São Paulo para obtenção do título de Doutor em Ciências

Programa de Pneumologia

Orientadora: Prof. ${ }^{a}$ Dr. ${ }^{a}$ Lisete Ribeiro Teixeira

São Paulo

2016 
Dados Internacionais de Catalogação na Publicação (CIP)

Preparada pela Biblioteca da

Faculdade de Medicina da Universidade de São Paulo

Creprodução autorizada pelo autor

Puka, Juliana

Perfil biomolecular do derrame pleural maligno experimentalmente induzido: frequência de mutações e impacto de terapias-alvo / Juliana Puka. -- São Paulo, 2016.

Tese(doutorado)--Faculdade de Medicina da Universidade de São Paulo. Programa de Pneumologia.

Orientadora: Lisete Ribeiro Teixeira.

Descritores: 1.Derrame pleural maligno 2.Adenocarcinoma 3.Pleura

4.Modelos animais 5.Carcinoma pulmonar de Lewis 6.Terapia combinada

USP/FM/DBD-348/16 
Aos meus pais,

Diogenes (in memoriam) e Maria Madalena, com amor, admiração e gratidão.

E ao meu filho, Marcel, amor maior que ilumina minha vida e me faz sempre buscar o melhor de mim. 


\section{Agradecimentos}

Agradeço à amiga, professora e orientadora, Lisete Ribeiro Teixeira, por ter me recebido com tanto carinho no Grupo de Doenças Pleurais, por todos os ensinamentos, pela confiança e por acreditar que eu tinha alguma contribuição a dar. Mais do que isso, agradeço pela compreensão, pela paciência e pelo consolo em momentos tão difíceis da minha vida.

Agradeço à Milena Marques Acencio, pela fundamental ajuda no desenvolvimento desta tese, e às minhas amigas, que sempre torceram pelo meu sucesso na profissão, na vida e na conclusão deste trabalho. Em especial à Alessandra Torquato e à Vanessa Alvarenga, pela amizade e pelo companheirismo sem igual.

Agradeço a Diogenes (in memoriam) e Maria Madalena Puka, pelo exemplo, pela educação, por tudo que sempre fizeram por mim e por sempre me incentivarem a fazer o que amo. Todos os dias, agradeço a Deus por ter tido pessoas tão especiais como pais. À minha mãe, em especial, agradeço pela compreensão da ausência, pelo incansável apoio e, sobretudo, por me ajudar na conclusão deste trabalho. Sem você, nada disto seria possível.

Ao amor da minha vida, meu filho, pela alegria que me dá todos os dias por simplesmente existir e, mesmo sem saber, por sempre me incentivar a prosseguir nos momentos de fraqueza ou em que me considero incapaz.

Por fim, agradeço aos pacientes que tive oportunidade de conhecer durante o trabalho no Instituto do Câncer do Estado de São Paulo, por tudo que me ensinaram sobre a doença e sobre a vida.

À Fundação de Amparo à Pesquisa do Estado de São Paulo (FAPESP), meu agradecimento pelo apoio financeiro para a realização deste estudo. 
"O homem nasceu para aprender, aprender tanto quanto a vida lhe permita." Guimarães Rosa 
Esta tese está de acordo com as seguintes normas, em vigor no momento desta publicação:

Referências: adaptado de International Committee of Medical Journals Editors (Vancouver).

Universidade de São Paulo. Faculdade de Medicina. Divisão de Biblioteca e Documentação. Guia de apresentação de dissertações, teses e monografias. Elaborado por Anneliese Carneiro da Cunha, Maria Júlia de A. L. Freddi, Maria F. Crestana, Marinalva de Souza Aragão, Suely Campos Cardoso, Valéria Vilhena. $3^{a}$ ed. São Paulo: Divisão de Biblioteca e Documentação; 2011.

Abreviaturas dos títulos dos periódicos de acordo com List of Journals Indexed in Index Medicus. 


\section{SUMÁRIO}

Lista de abreviações e siglas

Lista de símbolos

Lista de figuras

Lista de tabelas

Resumo

Abstract

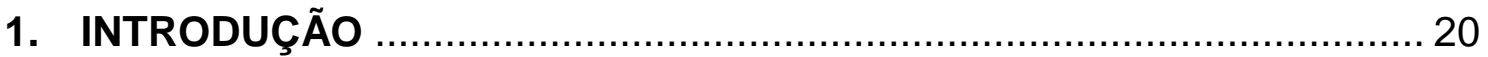

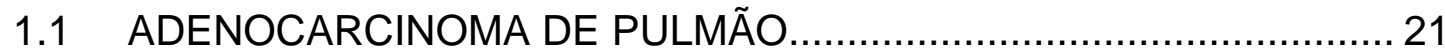

1.2 DERRAME PLEURAL MALIGNO ............................................... 23

1.3 TRATAMENTO DO DERRAME PLEURAL MALIGNO ........................ 25

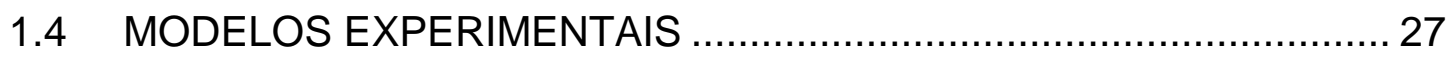

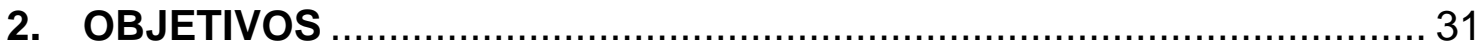

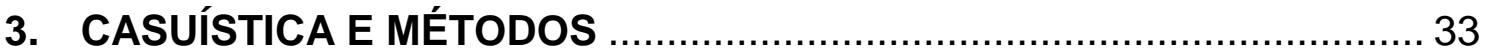

3.1 MODELO EXPERIMENTAL DE NEOPLASIA PLEURAL INDUZIDO COM DIFERENTES CONCENTRAÇÕES DE CÉLULAS NEOPLÁSICAS ... 34 3.2 AVALIAÇÃO DE TERAPIAS-ALVO EM NEOPLASIA PLEURAL EXPERIMENTALMENTE INDUZIDA

3.3 ANÁLISE IMUNOHISTOQUÍMICA EM NEOPLASIA PLEURAL EXPERIMENTALMENTE INDUZIDA ................................................ 42

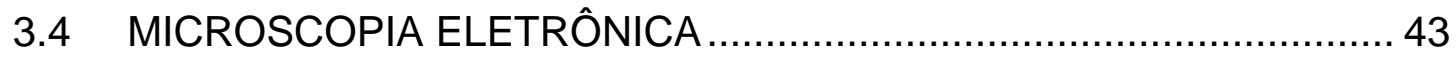

3.5 AVALIAÇÃO DA EXPRESSÃO GÊNICA DE VEGF, EGF, KRAS E ALK EM MODELO EXPERIMENTAL DE NEOPLASIA PLEURAL

3.6 AVALIAÇÃO DA FREQUÊNCIA DE MUTAÇÕES DO EGFR E DO KRAS EM MODELO EXPERIMENTAL DE NEOPLASIA PLEURAL ............ 45

3.7 ANÁLISE ESTATÍSTICA ..................................................... 46

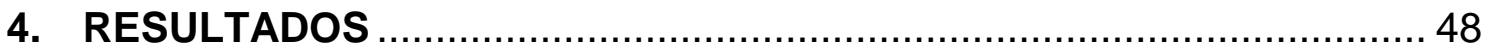

4.1 MODELO EXPERIMENTAL DE NEOPLASIA PLEURAL INDUZIDO COM DIFERENTES CONCENTRAÇÕES DE CÉLULAS NEOPLÁSICAS ... 48 4.2 ESTUDO DE TERAPIAS-ALVO EM NEOPLASIA PLEURAL EXPERIMENTALMENTE INDUZIDA 
4.3 ANÁLISE IMUNOHISTOQUÍMICA EM NEOPLASIA PLEURAL

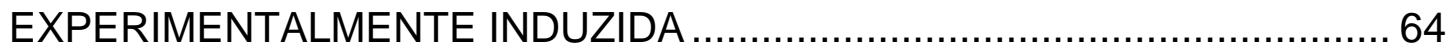

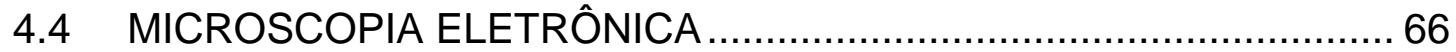

4.5 AVALIAÇÃO DA EXPRESSÃO GÊNICA DE VEGF, EGFR, KRAS E ALK EM MODELO EXPERIMENTAL DE NEOPLASIA PLEURAL ............... 70

4.6 AVALIAÇÃO DA FREQUÊNCIA DE MUTAÇÕES DO EGFR E DO KRAS EM MODELO EXPERIMENTAL DE NEOPLASIA PLEURAL ............ 72

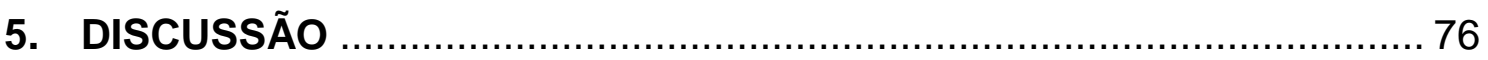

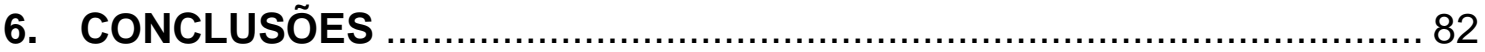

7. ANEXO

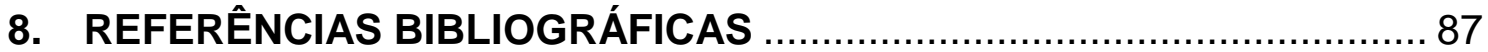

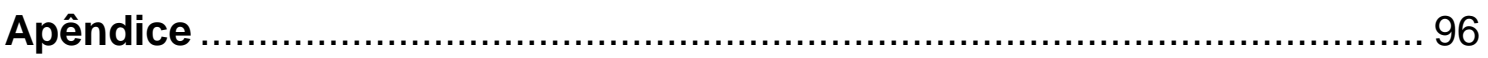




\section{Lista de abreviaturas e siglas}

ANOVA Analysis of Variance

ALK Anaplastic Lymphoma Kinase

ATCC American Type Culture Collection

ATP Adenosina Trifosfato

C57BL/6 Camundongos 57 black 6

CAPPesq Comitê de Ética e Pesquisa

CCL2 Chemokine Ligand 2

cDNA DNA complementar

CEA Carcinoembryonic Antigen

CEUA Comitê de Ética no Uso de Animais

CYFRA-21 Cytokeratin Fragment 21

DHL Desidrogenase Lática

DNA Deoxyribonucleic Acid

dNTPs Deoxynucleotide Triphosphates

EDTA Ethylenediamine Tetraacetic Acid

EGF Epidermal Growth Factor

EGFR Epidermal Growth Factor Receptor

ELISA Enzyme-Linked Immunosorben Assay

EML4 Echinoderm Microtubule-associated Protein-Like 4

EML4-ALK Fusão (translocação) de ALK com a proteína EML4

FMUSP Faculdade de Medicina da Universidade de São Paulo

GTP Guanosina Trifosfato

$\mathrm{H}_{2} \mathrm{O}_{2} \quad$ Peróxido de Hidrogênio

$\mathrm{H}_{2} \mathrm{SO}_{4} \quad$ Ácido Sulfúrico

H\&E Hematoxilina \& Eosina

IL Interleukin

INCA Instituto Nacional de Câncer

InCor Instituto do Coração

LLC Lewis Lung Cancer

MCP-1 Monocyte Chemoattractant Protein 1 

NF-kB Nuclear Factor Kappa B
OPN Osteopontin
OsO4 Tetróxido de ósmio
PBS Phosphate-Buffered Saline
PCNA Proliferating Cell Nuclear Antigen
PCR-RT Polymerase Chain Reaction real time
PDGF Platelet-derived Growth Factor
RNA Ribonucleic Acid
SF Solução Fisiológica
TGF- $\alpha \quad$ Transforming Growth Factor alpha
TGF- $\beta \quad$ Transforming Growth Factor beta
TNF Tumor Necrosis Factor
TUNEL Terminal Deoxyribonucleotide Nick-End Labeling
VEGF Vascular Endothelial Growth Factor 


\section{Lista de símbolos}

\begin{tabular}{|c|c|}
\hline$\%$ & Porcentagem \\
\hline${ }^{\circ} \mathrm{C}$ & Graus Celsius \\
\hline- & Negativo \\
\hline$X$ & Vezes \\
\hline $\mathrm{cm}$ & Centrímetro \\
\hline$\mu \mathrm{L}$ & Microlitro \\
\hline$\mu \mathrm{m}$ & Micrômetro \\
\hline$\mu \mathrm{g} / \mathrm{mL}$ & Micrograma/mililitro \\
\hline$g$ & Grama \\
\hline $\mathrm{g} / \mathrm{dL}$ & Grama/decilitro \\
\hline $\mathrm{G}$ & Gauge \\
\hline $\mathrm{mL}$ & Mililitro \\
\hline $\mathrm{mg}$ & Miligrama \\
\hline $\mathrm{mg} / \mathrm{kg}$ & Miligrama/quilograma \\
\hline $\mathrm{mg} / \mathrm{m}^{2}$ & Miligrama/metro-quadrado \\
\hline $\mathrm{mM}$ & Milimolar \\
\hline $\mathrm{mm}^{3}$ & Milímetro-cúbico \\
\hline $\mathrm{nm}$ & Nanômetro \\
\hline $\mathrm{ng} / \mu \mathrm{L}$ & Nanograma/microlitro \\
\hline $\mathrm{ng} / \mathrm{mL}$ & Nanograma/mililitro \\
\hline $\mathrm{pg} / \mathrm{mL}$ & Picograma/mililitro \\
\hline rpm & Rotações por minuto \\
\hline $\mathrm{J} / \mathrm{L}$ & Unidades internacionais/litro \\
\hline
\end{tabular}




\section{Lista de figuras}

Figura 1 - Camundongo C57BL/6 (Fonte: SDC/FMUSP) ................................ 33

Figura 2 - Células LLC (Fonte: Sonidel Limitada) .......................................... 33

Figura 3 - Modelo experimental de neoplasia pleural induzido com diferentes concentrações de células neoplásicas, sendo (A) com $1,5 \times 10^{5}$, (B) com $0,5 \times 10^{5}$ e (C) com $0,1 \times 10^{5}$ células LLC (40 animais por grupo)

Figura 4 - Modelo de estudo de terapias-alvo em neoplasia pleural experimentalmente induzida

Figura 5 - Avaliação do tempo de sobrevida após indução de neoplasia pleural com 1,5 (grupo C), 0,5 (grupo B) e $0,1 \times 10^{5}$ (grupo A) células LLC 48

Figura 6 - Volume, total de células e parâmetros bioquímicos do líquido pleural de camundongos submetidos à indução de neoplasia pleural com 1,5

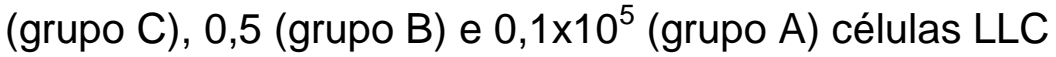

Figura 7 - Histologia de pleura, pulmão e diafragma de camundongos submetidos à injeção intrapleural de células LLC

Figura 8 - Histologia de outros órgãos de camundongos submetidos à injeção intrapleural de células LLC

Figura 9 - Curva de sobrevida comparativa de camundongos com doença pleural maligna não tratados e tratados.

Figura 10 - Tórax em bloco de camundongo com neoplasia pleural maligna, evidenciando implantes tumorais / massas (setas) em pleura visceral ..... 55

Figura 11 - Microscopia eletrônica de tumorações de camundongos expostos a células LLC (Aumento de 4.000X) 67

Figura 12 - Microscopia eletrônica de tumorações de camundongos expostos a células LLC (Aumento de 15.000X) 68

Figura 13 - Microscopia eletrônica de tumorações de camundongos expostos a células LLC (Aumento de 20.000X) 69 
Figura 14 - Expressão de VEGF (A) e de EGFR (B) ...................................... 70

Figura 15 - Expressão do KRAS................................................................. 72

Figura 16 - Expressão de ALK.................................................................... 72

Figura 17 - Exemplo de sequenciamento em rim de camundongo para avaliação do éxon 18 do gene EGFR (A) e sequenciamento dos éxons $18 \mathrm{e}$ 19 do gene EGFR em cultura de células LLC (B) e em tecido tumoral de camundongos 14 dias após implante de células LLC (C)......................... 74

Figura 18 - Mutação (setas) em sequenciamento do éxon 2 do gene KRAS em cultura de células LLC (A) e em tecido tumoral de camundongos 14 dias após implante de células LLC (B)............................................................ 75 


\section{Lista de tabelas}

Tabela 1 - Concentrações dos anticorpos utilizados no método ELISA.......... 85

Tabela 2 - Primers utilizados para a PCR-RT.............................................. 85

Tabela 3 - Primers utilizados para sequenciamento..................................... 65

Tabela 4 - Reações utilizadas para sequenciamento...................................... 86

Tabela 5 - Reagentes e volumes utilizados para sequenciamento.................. 86

Tabela 6 - Controle de peso (g) dos camundongos submetidos à injeção de LLC com e sem tratamento

Tabela 7 - Redução de atividade / mobilidade (0 = normal; 4 = inatividade)... 55

Tabela 8 - Avaliação do volume $(\mu \mathrm{L})$ de líquido pleural................................... 56

Tabela 9 - Total de células nucleadas $\left(\mathrm{mm}^{3}\right)$ no líquido pleural..................... 57

Tabela 10 - Contagem de leucócitos (\%) no líquido pleural............................ 58

Tabela 11 - Contagem diferencial de macrófagos (\%) no líquido pleural........ 58

Tabela 12 - Contagem diferencial de neutrófilos (\%) no líquido pleural.......... 58

Tabela 13 - Contagem diferencial de linfócitos (\%) no líquido pleural.............. 59

Tabela 14 - Dosagem de desidrogenase láctica (UI/L) no líquido pleural....... 59

Tabela 15 - Dosagem de proteínas totais $(\mathrm{g} / \mathrm{dL})$ no líquido pleural................. 60

Tabela 16 - Dosagem de VEGF (pg/mL) no líquido pleural............................. 60

Tabela 17 - Dosagem de EGF (pg/mL) no líquido pleural.............................. 60

Tabela 18 - Dosagem de TNF- $\alpha(\mathrm{pg} / \mathrm{mL})$ no líquido pleural............................ 61 
Tabela 19 - Dosagem de IL-6 (pg/mL) no líquido pleural. 61

Tabela 20 - Tumor em pleura visceral e/ou parietal (extensão x severidade) 62

Tabela 21 - Tumor em pericárdio e/ou músculo cardíaco (extensão x severidade) 62

Tabela 22 - Infiltrado inflamatório em parênquima pulmonar. 63

Tabela 23 - Degeneração hidrópica no fígado (extensão x severidade)......... 63

Tabela 24 - Esteatose microgoticular no fígado (extensão x severidade)....... 63

Tabela 25 - Infiltrado sinusoidal no fígado (extensão x severidade)................ 64

Tabela 26 - Degeneração hidrópica renal (extensão x severidade).................. 64

Tabela 27 - Esteatose renal (extensão x severidade) ................................... 64

Tabela 28 - Hiperplasia de polpa branca do baço (extensão x severidade).... 65

Tabela 29 - Fração de área de células tumorais positivas para expressão do EGFR 65

Tabela 30 - Fração de área de células tumorais positivas para expressão do VEGFR 66

Tabela 31 - Índices de apoptose em tecido tumoral......................................66 66

Tabela 32 - Determinação de atividade mitótica (PCNA) 66 


\section{Resumo}

Puka J. Perfil biomolecular do derrame pleural maligno experimentalmente induzido: frequência de mutações e impacto de terapias-alvo [Tese]. São Paulo: Faculdade de Medicina, Universidade de São Paulo; 2016.

INTRODUÇÃO: O câncer de pulmão é a principal causa de morte por câncer em todo o mundo e muitos pacientes apresentam derrame pleural em um estágio avançado da doença, com alta morbidade e mortalidade. Entretanto, a patogênese do derrame maligno é ainda pouco compreendida e as opções terapêuticas são limitadas. OBJETIVO: 1) Estudar a fisiopatologia do derrame pleural maligno em modelo animal com células de Lewis em diferentes concentrações; 2) Avaliar os efeitos da terapia intrapleural com anti-VEGF e anti-EGFR e a frequência de mutações de EGFR e KRAS neste modelo. MÉTODOS: Foi utilizado modelo de neoplasia pleural com camundongos C57BL/6 e células de Lewis (LLC) dividido em duas etapas: estudo com

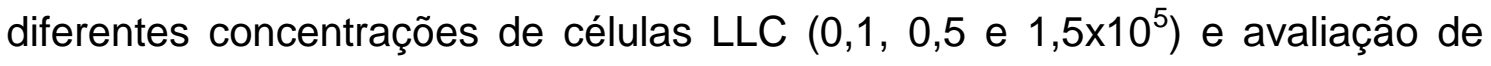
terapias-alvo. Após a padronização do modelo, quatro grupos de camundongos receberam tratamento intrapleural com anti-VEGF, anti-EGFR, anti-VEGF+antiEGFR ou solução fisiológica (não tratados) 3, 7, 10 e 14 dias após a indução da neoplasia pleural com $0,5 \times 10^{5}$ células LLC. Em vinte animais de cada grupo foi avaliada a curva de sobrevida. 160 animais foram submetidos à eutanásia 7 , 10, 14 ou 21 dias após e avaliados peso, mobilidade, volume de líquido pleural, marcadores inflamatórios, imunológicos e bioquímicos no líquido, presença de tumores e alterações histológicas em pleura, pulmão, rim, fígado e baço. Através de imunohistoquimica avaliou-se apoptose, proliferação tumoral, VEGF e EGFR. Analisou-se a expressão gênica do EGFR, VEGF, KRAS e ALK e a frequência de mutações do EGFR e KRAS. Análise estatística: One Way ANOVA, Kaplan-Meier, $p<0,05$. RESULTADOS: Na etapa de padronização do modelo observamos que a concentração que manteve os parâmetros de neoplasia pleural com maior sobrevida foi de $0,5 \times 10^{5}$ células LLC. Na segunda etapa do estudo, a carcinomatose pleural foi letal com sobrevida máxima de 25 
dias, sem diferença entre os grupos. Redução de peso foi observada em todos os grupos após 21 dias. A mobilidade foi melhor nos grupos que receberam anti-EGFR. O volume de líquido pleural foi maior no grupo não tratado durante todo o estudo. Parâmetros imunológicos e bioquímicos aumentaram temporalmente sendo mais evidentes no grupo sem tratamento. Implantes tumorais na pleura foram mais evidentes no grupo não tratado após 14 dias. A inflamação pulmonar foi mínima em todos os grupos. No grupo não tratado observou-se implantes tumorais no pericárdio e músculo cardíaco após 21 dias, esteatose hepática e renal após 14 dias e hiperplasia de polpa branca do baço no $21^{\circ}$ dia. Altos índices de apoptose e menores índices de proliferação tumoral foram observados nos grupos que receberam tratamento com antiEGFR e anti-VEGF+anti-EGFR. Houve mutação do gene KRAS e superexpressão gênica tumoral do EGFR e do KRAS. CONCLUSÃO: As terapias-alvo reduziram significativamente $\mathrm{o}$ derrame pleural, morbidade $\mathrm{e}$ parâmetros histológicos, embora sem impacto na sobrevida dos animais neste modelo experimental. Nossos dados indicam que a linhagem tumoral LLC possui um fenótipo tumoral agressivo demonstrado através da mutação do KRAS e superexpressão do EGFR, o que pode estar associado ao pior prognóstico e menor resposta aos inibidores do EGFR.

Descritores: derrame pleural maligno; adenocarcinoma; pleura; modelos animais; carcinoma pulmonar de Lewis; terapia combinada. 


\section{Abstract}

Puka J. Biomolecular profile in malignant pleural effusion experimentally induced: frequency of mutations and impact of targeted therapies [Thesis]. São Paulo: "Faculdade de Medicina, Universidade de São Paulo"; 2016.

INTRODUCTION: Lung cancer is the leading cause of death by cancer in the world. Many patients have pleural effusion in an advanced stage of the disease, with high morbidity and mortality. However, the pathogenesis of malignant pleural effusion is still poorly understood and the treatment options are limited. OBJECTIVE: 1) To study the pathophysiology of malignant pleural effusion in animal model with Lewis cells in different concentrations; 2) Evaluate the effects of the intrapleural therapy with anti-VEGF and anti-EGFR and the frequency of EGFR and KRAS mutations in this model. METHODS: We used pleural neoplasm experimental model with mice C57BL/6 and Lewis cells (LLC) divided into two steps: study with different concentrations of LLC cells $(0.1,0.5$ and $1.5 \times 10^{5}$ ) and evaluation of targeted therapies. After the standardization of the model, four groups of mice received intrapleural treatment with anti-VEGF, antiEGFR, anti-VEGF+anti-EGFR or saline (untreated) 3, 7, 10 and 14 days after induction of pleural neoplasm with injection of $0.5 \times 10^{5}$ LLC cells. In 20 animals of each group was evaluated the survival curve. 160 animals underwent euthanasia 7, 10, 14 or 21 days after and assessed weight, mobility, volume of pleural fluid, inflammatory, immunological and biochemical markers in the liquid, presence of tumor and histological changes in pleura, lung, kidney, liver and spleen. It was evaluated, through immunohistochemistry, tumor apoptosis and proliferation, VEGF and EGFR. Gene expression of EGFR, VEGF, KRAS and ALK and frequency of mutations of EGFR and KRAS were also evaluated. Statistical analysis: One Way ANOVA, Kaplan-Meier, $p<0.05$. RESULTS: In the standardization of the model we observed that the concentration that kept parameters of pleural neoplasm with higher survival rate was $0.5 \times 10^{5} \mathrm{LLC}$ cells. In the second stage, target-therapies, pleural carcinomatosis was lethal with maximum survival of 25 days, with no difference between the groups. Weight 
decrease was observed in all groups after 21 days. Mobility was better in groups that receiving anti-EGFR. Pleural fluid volume was greater in the untreated group throughout the study. Immunological and biochemical parameters have increased temporarily being most evident in the untreated group. Tumor implants in pleura were more apparent in the untreated group after 14 days. The lung inflammation was minimal in all groups. The untreated group showed tumor implants in the pericardium and heart muscle after 21 days, hepatic and renal steatosis after 14 days and spleen white pulp hyperplasia in 21 day. High rates of apoptosis and smaller tumor proliferation indices were observed in groups that received treatment with anti-VEGF and anti-EGFR+anti-EGFR. We also found gene KRAS mutation and tumoral gene overexpression of EGFR and KRAS. CONCLUSION: Targeted therapies reduced significantly the pleural effusion, morbidity and histological parameters, although without an impact on survival rate in this experimental model. Our data indicate that the tumor lineage LLC has an aggressive tumor phenotype shown by KRAS mutation and overexpression of EGFR, which can be associated with a worse prognosis and a lower response to EGFR inhibitors.

Descriptors: pleural effusion, malignant; adenocarcinoma; pleura; mod animal; carcinoma, Lewis lung; combined modality therapy. 
INTRODUÇÃO 


\section{INTRODUÇÃO}

O câncer é a segunda causa de morte no Brasil desde o ano 2000, sendo considerado um dos problemas de saúde mais importantes na atualidade. ${ }^{1,2}$ Com incidência em rápida ascensão, o pulmão vem se tornando o órgão mais frequentemente acometido, com grande mortalidade responsável por aproximadamente $12 \%$ das mortes por câncer ao ano no Brasil segundo dados do Instituto Nacional de Câncer (INCA). ${ }^{2-4}$

Neste cenário, o derrame pleural neoplásico, resultante principalmente de metástases pleurais de adenocarcinomas de pulmão, é um problema clínico comum e com importantes repercussões. ${ }^{5}$ Seu surgimento sinaliza doença de mau prognóstico, incurável por cirurgia, com comprometimento de qualidade de vida e tratamento limitado ao tumor primário e ao controle do derrame, práticas que não modificam a evolução da doença e não beneficiam todos os pacientes. ${ }^{6-17}$ Pode-se dizer, inclusive, que apesar dos grandes avanços no conhecimento do câncer nas últimas décadas, esta situação pouco evoluiu, pois alguns pontos sobre seu desenvolvimento permanecem incompreendidos e as curvas de sobrevida não apresentam modificações significativas. ${ }^{17-22}$

Nos últimos anos ocorreram mudanças importantes no tratamento do câncer de pulmão, sobretudo após a descoberta de alterações moleculares específicas e de terapias direcionadas a estes alvos moleculares. ${ }^{18-22} \mathrm{Da}$ mesma forma, vários estudos vêm sendo desenvolvidos na busca por melhor entendimento fisiopatológico que permita mudanças significativas na terapêutica do derrame pleural neoplásico secundário ao adenocarcinoma de pulmão. $^{23}$

Estudos promissores vêm avaliando a relação de células neoplásicas com tecidos sadios e outros sistemas, com ênfase em diferentes abordagens farmacológicas e na expressão e interação de mediadores inflamatórios e vasoativos, sem a pretensão de definir a cura para uma doença dependente de múltiplas variáveis, mas com a perspectiva de melhorar seu controle local e sua disseminação. ${ }^{23-32}$ 


\subsection{ADENOCARCINOMA DE PULMÃO}

O câncer de pulmão é uma doença com base genética, progênie clonal de uma célula geneticamente lesada, herdada na linhagem germinativa ou adquirida por alterações nas células somáticas por efeito de agentes ambientais. ${ }^{20}$ Pode ocorrer por quatro classes de genes - protoncogenes ou genes promotores do crescimento (Erb-B2, família Ras, N-myc, L-myc e Ciclina D4), genes supressores tumorais ou inibidores do crescimento (Rb, p53 e p16), genes que regulam a apoptose ( $\mathrm{p} 53$ e bcl-2) e os que regulam o reparo do DNA (hMSH2). ${ }^{20}$

O adenocarcinoma é o seu subtipo histológico mais comum contribuindo com aproximadamente metade dos casos no mundo. Tem elevadas taxas de morbidade e mortalidade, apesar dos grandes avanços em sua compreensão e em seu tratamento nos últimos anos. ${ }^{1,433,34}$

Os pacientes com adenocarcinoma podem ser divididos em três grupos que refletem a extensão da doença e sua abordagem. ${ }^{19,34} \mathrm{O}$ primeiro grupo compreende aqueles pacientes com tumores cirurgicamente ressecáveis, com melhor prognóstico e melhor taxa de sobrevida em cinco anos, de 67\% (I) a $24 \%$ (IIB). ${ }^{19,34}$ Já o segundo grupo inclui pacientes com tumores avançados local (IIIA) ou regionalmente (IIIB) com muitos aspectos controversos quanto a um tratamento ideal, optando-se por melhor estadiamento patológico do mediastino para decisão cirúrgica ou quimio e radioterapia em virtude dos altos índices de recorrência local e à distância após as ressecções. ${ }^{18,19,21}$

Por fim, mais de $40 \%$ dos pacientes apresentam doença avançada com metástases ao diagnóstico (IV), para os quais se indica cuidados de suporte ou para paliação dos sintomas, quimioterapia exclusiva ou combinada à radioterapia. ${ }^{18,19,21-48}$ Neste grupo, o prognóstico é pior sofrendo maior influência adversa por fatores tais como presença de sintomas pulmonares, grande tamanho tumoral, acometimento linfonodal, sexo masculino, idade superior a 60 anos, positividade da oncoproteína c-erbB2, mutação do gene KRAS, invasão vascular, aumento no número de vasos sanguíneos no espécime tumoral, diminuição da expressão de e-caderinas, níveis elevados de 
um fragmento da citoqueratina 19 (CYFRA-21) e do antígeno cárcinoembrionário (CEA). ${ }^{18,20,49}$

Houve grandes avanços terapêuticos nas últimas décadas principalmente pelo melhor conhecimento da biologia tumoral, sobretudo de alterações moleculares específicas como a translocação EML4-ALK e as mutações do receptor do fator de crescimento epidérmico (EGFR) e do gene KRAS. $^{20-22,49-58} \mathrm{Na}$ prática, o conhecimento destas alterações levou à descoberta de biomarcadores, hoje utilizados como alvos-terapêuticos. Há, por exemplo, os inibidores da tirosina-quinase, do EGFR e da quinase ALK, e os anticorpos monoclonais contra os receptores do fator de crescimento do endotélio vascular (VEGF) e do fator de crescimento epidérmico (EGF). Estas terapias-alvo vêm discretamente melhorando a sobrevida global e a sobrevida livre de progressão em pacientes com doença avançada ou metastática. ${ }^{20-22,49-}$ 58

O EGFR, também conhecido como HER-1/ErbB1, é um receptor da tirosina-quinase considerado oncogênico, responsável por crescimento, sobrevida, proliferação e diferenciação de vários tipos celulares. ${ }^{20,31,40}$ Sua ativação ocorre pelo EGF ou, em casos de mutações, pela ativação da porção tirosina-quinase do receptor por outros mediadores como, por exemplo, o fator de crescimento transformador alfa (TGF- $\alpha$ ), iniciando múltiplas cascatas de eventos intracelulares. ${ }^{20,31,40}$

O EGFR está alterado em vários tipos de tumores, principalmente nos epiteliais, seja por hiperexpressão, amplificação ou mutações, induzindo crescimento descontrolado ou fenótipo maligno, já que esta via regula fisiologicamente aspectos de proliferação e sobrevida celular. ${ }^{40}$ Seu gene está localizado no braço curto do cromossomo 7 (7p21) e está comumente amplificado em 31 a 47\% dos cânceres de pulmão de células não-pequenas, $50 \%$ deles adenocarcinomas, com mutações relevantes geralmente no éxon 18, 19, 20 ou 21, afetando o sítio de ligação da adenosina trifosfato (ATP) ao domínio tirosina-quinase, local onde também se ligam seus potenciais inibidores. $^{20,31,36-38,40}$ Esta via tirosina-quinase também pode ser ativada pela translocação EML4-ALK, quando a quinase proveniente do gene ALK, primeiramente detectado em linfomas de células anaplásicas, funde-se com a 
proteína EML4..$^{20,42,43}$ Esta mutação, recentemente detectada em cerca de 7\% dos pacientes japoneses com cânceres de pulmão de células não-pequenas, leva à ativação da via tirosina-quinase principalmente em pacientes mais jovens, não-tabagistas e com adenocarcinomas. ${ }^{20,42,43,49,50}$

Os genes KRAS codificam uma família de proteínas ligantes da guanosina trifosfato (GTP) e são elementos fundamentais nesta via de sinalização mediada pelo EGF, regulando crescimento celular, diferenciação e apoptose através da interação com múltiplos efetores. ${ }^{52}$ Suas mutações presentes em 15 a $30 \%$ dos casos de adenocarcinomas de pulmão, a maioria em pacientes tabagistas (96\%) - são um mau prognóstico. Estão possivelmente relacionadas a uma menor resposta aos medicamentos inibidores do EGFR, tanto de efeito em sua porção extracelular (cetuximabe) quanto em seu domínio tirosina-quinase (erlotinibe e gefitinibe). ${ }^{20,55,58}$

Assim, desde a demonstração de mutações do EGFR em 2004, pacientes jovens, não-fumantes e com adenocarcinomas vêm sendo testados para estas mutações, sempre que possível, para inclusão em estudos com agentes específicos. ${ }^{54-58}$ Buscam-se também novas drogas e novas estratégias no arsenal terapêutico, em particular aquelas cujo alvo molecular já tenha sido estabelecido, a fim de otimizar a taxa de controle da doença. ${ }^{20,54-58}$ Grandes centros americanos estão, inclusive, genotipando precocemente os pacientes com câncer de pulmão, a fim de direcionar a terapia, dentro ou fora de estudos clínicos. Considera-se, sobretudo, que pacientes com adenocarcinomas de pulmão sejam beneficiados pela investigação biológica pesquisando-se mutações específicas no EGFR e no KRAS e a translocação EML4-ALK, para individualizar a abordagem terapêutica. ${ }^{20,54-58}$

\subsection{DERRAME PLEURAL MALIGNO}

O derrame pleural maligno ou neoplásico acomete pacientes com neoplasias torácicas primárias ou metastáticas para o tórax, com incidência aproximada de 150 a 175 mil casos por ano em países como a Inglaterra e os Estados Unidos, e mais de 2 milhões em todo o mundo. ${ }^{5,9}$ 
Definido como um derrame pleural com presença de células malignas no líquido ou na superfície pleural, em pacientes com suspeita ou diagnóstico de câncer, ocorre como sua primeira manifestação ou como sinal de recorrência da doença após tratamento. ${ }^{5,9}$

Quase todos os tipos de câncer podem produzi-lo, principalmente os de pulmão e mama, responsáveis conjuntamente por 50 a $75 \%$ de todos os derrames neoplásicos. ${ }^{5,959-65} \mathrm{E}$ trata-se de uma manifestação de neoplasias avançadas ou disseminadas, geralmente sem possibilidade de cura, com baixa expectativa de vida (em média de 3 a 15 meses) e alta morbidade, cursando com dispneia debilitante em mais de $50 \%$ dos casos. ${ }^{5,9}$

Pode ocorrer pela embolização de um tumor para a pleura visceral, por metástases hematogênicas para a pleura parietal, por metástases da pleura visceral para a parietal ou por invasão direta de estruturas vizinhas. ${ }^{5,9,59-65}$ No adenocarcinoma de pulmão, o mecanismo de acometimento pleural mais frequente é a invasão direta (propagação contígua) e a disseminação vascular de células tumorais para outras áreas pulmonares e para a pleura visceral, com implantes secundários na pleural parietal. ${ }^{5,959-65}$

Entretanto, o mero acometimento maligno da pleura não é suficiente para a ocorrência do derrame neoplásico destacando-se como fatores essenciais a alteração da drenagem linfática pela infiltração carcinomatosa de linfonodos mediastinais e o aumento da permeabilidade capilar pela maior resposta inflamatória. ${ }^{59-66}$

Os folhetos pleurais, no passado considerados apenas membranas inativas de revestimento, são atualmente considerados órgãos ativos na manutenção da homeostase do espaço pleural, participando dinamicamente da resposta a processos que acometem o espaço pleural. ${ }^{63} \mathrm{Seu}$ acometimento desencadeia uma sequência de eventos vasculares e celulares e a liberação de mediadores inflamatórios e anti-inflamatórios, que atuam de forma sinérgica ou antagônica na tentativa de resolução da agressão pleural. ${ }^{61,62,65}$

Há, primariamente, um grande afluxo de leucócitos do compartimento intravascular para o espaço pleural, desencadeando a ativação de células mesoteliais e demais leucócitos que, por sua vez, liberam fatores que regulam a proliferação, migração e diferenciação celular. ${ }^{61,62,65}$ Além do EGF e do 
VEGF, vários mediadores já foram descritos, como o fator de crescimento transformador beta (TGF- $\beta$ ), o fator de crescimento derivado de plaquetas (PDGF), o fator de necrose tumoral (TNF), o fator nuclear kappa beta (NF-kB), a osteopontina (OPN), as interleucinas 8,5 e 6 (IL-8, IL-5 e IL-6), as endostatinas e a proteína quimiotática de monócitos 1 ou citocina ligante 2 (MCP-1 ou CCL2). ${ }^{23,67-82}$

As células mesoteliais, protagonistas desta resposta, secretam e liberam imunomoduladores pró e anti-inflamatórios e fatores pró e anticoagulantes, promovendo a angiogênese e a movimentação de líquido, partículas e células para o espaço pleural. ${ }^{64-66}$ Já no microambiente tumoral, os macrófagos e os linfócitos T são as células-chave, por liberarem uma quantidade significativa de moléculas imunomoduladoras, embora as células malignas também sejam produtoras de citocinas e mediadores vasoativos. . $^{30,61,62,65}$

Sabe-se, ainda, que existem reações em cadeia entre células pleurais, células tumorais, vasos pleurais e o sistema imune, com evidências de que as interações entre fatores do hospedeiro e fatores tumorais sejam determinantes para a formação do derrame pleural maligno e seu diferente comportamento em diferentes pacientes. . $^{23,25,30}$

\subsection{TRATAMENTO DO DERRAME PLEURAL MALIGNO}

O tratamento específico do derrame pleural maligno baseia-se em fatores como expectativa de vida, sintomatologia e capacidade de desempenhar atividades cotidianas, dependentes principalmente do estado geral do paciente, do tipo histológico do tumor, de seu estágio e da perspectiva de resposta aos tratamentos oncológicos e à toracocentese inicial. ${ }^{9,19,83}$

De acordo com estes fatores podem ser utilizados diferentes métodos terapêuticos como observação clínica, toracocenteses recorrentes, drenagem pleural, pleurodese através de dreno de tórax ou procedimento cirúrgico, cateteres pleurais de longa permanência ou shunt pleuroperitoneal. ${ }^{5-16}$ Os objetivos restringem-se a controlar de forma duradoura o derrame, suprimir ou ao menos aliviar os sintomas diretamente relacionados à sua presença e re- 
expandir o pulmão, preferencialmente com o procedimento mais simples, mais rápido e de menor custo possível. ${ }^{5-16}$

A drenagem com subsequente pleurodese química ainda é um dos procedimentos mais utilizados na maior parte do mundo, indicada em casos confirmadamente neoplásicos, sintomáticos ou recidivantes, causados por tumores não responsivos ao tratamento oncológico, em pacientes com sobrevida maior do que 2 a 3 meses. ${ }^{5-16,83-88}$ A abrasão ou instilação de substâncias esclerosantes na cavidade pleural determina uma importante reação inflamatória aguda das superfícies pleurais resultando em intensa fibrose e sínfise destes folhetos, prevenindo assim a recidiva do derrame. ${ }^{83}$

No entanto, é um procedimento contra-indicado se não houver reexpansão pulmonar de pelo menos $50 \%$ após toracocentese inicial ou drenagem, bem como na presença de outras condições relacionadas à dispneia como linfangite carcinomatosa, obstrução brônquica ou encarceramento neoplásico do pulmão. ${ }^{5-16}$ Nestes casos, a colocação de um cateter de drenagem pleural de longa permanência como o Pleurx $\AA^{\circledR}$ vem se tornando o método de escolha, com bons resultados. ${ }^{5-16,88}$

Busca-se primordialmente melhor qualidade de vida, melhorando a dispneia causada pelo acúmulo de líquido. Entretanto, estes procedimentos não beneficiam todos os pacientes e, principalmente, não modificam a evolução da doença de base - o câncer. ${ }^{5-16}$

O tratamento oncológico, por sua vez, pode incluir quimioterapia destinada à redução do tumor e à absorção do líquido pleural, porém sendo o derrame pleural neoplásico uma manifestação de doença maligna avançada e sistemicamente disseminada, o tratamento é hoje considerado paliativo. ${ }^{9,19,44-48}$

Diversos estudos de fase III tentaram determinar qual, entre as diversas combinações possíveis de quimioterápicos, seria a mais eficaz na redução da mortalidade de pacientes com câncer de pulmão localmente avançado ou metastático - estágio em que se incluem os portadores de derrame pleural maligno. ${ }^{41,44-48}$ Entretanto, não foi possível determinar um regime quimioterápico padrão e o consenso atual é que qualquer combinação contendo uma platina (carboplatina ou cisplatina) e uma droga de segunda ou terceira geração (paclitaxel, vinorelbine, docetaxel, gemcitabina e irinotecano) é 
igualmente eficaz, devendo a escolha ser baseada na preferência do médico e no perfil do paciente. ${ }^{18,19,44-48}$

Aos intolerantes à platina pode ser oferecida uma única droga de segunda ou terceira geração, porém habitualmente recomenda-se uma destas drogas combinada a uma platina - desde 1995 considerado o tratamento de primeira linha, com redução de $27 \%$ na mortalidade e melhora da qualidade de vida. $^{18,19,44-48}$

Sobre o derrame pleural maligno, os efeitos da quimioterapia ainda são incertos, porém novas drogas vêm lentamente melhorando o prognóstico dos pacientes com câncer de pulmão, com efeitos promissores também em pacientes com derrame pleural maligno. ${ }^{34-48}$

Trabalhos recentes vêm ainda expandindo o papel de drogas previamente indicadas apenas como terapia de manutenção. ${ }^{19} \mathrm{O}$ antifolato pemetrexed, por exemplo, combinado à cisplatina, é hoje um dos tratamentos de manutenção para o câncer de pulmão de células não-pequenas localmente avançado ou metastático, assim como os inibidores seletivos da tirosinaquinase. ${ }^{19,34-48}$ Como agente único, vem sendo utilizado como segunda linha para pacientes com carcinoma de células escamosas, sendo um agente terapêutico promissor para pacientes com derrame pleural maligno por adenocarcinoma, pois não há comprometimento de sua eficácia e segurança em pacientes com derrame pleural. ${ }^{19,34-48}$

Já os inibidores seletivos da tirosina-quinase como gefitinibe, erlotinibe e crizotinibe, que atuam sobre o EGFR, são atualmente indicados como terapia de terceira linha para o mesmo grupo de pacientes ou, se a pesquisa da quinase ALK for positiva e o paciente apresentar um tumor com EGFR mutado, como primeira linha. ${ }^{19,34-48}$

\subsection{MODELOS EXPERIMENTAIS}

Sabe-se que nem todos os tumores metastáticos para a pleura causam derrame pleural maligno e que a evolução pode ser completamente distinta, mesmo em pacientes com características semelhantes e com tumores de tipos 
histológicos e em estágios semelhantes. ${ }^{5-9,23,25}$ Partindo-se deste princípio, vários estudos já foram realizados avaliando as características tumorais responsáveis pelo derrame pleural maligno e os mediadores do hospedeiro que conduzem a eventos vasoativos justapleurais. ${ }^{25}$

Foram descobertas importantes interações entre células tumorais e células inflamatórias, mesoteliais e endoteliais do microambiente pleural, ou seja, entre o tumor e o hospedeiro. ${ }^{25,29,30} \mathrm{E}$, embora o completo papel destas interações no desenvolvimento e na evolução do derrame pleural maligno ainda seja objeto de pesquisa, sabe-se que são determinantes para sua formação e passíveis de inibição terapêutica. . $3,61-82^{2}$

Esta patogênese foi mal compreendida durante muito tempo, mas houve um progresso substancial nos últimos anos, após o desenvolvimento de modelos experimentais de neoplasia pleural. ${ }^{24}$ Isto porque, até há algum tempo, a maioria dos modelos experimentais envolvia animais com pleura normal, sobretudo para testar condutas paliativas como a pleurodese. ${ }^{89-95}$ Pela ausência de doença maligna, a avaliação da evolução natural do câncer de pulmão, da interação neoplasia-hospedeiro, da resposta imunológica ou de possíveis terapias era expeculativa. ${ }^{89-95}$ Já com os modelos experimentais de neoplasia pleural, foi possível mimetizar a condição humana, com significativos avanços na compreensão da patogênese do adenocarcinoma de pulmão, dos mecanismos de formação do derrame pleural maligno decorrente do câncer de pulmão, da disseminação do tumor e de possíveis terapias-alvo. ${ }^{23-28}$

Vários mediadores foram estudados, como o VEGF, por exemplo. ${ }^{20}$ Também conhecido como fator de permeabilidade vascular, este é um dos principais fatores na formação do derrame pleural maligno, seja pelo aumento da permeabilidade vascular ou por seu grande potencial angiogênico. ${ }^{67,68}$ Ao estimular o crescimento de capilares e a neovascularização da superfície pleural inibe os mecanismos de defesa pleurais, permitindo que as células malignas desenvolvam um ambiente rico em vasos para sua nutrição e, assim, facilitando o crescimento do tumor e a formação de implantes pleurais. ${ }^{67,68} \mathrm{Seu}$ bloqueio isolado com o uso de anticorpos anti-VEGF (bevacizumabe), entretanto, não trouxe os resultados esperados questionando-se, por exemplo, se outras alterações seriam predisponentes à metástase pleural ou 
provocariam o derrame pleural maligno, e se outras terapias-alvo teriam impacto favorável em pacientes com derrame pleural maligno. ${ }^{21,34-38,66-82}$

Em 2006, Stathopoulos e colaboradores desenvolveram e caracterizaram um modelo experimental animal de derrame pleural maligno, injetando $1,5 \times 10^{5}$ células de Lewis diretamente no espaço pleural de camundongos C57BL/6 - um protótipo de camundongo imunocompetente que permite 0 implante destas células específicas. ${ }^{24}$ Provenientes de um adenocarcinoma de pulmão que surgiu espontaneamente nestes camundongos, as células de Lewis ou LLC (Lewis Lung Cancer) tem curto tempo de duplicação in vitro e in vivo, porém comportamento biológico agressivo. ${ }^{24}$ Quando inoculadas nestes camundongos dão origem a adenocarcinomas de pulmão e derrame pleural maligno semelhante aos dos seres humanos - exsudato com celularidade semelhante e com altos níveis de proteínas, desidrogenase lática (DHL) e VEGF. ${ }^{24}$

Trata-se de um modelo altamente reprodutível, uma vez que utiliza animais imunocompetentes, que cursam com derrame pleural maligno semelhante ao dos seres humanos em 14 dias e com desfechos reprodutíveis, podendo ser também utilizado para estudar a influência de fatores tumorais e do hospedeiro específicos sobre a patogênese do derrame pleural maligno, e para avaliar novas estratégias terapêuticas. ${ }^{23-25}$

Estudos recentes com este modelo vêm demonstrando a possibilidade de se obter um microambiente menos permissivo para o desenvolvimento do derrame pleural maligno com drogas conhecidas, administradas na primeira evidência de doença pleural maligna, por outras vias ou combinadas a outros

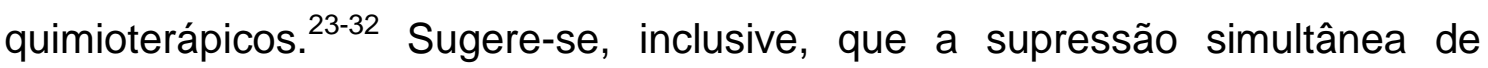
múltiplas vias de disseminação seria um direcionamento terapêutico vantajoso. No entanto, a sobrevida máxima dos animais neste modelo é de apenas 17 dias, o que impede a avaliação mais criteriosa dos resultados e de outros possíveis desfechos. ${ }^{23-32}$ 
OBJETIVOS 


\section{OBJETIVOS}

Partindo-se do princípio que o câncer de pulmão de células nãopequenas tem várias vias de propagação e vários mediadores atuantes e que as abordagens mais promissoras para o seu tratamento são drogas com múltiplos alvos ou terapias-alvo combinadas, principalmente em pacientes com múltiplas variáveis como os portadores de derrame pleural maligno, objetivouse:

- Estudar a fisiopatologia do derrame pleural neoplásico decorrente do câncer de pulmão em modelo animal de neoplasia pleural com células de Lewis, bem como a configuração deste modelo utilizando diferentes concentrações de células, a fim de estabelecer um modelo com maior sobrevida;

- Analisar o comportamento deste modelo experimental com terapias-alvo administradas isoladamente ou em combinação por via intrapleural em diferentes fases da doença pleural maligna, estudando parâmetros bioquímicos, imunológicos e celulares no líquido pleural e alterações histológicas em órgãos passíveis de acometimento metastático;

- Avaliar a ação das terapias-alvo sobre os implantes tumorais da cavidade pleural, através de marcação imunohistoquimica e expressão gênica;

- Avaliar a frequência de mutações de EGFR e KRAS em uma linhagem tumoral de adenocarcinoma utilizada em modelos experimentais. 


\section{MÉTODOS}




\section{CASUÍSTICA E MÉTODOS}

O estudo foi realizado no Laboratório de Pleura do Instituto do Coração (InCor), após aprovação pelo Comitê de Ética e Pesquisa (CAPPesq) e Comitê de Ética no Uso de Animais (CEUA) do Hospital das Clínicas da Faculdade de Medicina da Universidade de São Paulo (FMUSP) - número 0628/09.

Para o seu desenvolvimento foi utilizado modelo animal de neoplasia pleural com camundongos C57BL/6 e células de Lewis - LLC (Lung Lewis Carcinoma). ${ }^{24-28}$

Os camundongos C57BL/6 (Figura 1), machos, com idade de 6 a 8 semanas e peso entre 20 e 25 gramas, foram provenientes do Biotério Central da FMUSP (São Paulo/Brasil).

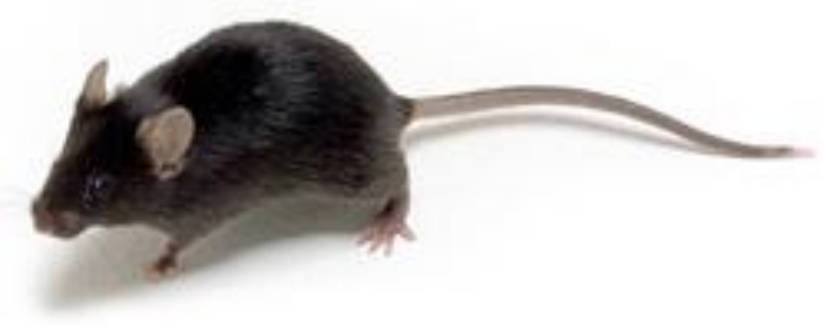

Figura 1 - Camundongo C57BL/6 (Fonte: SDC/FMUSP)

As células LLC (Figura 2) foram adquiridas do banco de células American Type Culture Collection - ATCC (Virgínia/Estados Unidos).

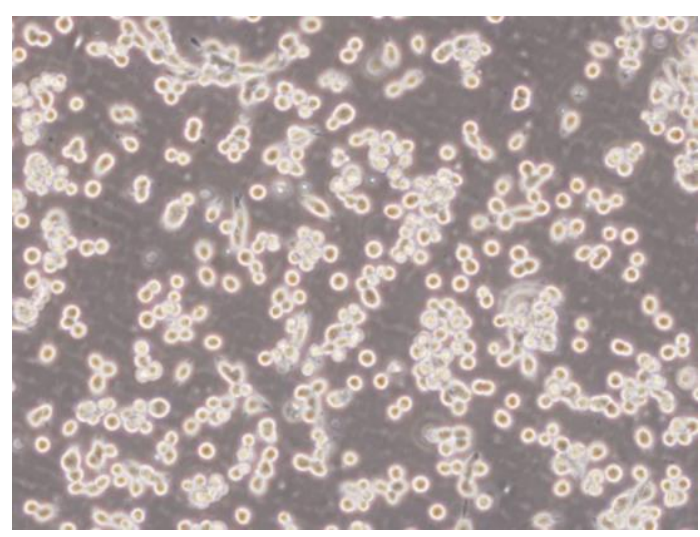

Figura 2 - Células LLC (Fonte: Sonidel Limitada) 


\subsection{MODELO EXPERIMENTAL DE NEOPLASIA PLEURAL INDUZIDO COM DIFERENTES CONCENTRAÇÕES DE CÉLULAS NEOPLÁSICAS}

Para esta fase foram utilizados 130 camundongos C57BL/6 divididos em 3 grupos de 40 animais e 1 grupo de 10 animais, da seguinte forma (Figura 3):

- Grupo A (modelo experimental descrito na literatura): desenvolvimento de neoplasia pleural com $1,5 \times 10^{5}$ células LLC;

- Grupo B: desenvolvimento de neoplasia pleural com $0,5 \times 10^{5}$ células LLC;

- Grupo C: desenvolvimento de neoplasia pleural com $0,1 \times 10^{5}$ células LLC;

- Grupo D: injeções intrapleurais de solução fisiológica 0,9\%.

A

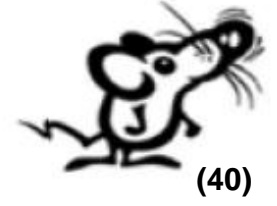

B

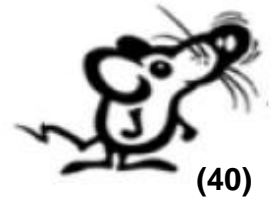

C

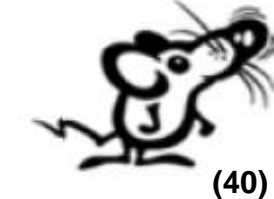

D

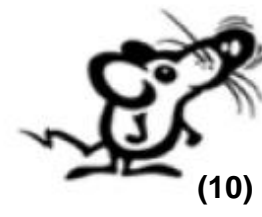

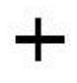

(40)
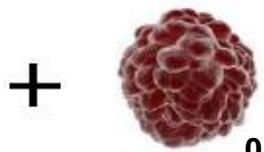

$0,5 \times 10^{5}$ células LLC

$1,5 \times 10^{5}$ células LLC
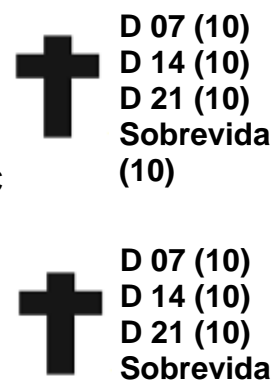

(10)

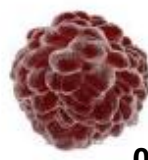

$0,1 \times 10^{5}$ células LLC

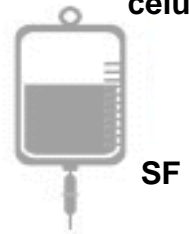

D 07 (10)

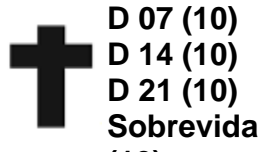

(10)

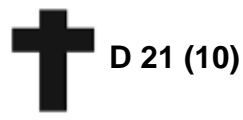

Figura 3 - Modelo experimental de neoplasia pleural induzido com diferentes concentrações de células neoplásicas, sendo $(A) \operatorname{com} 1,5 \times 10^{5}$,

(B) com $0,5 \times 10^{5}$ e (C) com $0,1 \times 10^{5}$ células LLC (40 animais por grupo).

† Eutanásia aos 7, 14 e 21 dias (D7 / D14 / D21) após o desenvolvimento da neoplasia pleural, ou óbito espontâneo (sobrevida). Grupo D = solução fisiológica (SF) intrapleural em 10 animais, eutanasiados aos 21 dias (D21) 
Para a indução da neoplasia, após anestesia por injeção intraperitoneal de $35 \mathrm{mg} / \mathrm{kg}$ de ketamina (Cristália, São Paulo/Brasil) e $5 \mathrm{mg} / \mathrm{kg}$ de xylazina (Bayer, São Paulo/Brasil), os camundongos foram posicionados em uma mesa cirúrgica e a pele da região torácica foi limpa com álcool a 70\% (Rioquímica, São Paulo/Brasil). Foi então inserida uma agulha de calibre 23 (23-G) na região torácica direita, para injeção intrapleural por diferença de pressão de $0,5 \mathrm{~mL}$ de solução contendo células neoplásicas em diferentes concentrações - $1,5 \times 10^{5}$ células LLC no grupo A (semelhante ao modelo animal de neoplasia pleural descrito na literatura), ${ }^{24-28}$ e $0,5 \times 10^{5}$ e $0,1 \times 10^{5}$ células LLC, respectivamente, nos grupos B e C. Terminada a instilação, todo o sistema foi imediatamente removido, para prevenir a entrada de ar inadvertidamente na cavidade pleural.

No grupo D, 10 animais foram igualmente submetidos a injeções intrapleurais de solução fisiológica, para mimetizar o procedimento realizado nos demais grupos.

\section{Análise de peso, mobilidade e sobrevida}

Os animais tiveram livre acesso à água, receberam alimentação apropriada e foram diariamente pesados (em gramas), com análise diária de atividade e de mortalidade. Para esta análise de atividade, foi utilizado um escore subjetivo de mobilidade de 0 a 3 , sendo $0=$ normal e $3=$ imobilidade.

Para a curva de sobrevida, observou-se a taxa diária de mortalidade em todos os grupos, com anotação do tempo máximo de vida após o implante de células de Lewis.

\section{Eutanásia e coleta de amostras}

Nos grupos A, B e C, 10 animais de cada grupo foram submetidos à eutanásia aos 7 (D7), 14 (D14) e 21 dias (D21) após o desenvolvimento da neoplasia pleural e os 10 animais restantes foram mantidos em observação até o óbito espontâneo, para análise da curva de sobrevida. No grupo D, os 10 animais foram eutanasiados ao fim do estudo, aos 21 dias. 
Os camundongos foram anestesiados e submetidos à incisão abdominal em região mediana avaliando-se a presença ou não de líquido na cavidade pleural e abdominal. Após, foram eutanasiados através de exsanguinação, retirando-se o sangue por punção de aorta abdominal com agulha 23-G. Quando presente, o líquido pleural foi coletado por punção transdiafragmática da cavidade pleural com agulha 23-G, para quantificação volumétrica e posterior análise. A seguir, o tórax foi removido em bloco e os pulmões expandidos e fixados em formol a $10 \%$ em temperatura ambiente, juntamente com rins, fígado e baço.

\section{Análise histológica}

Depois de 24 horas em formaldeído, o tórax foi aberto através de incisões longitudinais, para exposição e análise da cavidade pleural (exame macroscópico). Foram então coletados fragmentos de parede torácica (pleura parietal), pulmões, coração, rins, fígado e baço e fixados em formalina neutra tamponada a $10 \%$ durante 24 horas. Posteriormente, os tecidos foram embebidos em parafina, e cortes de $5-\mu \mathrm{m}$ de espessura foram montados em lâminas de vidro e corados com hematoxilina e eosina (H\&E) para posterior análise histológica.

\section{Análises bioquímicas e citologia}

Uma alíquota de líquido pleural colhida em tubo sem adição de anticoagulante foi submetida a dosagens de proteínas totais e desidrogenase lática (DHL) em aparelho semi-automático (método do biureto e UV cinético, respectivamente), através de kits comerciais (Wiener, Rosário/Argentina).

Amostras de líquido pleural acondicionadas em tubos contendo anticoagulante ácido diaminoetiltetracético (EDTA) foram submetidas à avaliação citológica através de aparelho automatizado e manualmente (lâminas coradas com Leishman para confirmação do diferencial celular e avaliação de células neoplásicas na amostra). Realizou-se contagem total de células e diferencial de leucócitos. 


\subsection{AVALIAÇÃO DE TERAPIAS-ALVO EM NEOPLASIA PLEURAL EXPERIMENTALMENTE INDUZIDA}

Nesta fase, foram utilizados 240 camundongos C57BL/6, divididos da seguinte forma (Figura 4):

- Grupo 1 (sem tratamento) = 60 animais com doença pleural maligna não-tratados;

- Grupo 2 (com tratamento) $=180$ animais com doença pleural maligna tratados, sendo 60 camundongos tratados com anti-VEGF intrapleural (2A), 60 com anti-EGFR (2B) e 60 com anti-VEGF e anti-EGFR (2C).

1

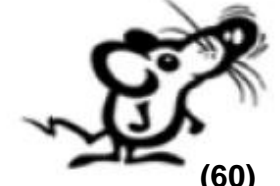

(60)
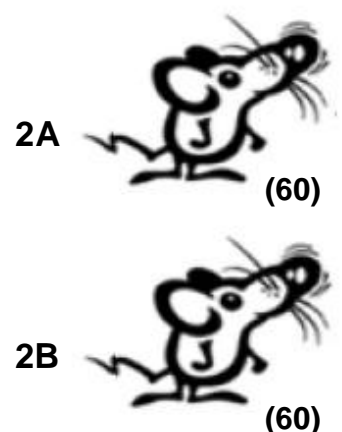

(60)

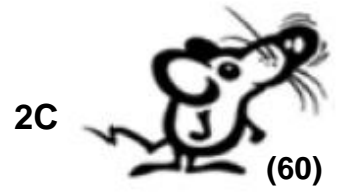

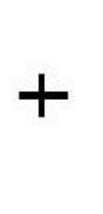

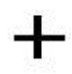

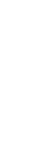
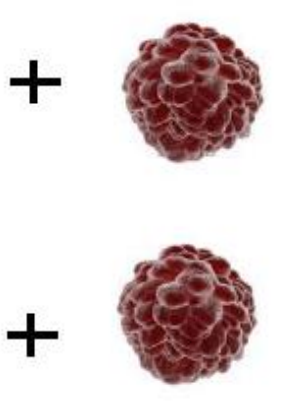
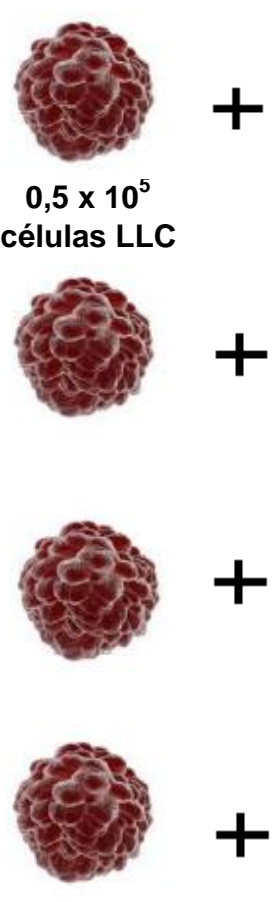
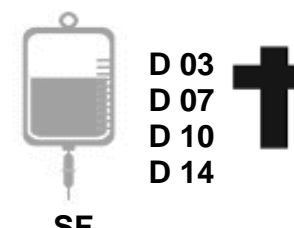

SF

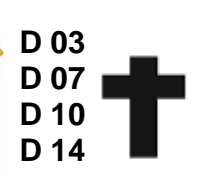

Anti-VEGF
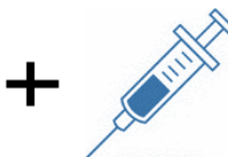

Anti-EGFR

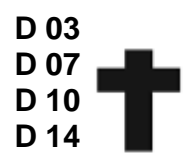

D 14

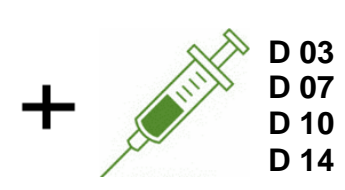

Anti-VEGF + Anti-EGFR
D 07 (10)

D 10 (10)

D 14 (10)

D 21 (10)

Sobrevida

(20)

D 07 (10)

D 10 (10)

D 14 (10)

D 21 (10)

Sobrevida

(20)

D 07 (10)

D 10 (10)

D 14 (10)

D 21 (10)

Sobrevida

(20)

D 07 (10)

D 10 (10)

D 14 (10)

D 21 (10)

Sobrevida

(20)

Figura 4 - Modelo de estudo de terapias-alvo em neoplasia pleural experimentalmente induzida. Grupo 1 (sem tratamento) = solução fisiológica (SF) intrapleural no terceiro (D3), sétimo (D7), décimo (D10) e décimo-quarto

(D14) dia após a inoculação de células LLC. Grupo 2 (com tratamento) = animais em tratamento intrapleural, sendo (A) com anti-VEGF, (B) com antiEGFR e (C) com anti-VEGF + anti-EGFR, no terceiro (D3), sétimo (D7), décimo

(D10) e décimo-quarto (D 14) dia após a inoculação de células LLC.

† Eutanásia aos 7, 10, 14 e 21 dias (D7 / D10 / D14 / D21) após o desenvolvimento da neoplasia pleural, ou óbito espontâneo (sobrevida) 
Para o desenvolvimento da neoplasia pleural, após anestesia por injeção intraperitoneal de $35 \mathrm{mg} / \mathrm{kg}$ de ketamina (Cristália, São Paulo/Brasil) e $5 \mathrm{mg} / \mathrm{kg}$ de xylazina (Bayer, São Paulo/Brasil), os camundongos foram posicionados em uma mesa cirúrgica e a pele da região torácica foi limpa com álcool a $70 \%$ (Rioquímica, Brasil). Foi então inserida uma agulha 23-G na região torácica direita, para injeção intrapleural por diferença de pressão de $0,5 \mathrm{~mL}$ de solução contendo $0,5 \times 10^{5}$ células LLC, com remoção imediata de todo o sistema.

A escolha desta concentração de células foi baseada nos resultados da primeira parte deste estudo, pela melhor sobrevida dos camundongos com neoplasia pleural induzida com $0,5 \times 10^{5}$ células LLC, em comparação com o modelo experimental descrito na literatura, utilizando $1,5 \times 10^{5}$ células (Apêndice).

No grupo 1 (sem tratamento), 60 animais receberam injeções intrapleurais de solução fisiológica no terceiro (D3), sétimo (D7) décimo (D10) e décimo quarto (D14) dia após o desenvolvimento da neoplasia pleural (implante das células de Lewis), a fim de mimetizar os procedimentos realizados nos demais grupos. Estas injeções foram realizadas inserindo-se uma agulha 23-G no espaço pleural direito para injeção de $0,5 \mathrm{~mL}$ de solução fisiológica $0,9 \%$ por diferença de pressão, semelhante à injeção de células neoplásicas.

No grupo 2 (com tratamento), 180 animais receberam tratamento com anti-VEGF, anti-EGFR ou ambos, através de procedimento semelhante à injeção de células neoplásicas anteriormente descrito. No grupo $2 \mathrm{~A}$ (antiVEGF), no terceiro (D3), sétimo (D7), décimo (D10) e décimo quarto (D14) dia após o desenvolvimento da neoplasia pleural, os animais foram submetidos à injeção intrapleural de $15 \mathrm{mg} / \mathrm{kg}(0,375 \mathrm{mg})$ do anti-VEGF bevacizumabe (Avastin ${ }^{\circledR}$, Roche, Basileia/Suíça). No grupo 2B (anti-EGFR), no terceiro (D3), sétimo (D7), décimo (D10) e décimo quarto (D14) dia após o desenvolvimento da neoplasia pleural, os animais foram submetidos à injeção intrapleural de $400 \mathrm{mg} / \mathrm{m}^{2} \quad(2,8 \mathrm{mg})$ do anti-EGFR cetuximabe (Erbitux ${ }^{\circledR}$, Merck, Darmstadt/Alemanha). No grupo 2C (anti-VEGF + anti-EGFR), no terceiro (D3), sétimo (D7), décimo (D10) e décimo quarto (D14) dia após o desenvolvimento da neoplasia pleural, os animais foram submetidos à injeção intrapleural de $15 \mathrm{mg} / \mathrm{kg}$ do anti-VEGF bevacizumabe e $400 \mathrm{mg} / \mathrm{m}^{2}$ do anti-EGFR cetuximabe. 


\section{Análise de peso, mobilidade e sobrevida}

Os animais tiveram livre acesso à água, receberam alimentação apropriada e foram diariamente monitorados, com análise de atividade e peso (em gramas) nos tempos de 7, 14 e 21 dias.

Para a análise de atividade, foi utilizado um escore subjetivo de 0 a 4 , sendo $0=$ normal e 4 = imobilidade.

Para a curva de sobrevida observou-se a taxa diária de mortalidade, com anotação do tempo máximo de vida após o implante de células de Lewis. Vinte animais de cada grupo foram mantidos em observação até o óbito espontâneo. De acordo com o grupo, foram igualmente submetidos a injeções intrapleurais de solução fisiológica ou medicamentos no terceiro (D3), sétimo (D7), décimo (D10) e décimo quarto (D14) dia após o desenvolvimento da neoplasia pleural, com controle de atividade e peso semanalmente, e observação diária para anotação do tempo máximo de vida após o implante de células de Lewis.

\section{Eutanásia e coleta de amostras}

No sétimo (D7), décimo (D10), décimo-quarto (D14) e vigésimo-primeiro (D21) dia após o desenvolvimento da neoplasia pleural, 10 animais de cada grupo foram anestesiados e submetidos à incisão abdominal em região mediana, avaliando-se a presença ou não de líquido na cavidade pleural e abdominal. Após esta avaliação foram eutanasiados através de exsanguinação, coletando-se o sangue por punção de aorta abdominal com agulha 23-G para posterior análise. Quando presente, o líquido pleural foi coletado por punção transdiafragmática da cavidade pleural com agulha 23-G para quantificação volumétrica e posterior análise.

A seguir, o tórax foi removido em bloco e os pulmões expandidos e fixados em formol a 10\% e temperatura ambiente. Após 24 horas, foi realizado o exame macroscópico da cavidade pleural e amostras de pleura visceral e parietal foram preparadas para análise microscópica, bem como fragmentos de 
pulmão, coração, fígado, rim, baço para verificação de possíveis implantes tumorais.

Os tumores obtidos durante o procedimento de necropsia (massas) foram divididos da seguinte forma:

- Uma parte foi congelada em nitrogênio líquido e armazenada a -80 graus Celsius $\left(-80^{\circ} \mathrm{C}\right)$ para seu posterior estudo molecular;

- Uma segunda parte foi fixada em formalina tamponada a $10 \%$ por um período variável de 4 a 16 horas para posterior estudo histológico, imunohistoquímico e reação do TUNEL;

- Uma terceira parte (aproximadamente 2 a $3 \mathrm{~mm}$ ) foi fixada em tampão de glutaraldeído a $2 \%$ e acondicionado para posterior estudo de microscopia eletrônica.

\section{Análise de sangue e líquido pleural}

Amostras de sangue e de líquido pleural acondicionadas em tubos contendo anticoagulante EDTA foram submetidas à avaliação hematológica e citológica através de aparelho automatizado (painel completo) e manualmente (lâminas coradas com Leishman para confirmação do diferencial celular e avaliação de células neoplásicas na amostra).

Adicionalmente, uma fração do líquido pleural foi centrifugada e posteriormente submetida à análise dos níveis de IL-6, TNF- $\alpha$, EGF e VEGF por técnica imuno-enzimática (ELISA) de captura (R\&D System, Minnesota/Estados Unidos), conforme Anexo, Tabela 1.

Para tal, placas com 96 poços (Costar/Corning, Massachusetts/Estados Unidos) foram sensibilizadas com $100 \mu \mathrm{L}$ de anticorpo monoclonal e incubadas a $4^{\circ} \mathrm{C}$ por 18 horas. Para evitar ligações inespecíficas a placa foi bloqueada com $300 \mu \mathrm{L}$ de solução de bloqueio (BSA $2 \%$ ) e incubada a $37^{\circ} \mathrm{C}$ por 2 horas. Após, foi adicionado $100 \mu \mathrm{L}$ por poço das amostras e dos padrões diluídos previamente em PBS; e em dois poços, colocado somente PBS para caracterização do branco. A placa foi incubada a $4^{\circ} \mathrm{C}$ por 18 horas com adição de $100 \mu \mathrm{L}$ do anticorpo conjugado (biotinilado) na concentração estabelecida e 
incubação a $37^{\circ} \mathrm{C}$ por 3 horas. Posteriormente, foram adicionados $100 \mu \mathrm{L}$ de Streptavidina HRP (1:250) por poço, com incubação a $37^{\circ} \mathrm{C}$ por 30 minutos. A cada etapa a placa foi lavada com tampão de lavagem (PBS + Tween 20) por 6 vezes.

A revelação foi realizada através da adição de $100 \mu \mathrm{L}$ por poço da solução de revelação $\left(\mathrm{H}_{2} \mathrm{O}_{2}+\right.$ Tetrametilbenzidina), incubando-se a $37^{\circ} \mathrm{C}$ por 5 a 60 minutos, de acordo com cada citocina. A reação foi interrompida com $50 \mu \mathrm{L}$ por poço de $\mathrm{H}_{2} \mathrm{SO}_{4} 30 \%$, agitando-se lentamente, e a leitura foi feita em leitor de ELISA PowerWave ${ }^{\circledR}$ (BioTek, Vermont/Estados Unidos) utilizando filtro de $450 \mathrm{~nm}$.

Uma alíquota de líquido pleural colhida em tubo sem adição de anticoagulante foi submetida a dosagens de proteínas totais e desidrogenase lática (DHL), com kit de reação bioquímica (Wiener, Santa Fé/Argentina).

Para análise do $\mathrm{DHL}, 20 \mu \mathrm{L}$ de cada amostra foi adicionado a $1 \mathrm{~mL}$ do reagente específico com pré-incubação em banho-maria a $37^{\circ} \mathrm{C}$ por 15 minutos. Após este período, a solução foi homogeneizada em vórtex por 30 segundos e submetida a leitura cinética em aparelho bioquímico semiautomático Quick-Lab® (BioTécnica, Minas Gerais/Brasil), utilizando-se o comprimento de onda de $340 \mathrm{~nm}$.

A dosagem de proteínas totais foi realizada com adição de $3,5 \mathrm{~mL}$ do reagente EDTA/Cu a $50 \mu \mathrm{L}$ de líquido pleural, pré-incubado em banho-maria a $37^{\circ} \mathrm{C}$ por 15 minutos. Após, as amostras foram submetidas a leitura em aparelho bioquímico semi-automático Quick-Lab®, utilizando-se o comprimento de onda de $540 \mathrm{~nm}$.

\section{Análise histológica}

Amostras teciduais foram coradas por H\&E e avaliadas qualitativa e semi-quantitativamente para índices como infiltrado inflamatório em parênquima pulmonar, tumores em pleura visceral, pleura parietal, diafragma e coração (músculo cardíaco e pericárdio), esteatose hepática, alterações renais 
e esplênicas. Estes índices foram graduados de 0 a 4, de acordo com sua extensão e severidade.

O grau de disseminação metastática foi avaliado em amostras teciduais de coração (músculo cardíaco e pericárdio), diafragma, pulmões, peritônio, rins, baço e fígado, os locais mais frequentemente acometidos por possíveis implantes (metástases).

\subsection{ANÁLISE IMUNOHISTOQUÍMICA EM NEOPLASIA PLEURAL EXPERIMENTALMENTE INDUZIDA}

Cortes histológicos de $3 \mu \mathrm{m}$ de espessura contendo amostras representativas de tumores pleurais de animais não-tratados e tratados foram submetidos à análise imunohistoquímica para identificação do fator de crescimento epidérmico (EGF) e do fator de crescimento do endotélio vascular (VEGF), bem como para determinação de atividade mitótica (PCNA Proliferating Cell Nuclear Antigen).

\section{Reação do TUNEL para apoptose}

A identificação de apoptose nos núcleos de células tumorais de animais não tratados e tratados foi realizada pelo teste de TUNEL (Terminal deoxyribonucleotide Transferase-mediated Nick-End Labeling).

Este procedimento baseia-se na presença de clivagem do DNA genômico durante a apoptose e, assim, permite diferenciar a apoptose da necrose e das clivagens primárias de DNA induzidas por drogas citostáticas ou por irradiação.

\section{Histomorfometria}

A quantificação histomorfométrica da expressão dos marcadores VEGF e EGF foi realizada através da análise de cinco diferentes campos randomicamente selecionados em aumento de 400X, utilizando um analisador 
de imagem acoplado ao microscópio. O sistema consiste de uma câmera Olympus-5 acoplada a um microscópio Olympus, a partir do qual as imagens são visualizadas no monitor e avaliadas em um sistema digital de imagens (Software Image Pro-Plus 6.0). Foi utilizado o cálculo da área marcada positivamente e negativamente dos cinco diferentes campos de cada imagem.

Para avaliação de TUNEL e PCNA foi realizado um escore no qual foram consideradas as marcações positivas, avaliando extensão e severidade ( $0-4)$, com o resultado final apresentado através da multiplicação destes fatores.

\subsection{MICROSCOPIA ELETRÔNICA}

Fragmentos de tumor fixados em tampão de glutaraldeído $2 \%$ e pósfixados em $1 \%$ de $\mathrm{OsO} 4$ foram lavados durante a noite em solução salina a 0,9\% contendo uranila e sacarose e, finalmente, embebidos em Epon. Para cada caso, 3 a 5 fragmentos do tumor foram seccionados a 1 micrômetro e selecionados por microscopia óptica.

Seus respectivos blocos embebidos em Epon foram seccionados a 55 a $60 \mathrm{~nm}$, corados com acetato de uranila e citrato de chumbo e finalmente examinados com um microscopio eletrônico JEOL JEM - 1010.

\subsection{AVALIAÇÃO DA EXPRESSÃO GÊNICA DE VEGF, EGF, KRAS E ALK EM MODELO EXPERIMENTAL DE NEOPLASIA PLEURAL}

Para avaliação da expressão gênica de VEGF, EGF, KRAS e ALK foi extraído RNA do tumor utilizando o kit Rnase Microarray Tissue (Qiagen, Renania do Norte/Alemanha).

Para tal procedimento, $1 \mathrm{~mL}$ de QIAzol foi acrescentado às amostras de tecido neoplásico (massas decorrentes de implantes de células LLC) e o material homogeneizado foi transferido para um tubo de $1,5 \mathrm{~mL}$, incubado em temperatura ambiente por 5 minutos, com adição de $0,2 \mathrm{~mL}$ de clorofórmio. Esta solução foi homogeneizada por inversão e mantida em temperatura ambiente 
por 3 minutos, sendo posteriormente submetida à centrifugação de $12.000 \mathrm{rpm}$ por 15 minutos a $4^{\circ} \mathrm{C}$. A fase aquosa resultante foi transferida para um novo tubo contendo $0,6 \mathrm{~mL}$ de etanol a $70 \%$. Desta solução, $0,7 \mathrm{~mL}$ foi transferido para uma coluna de separação contendo um tubo coletor, sendo centrifugada à $10.000 \mathrm{rpm}$ por 15 minutos em temperatura ambiente. Este procedimento foi realizado novamente com o restante da solução. Após, adicionou-se $0,5 \mathrm{~mL}$ do tampão RW1 (provido com o kit) à coluna de separação, que foi centrifugada, acrescida de 0,5mL do tampão RPE (provido com 0 kit) e novamente centrifugada. Foi então acrescentada $120 \mu \mathrm{L}$ de água RNAse free e centrifugado à 10.000rpm por 1 minuto.

A leitura do material obtido foi feita com uso do espectrofotômetro Thermo Scientific NanoDrop 2000c, acoplado a um notebook AB - Applied Biosystems. E o RNA obtido foi, então, processado para obtenção do cDNA utilizando o kit SuperScript III First-Strand Synthesis SuperMix (Invitrogen, Califórnia/Estados Unidos), com todos os reagentes fornecidos no kit.

Para tal, à $100 \mathrm{ng} / \mu \mathrm{L}$ de RNA foi adicionado $1 \mu \mathrm{L}$ de Oligo(dT), $1 \mu \mathrm{L}$ de Annealing buffer e $8 \mu \mathrm{L}$ de água RNase/DNase free, incubados a $65^{\circ} \mathrm{C}$ por 5 minutos, com adição de $10 \mu \mathrm{L}$ First-Strand Reaction Mix e $2 \mu \mathrm{l}$ de Enzima Mix. $\mathrm{O}$ material foi homogeneizado e incubado por 50 minutos a $50^{\circ} \mathrm{C}$ e, após, o cDNA foi armazenado a $-20^{\circ} \mathrm{C}$.

Para a reação em cadeia da polimerase real time (PCR-RT), foi utilizada uma solução de $625 \mu \mathrm{L}$ de $R T^{2}$ YBR Green Mastermix (Qiagen, Renania do Norte/Alemanha), $525 \mu \mathrm{L}$ de água RNAse free e $25 \mu \mathrm{L}$ de cada primer (forward e reverse), de acordo com Anexo, Tabela 2.

Na placa de PCR, adicionou-se $1 \mu \mathrm{L}$ do cDNA obtido com a solução contendo os primers, centrifugando-se à 1000rpm e $4^{\circ} \mathrm{C}$ por 1 minuto e, então, colocando-se no ciclador da Applied Biosystems, modelo 7500. Para a PCRRT, o equipamento foi ajustado com 1 ciclo de 10 minutos a 95으, 50 ciclos de 15 segundos a $95^{\circ} \mathrm{C}$, e 1 minuto a $60^{\circ} \mathrm{C}$. E, após os 50 ciclos, foi realizada uma curva de dissociação (melting curve) com resultados exportados para uma planilha do Excel e analisados utilizando o modelo matemático $2^{-\Delta \Delta C T}$. 


\subsection{AVALIAÇÃO DA FREQUÊNCIA DE MUTAÇÕES DO EGFR E DO KRAS EM MODELO EXPERIMENTAL DE NEOPLASIA PLEURAL}

Para a avaliação das mutações foi realizado o sequenciamento dos exons 18, 19, 20, 21 e 22 do gene do EGRF, e do exon 2 do gene KRAS.

As regiões de interesse foram primeiramente amplificadas por PCR utilizando primers e mix de reações conforme Anexo, Tabelas 3 e 4 .

Todas as reações foram amplificadas utilizando 1 ciclo de 2 minutos a $95^{\circ} \mathrm{C}, 40$ ciclos de 30 segundos a $95^{\circ} \mathrm{C}$ e 30 segundos a $55^{\circ} \mathrm{C}$, e 1 ciclo de 5 minutos a $72^{\circ} \mathrm{C}$.

Após, os produtos foram submetidos a eletroforese em gel de agarose a $2 \%$ para verificação de presença de amplificação e se estas apresentavam o tamanho em pares de base esperado. Em seguida, foram purificadas para a eliminação de primers e dNTPs não incorporados (Illustra ExoProStar, GE Healthcare), a $37^{\circ} \mathrm{C}$ por 15 minutos, seguido de um passo de inativação da enzima a $80^{\circ} \mathrm{C}$ por 15 minutos.

As amostras purificadas foram sequenciadas através de eletroforese capilar utilizando a técnica de Sanger no equipamento 3500xL Genetic Analyzer, com reagentes e volumes descritos no Anexo, Tabela 5.

No termociclador foram realizados 1 ciclo de 2 minutos a $96^{\circ} \mathrm{C}, 25$ ciclos de 10 segundos a $96^{\circ} \mathrm{C}, 5$ segundos a $55^{\circ} \mathrm{C}$ e 1 minuto a $60^{\circ} \mathrm{C}$, e 1 ciclo de 5 minutos a $72^{\circ} \mathrm{C}$. Em seguida, as reações foram purificadas por precipitação com etanol e EDTA $125 \mathrm{mM}$, seguida por uma precipitação com etanol 70\% e, posteriormente, colocadas em banho seco a $96^{\circ} \mathrm{C}$ por 3 minutos, para a total evaporação do etanol. Foram então suspensas em $10 \mu \mathrm{L}$ de Hi-Di Formamide (Thermo Fisher), desnaturadas em banho seco a $96^{\circ} \mathrm{C}$ por 3 minutos e submetidas à eletroforese utilizando capilar de $50 \mathrm{~cm}$ e POP-7 (Thermo Fisher).

Os dados obtidos foram analisados através do Software Geneious 8.1, comparando a sequência obtida com a sequência referência de cada um dos genes sequenciados. 


\subsection{ANÁLISE ESTATÍSTICA}

Os dados foram submetidos à análise descritiva demonstrada através de média e desvio padrão para cada um dos parâmetros avaliados.

Para análise comparativa utilizou-se o teste ANOVA one-way seguido de um teste de múltiplas comparações.

$\mathrm{Na}$ análise de sobrevida foram feitas comparações entre as curvas pelo teste estatístico de Kaplan-Meier, e os sobreviventes foram comparados por meio de teste de log-rank.

Todos os procedimentos estatísticos foram realizados com ajuda do software para Windows SPSS, versão 9.0 (Illinois/Estados Unidos) e com 0 programa SigmaStat 3.1 (Systat, Califórnia/Estados Unidos), com nível de significância estatística fixado em $p<0,05$. 
RESULTADOS 


\section{RESULTADOS}

\subsection{MODELO EXPERIMENTAL DE NEOPLASIA PLEURAL INDUZIDO COM DIFERENTES CONCENTRAÇÕES DE CÉLULAS NEOPLÁSICAS}

Após a injeção intrapleural de diferentes concentrações de células LLC (grupos $\mathrm{A}, \mathrm{B}$ e $\mathrm{C}$ ), todos os animais desenvolveram neoplasia pleural, com implantes tumorais e derrame pleural maligno, porém com diferenças entre os grupos de acordo com o tempo e o estágio da doença (Apêndice). ${ }^{96}$

Todos os animais apresentaram emagrecimento evolutivo após o desenvolvimento da neoplasia pleural, bem como redução progressiva de atividade / mobilidade. Isto foi bastante evidente no grupo A, que apresentou redução de peso e mobilidade já no 14ํ dia, notadas somente após 21 dias nos demais grupos $(p<0,05)$.

A carcinomatose pleural foi letal após o implante de células de Lewis, com sobrevida máxima de 19 dias no grupo que recebeu maior concentração de células LLC (grupo A), 25 dias no grupo $B\left(0,5 \times 10^{5}\right)$ e 27 no grupo $C$ $\left(0,1 \times 10^{5}\right)$, conforme Figura 5 .

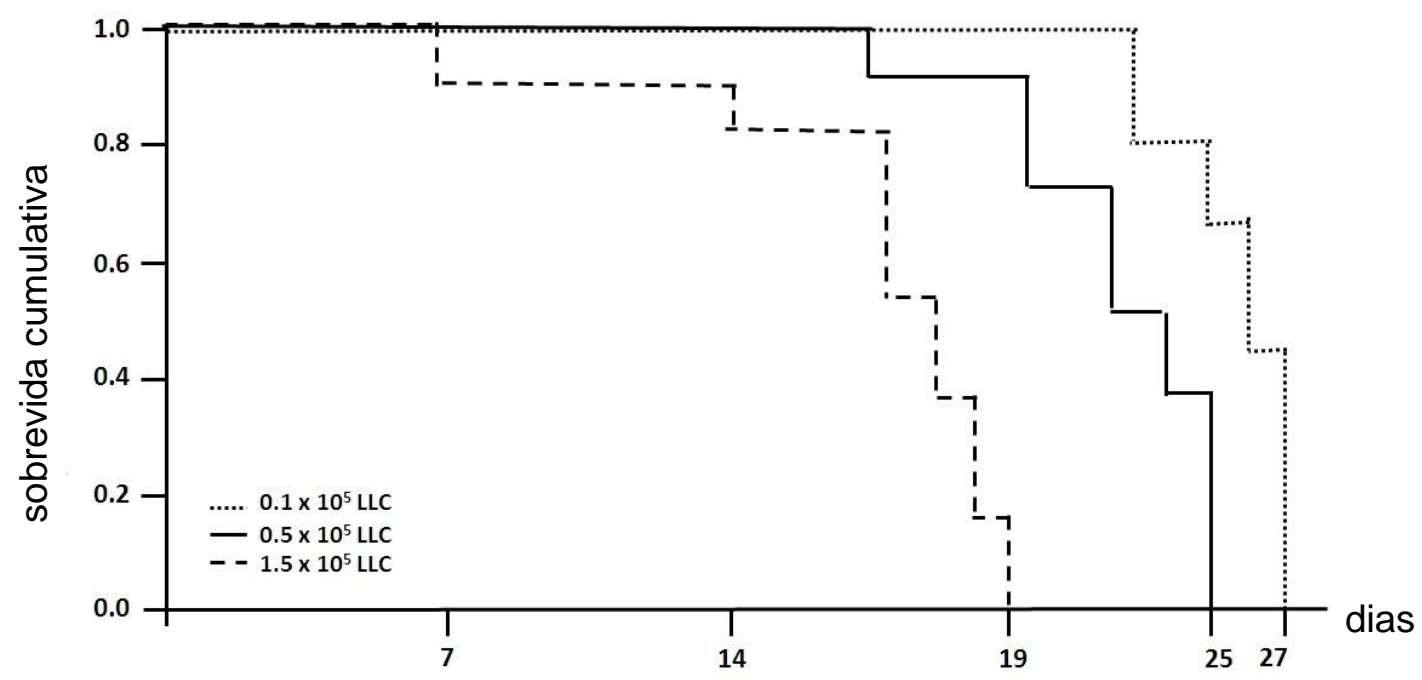

Figura 5 - Avaliação do tempo de sobrevida após indução de neoplasia pleural com 1,5 (grupo C), 0,5 (grupo B) e $0,1 \times 10^{5}$ (grupo A) células LLC 
O líquido pleural foi mensurado aos 7, 14 e 21 dias. O volume foi aumentando significativamente de acordo com o tempo e a concentração de células LLC instiladas $(p<0,05)$. O grupo $C$ apresentou derrame pleural somente após o $14^{\circ}$ dia, em poucos animais, enquanto o grupo $A$ foi avaliado somente até $014^{\circ}$ dia, pois os animais sobreviveram apenas até o $19^{\circ}$ dia, não sendo possível realizar a última medida $\left(21^{\circ} \mathrm{dia}\right)$.

O líquido foi macroscopicamente hemático, posteriormente caracterizado como um exsudato mononuclear (Figura 6).
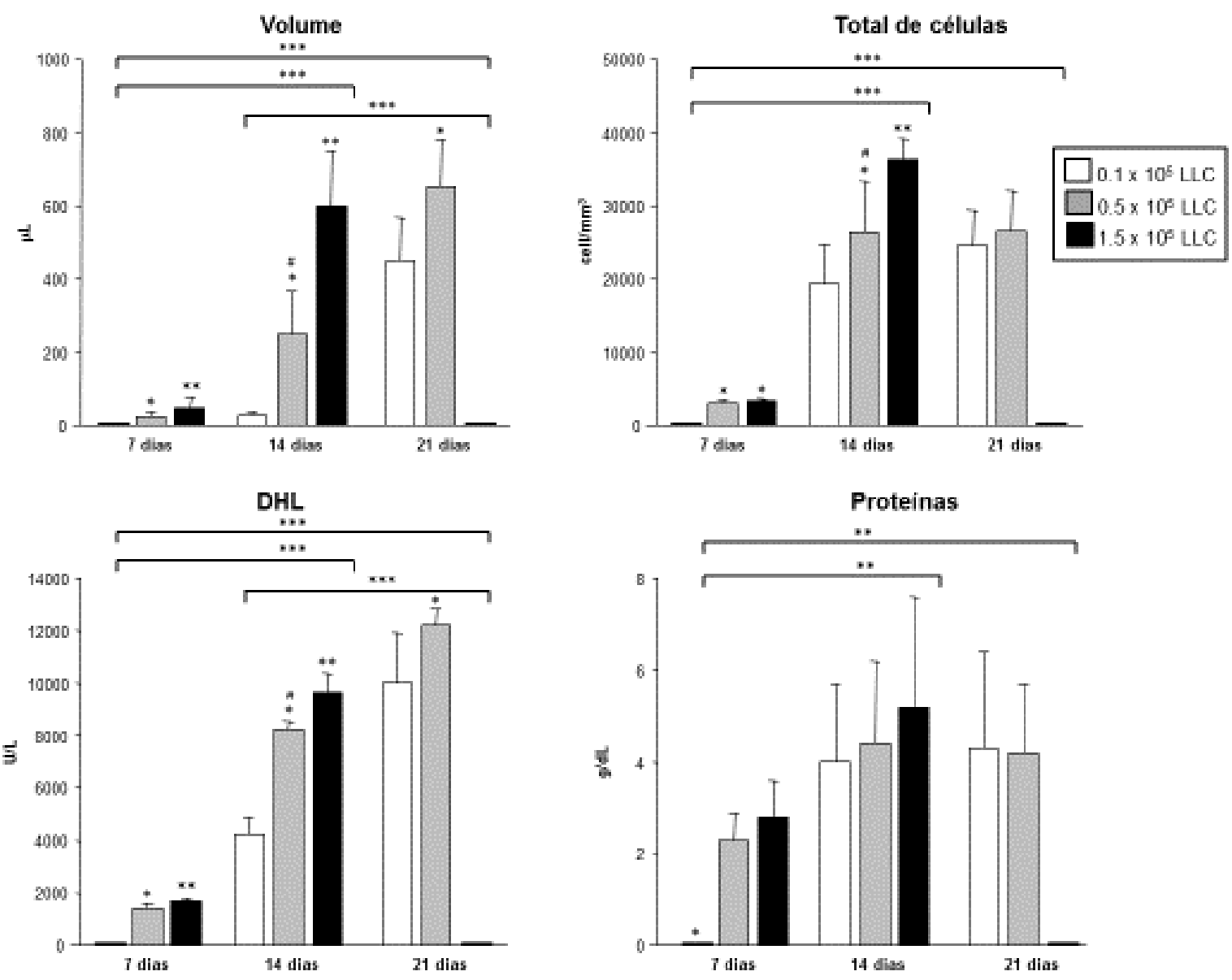

Figura 6 - Volume, total de células e parâmetros bioquímicos do líquido pleural de camundongos submetidos à indução de neoplasia pleural com

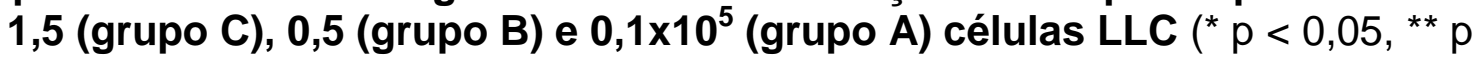
$<0,001,{ }^{* * *} p<0,001$ entre os grupos e \# $p<0,05$ entre os grupos)

A contagem total de células no líquido pleural aumentou progressivamente, sendo mais evidente nos casos induzidos com maiores concentrações de células LLC (Figura 6). A análise citológica diferencial 
revelou um infiltrado inflamatório misto com células malignas intercaladas, e as células inflamatórias foram predominantemente células mononucleares $(60 \%)$ e linfócitos (20\%), com apenas $10 \%$ de neutrófilos.

Exceto no grupo $C\left(0,1 \times 10^{5}\right)$ aos 7 dias, em que poucos animais tinham líquido pleural para análise, a dosagem de $\mathrm{DHL}$ no líquido pleural foi maior em proporção ao tempo de estudo $(p<0,001)$ e à concentração de células LLC injetadas $(p<0,05)$, enquanto os níveis de proteínas foram semelhantes entre os grupos (Figura 6 ).

Os implantes tumorais pleurais foram observados mais precocemente nos grupos que receberam maior concentração de células LLC, assim como a presença de tumores soltos no espaço pleural a partir do $7^{\circ}$ dia. Tumores soltos são grandes tumores pleurais formando pontes entre 0 parênquima pulmonar e a caixa torácica e infiltrando estruturas anatômicas vizinhas, incluindo parede torácica, mediastino e diafragma. Isto foi mais evidente no grupo $A\left(1,5 \times 10^{5}\right)$, que apresentou numerosos implantes tumorais em pleura visceral e pleura parietal 7 dias após a injeção das células neoplásicas. No grupo $\mathrm{B}\left(0,5 \times 10^{5}\right)$, neste dia, observamos alguns implantes dispersos, mas a implantação foi mais pronunciada no $14^{\circ}$ dia. No grupo $\mathrm{C}$, os implantes foram observados somente após 14 dias (Figura 7).

Em alguns animais, houve infiltração neoplásica do parênquima pulmonar, porém sem correlação com a concentração de células neoplásicas utilizadas na indução da neoplasia pleural ou o tempo de exposição. No entanto, com exceção do grupo $C$ no $7^{\circ}$ dia, houve inflamação do parênquima pulmonar em todos os grupos, em todas as amostras avaliadas.

A avaliação histológica do pericárdio e do músculo cardíaco mostrou implantes tumorais já no $7^{\circ}$ dia após a injeção de $1,5 \times 10^{5}$ células LLC, com progressão ao longo do tempo. Nas outras concentrações, foram observados poucos implantes tumorais cardíacos durante o estudo (Figura 8). 


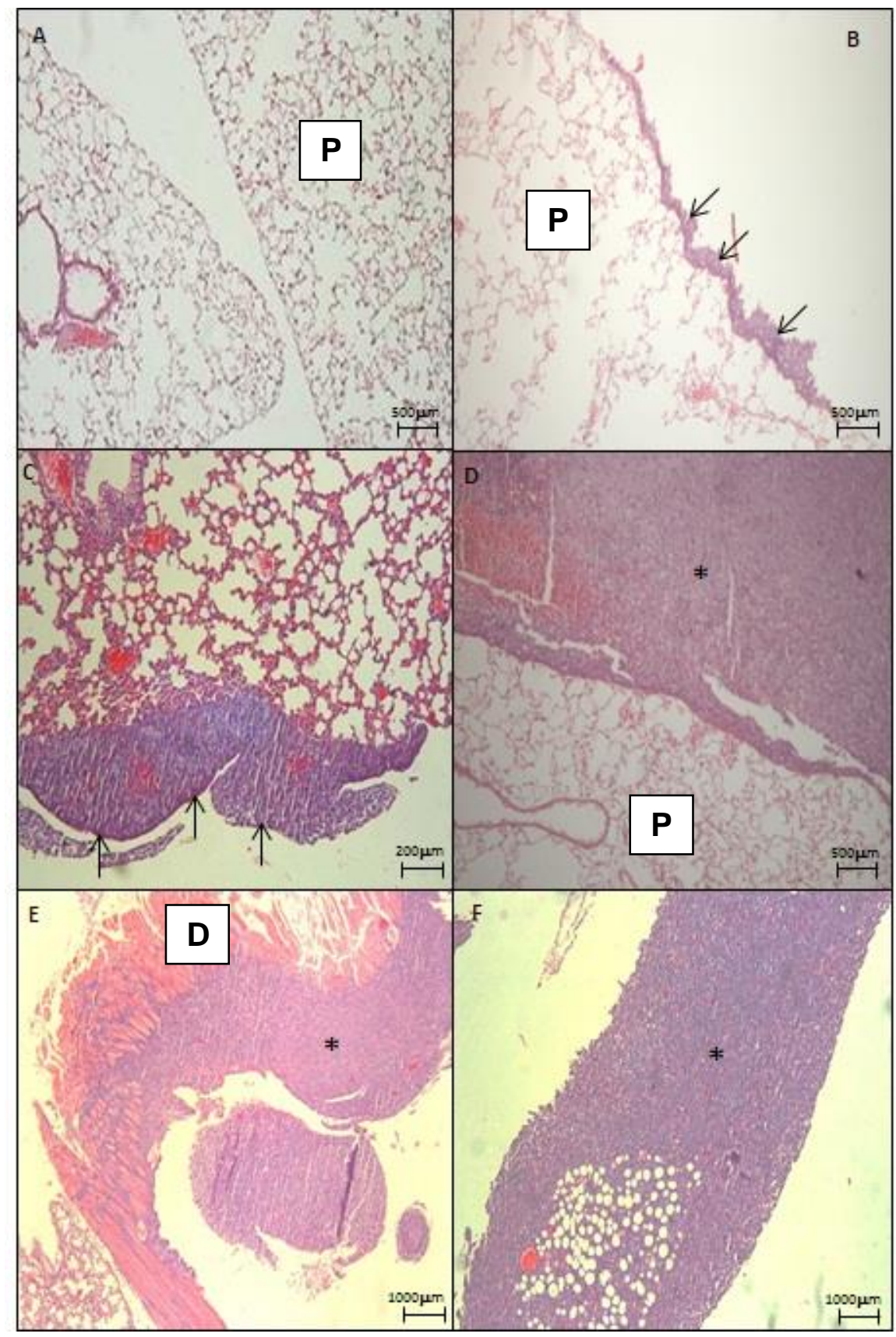

Figura 7 - Histologia de pleura, pulmão e diafragma de camundongos submetidos à injeção intrapleural de células LLC, sendo $(A)$ pleura $e$ parênquima pulmonar 7 dias após a injeção de $0,1 \times 10^{5}$ células, (B) implante na pleura visceral 7 dias após a injeção de $0,5 \times 10^{5}$ células (setas), (C) implante em pleura visceral 14 dias após a injeção de $0,5 \times 10^{5}$ células (setas), (D) implante na pleura visceral 14 dias após a injeção de $1,5 \times 10^{5}$ células $\left(^{*}\right),(E)$ invasão tumoral de diafragma 14 dias após a injeção de $1,5 \times 10^{5}$ células $\left(^{*}\right)$ e (F) massa 21 dias após a injeção de $1,5 \times 10^{5}$ células LLC $\left(^{*}\right)$. $P=$ pulmão e $D=$ diafragma 


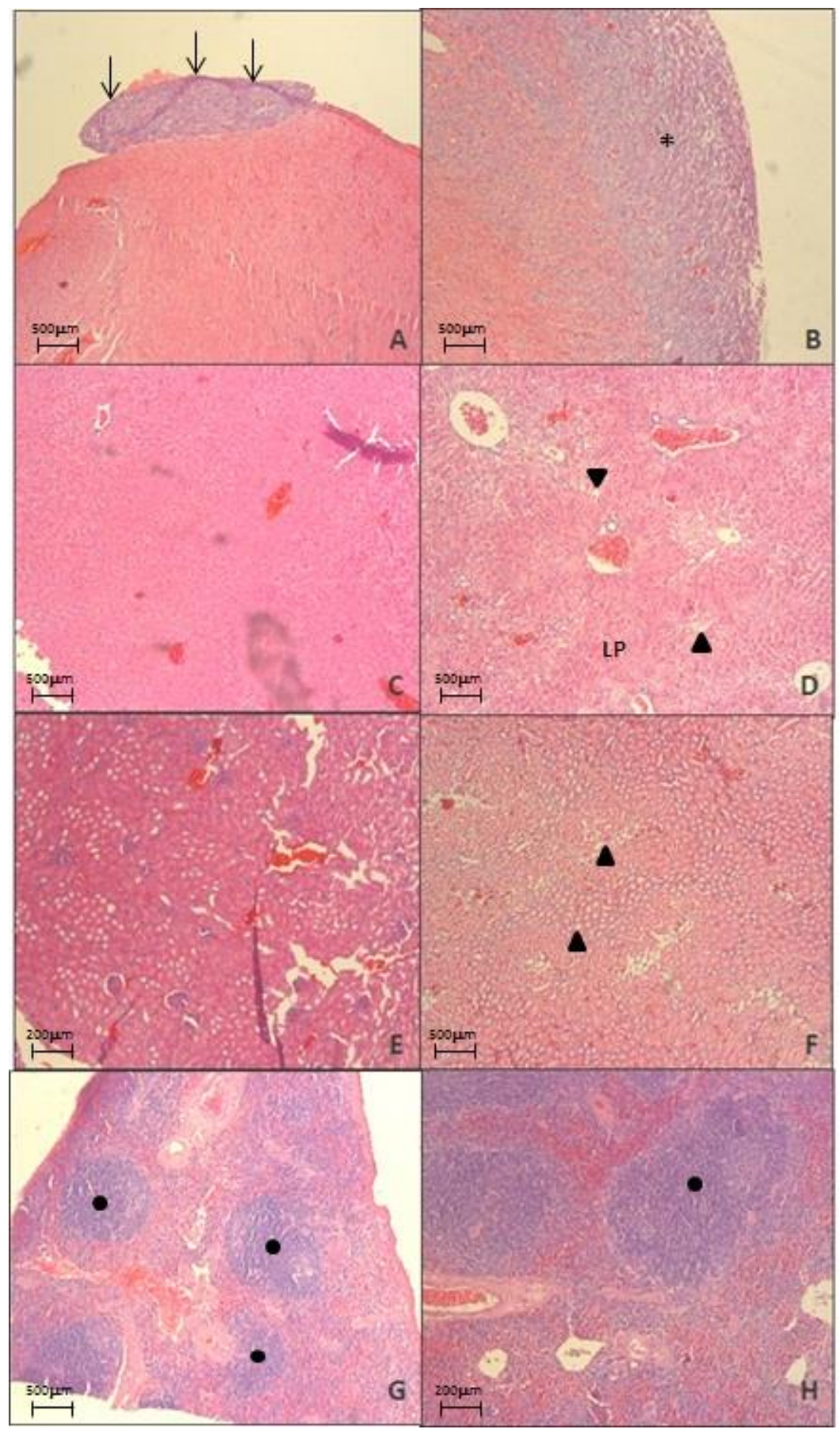

Figura 8 - Histologia de outros órgãos de camundongos submetidos à injeção intrapleural de células LLC, sendo (A) implante em pericárdio 7 dias após a injeção de $1,5 \times 10^{5}$ células (setas), (B) células neoplásicas infiltrando o miocárdio 14 dias após a injeção de $1,5 \times 10^{5}$ células $\left.{ }^{*}\right)$, (C) fígado normal 7 dias após a injeção de $0,5 \times 10^{5}$ células, (D) fígado com esteatose 14 dias após indução da neoplasia (triângulos), (E) e (F) rins com esteatose tubular 7 e 14 dias após indução da neoplasia (triângulos) e $(G)$ e $(H)$ hiperplasia esplênica 7 e 14 dias após indução da neoplasia (círculos) 
Não houve alterações histológicas relevantes em amostras de rins, porém houve hiperplasia da polpa branca do baço em todos os grupos, mais evidente nos grupos A e B. Nestes dois grupos, também foram observados focos de micro-esteatose hepática após o 14ํ dia (Figura 8).

No grupo sem doença (D), que recebeu solução salina intrapleural, não houve acúmulo de líquido pleural, achado de tumorações, perda de peso, redução de mobilidade, óbito espontâneo ou alterações histológicas.

\subsection{ESTUDO DE TERAPIAS-ALVO EM NEOPLASIA PLEURAL EXPERIMENTALMENTE INDUZIDA}

Todos os animais apresentaram emagrecimento progressivo após o desenvolvimento da neoplasia pleural (implante das células LLC), porém não houve diferença significativa entre os animais não tratados e tratados (Tabela $6)$.

Tabela 6 - Controle de peso $(\mathrm{g})$ dos camundongos submetidos à injeção de LLC com e sem tratamento

\begin{tabular}{cccccc}
\hline \multirow{2}{*}{ Tempo } & Sem & \multicolumn{3}{c}{ Com tratamento } & \multirow{2}{*}{$\mathbf{p}$} \\
\cline { 3 - 5 } & tratamento & Anti-VEGF (A) & Anti-EGFR (E) & $(\mathbf{A})+(\mathrm{E})$ & \\
\hline $\mathbf{0 7}$ dias & $24,1 \pm 2,0$ & $24,1 \pm 0,6$ & $24,6 \pm 1,3$ & $23,1 \pm 1,6$ & 0,181 \\
$\mathbf{1 0}$ dias & $23,4 \pm 1,1$ & $23,9 \pm 1,0$ & $25,0 \pm 1,3$ & $23,2 \pm 1,4$ & 0,178 \\
$\mathbf{1 4}$ dias & $22,8 \pm 2,5$ & $23,4 \pm 1,8$ & $24,3 \pm 0,4$ & $23,2 \pm 1,0$ & 0,684 \\
$\mathbf{2 1}$ dias & $18,5 \pm 0,78^{*}$ & $19,7 \pm 0,8^{*}$ & $19,8 \pm 2,0^{*}$ & $19,5 \pm 0,5^{*}$ & 0,353 \\
\hline $\mathbf{p}$ & 0,024 & 0,038 & 0,026 & 0,032 & \\
\hline
\end{tabular}

* diferença entre os tempos

Houve redução progressiva de atividade / mobilidade, bastante evidente e sem diferença entre os grupos no $21^{\circ}$ dia da doença (Tabela 7). Entretanto, os animais tratados com anti-EGFR e com anti-VEGF + anti-EGFR, no $10^{\circ}$ e no 
$14^{\circ}$ dias, estavam significativamente mais ativos do que os animais não tratados ou tratados apenas com anti-VEGF $(p<0,05)$.

Tabela 7 - Redução de atividade $/$ mobilidade $(0=$ normal; 4 = inatividade $)$

\begin{tabular}{|c|c|c|c|c|c|}
\hline \multirow{2}{*}{ Tempo } & \multirow{2}{*}{$\begin{array}{c}\text { Sem } \\
\text { tratamento }\end{array}$} & \multicolumn{3}{|c|}{ Com tratamento } & \multirow{2}{*}{ p } \\
\hline & & Anti-VEGF (A) & Anti-EGFR (E) & $(A)+(E)$ & \\
\hline 07 dias & 0 & 0 & 0 & 0 & 1,000 \\
\hline 10 dias & $1^{+}$ & $1^{+}$ & 0 & 0 & 0,026 \\
\hline 14 dias & $2^{*+}$ & $2^{*+}$ & 1 & 1 & 0,026 \\
\hline 21 dias & $3^{*}$ & $3^{*}$ & $3^{*}$ & $3^{*}$ & 1,000 \\
\hline $\mathbf{p}$ & $<0,001$ & $<0,001$ & $<0,001$ & $<0,001$ & \\
\hline
\end{tabular}

A carcinomatose pleural foi letal em todos os grupos, com mortalidade de $100 \%$, sem diferença de sobrevida entre os animais tratados ou não máximo de 24 dias no Grupo Anti-VEGF e de 25 no grupo não tratado e demais grupos de animais tratados (Figura 5).

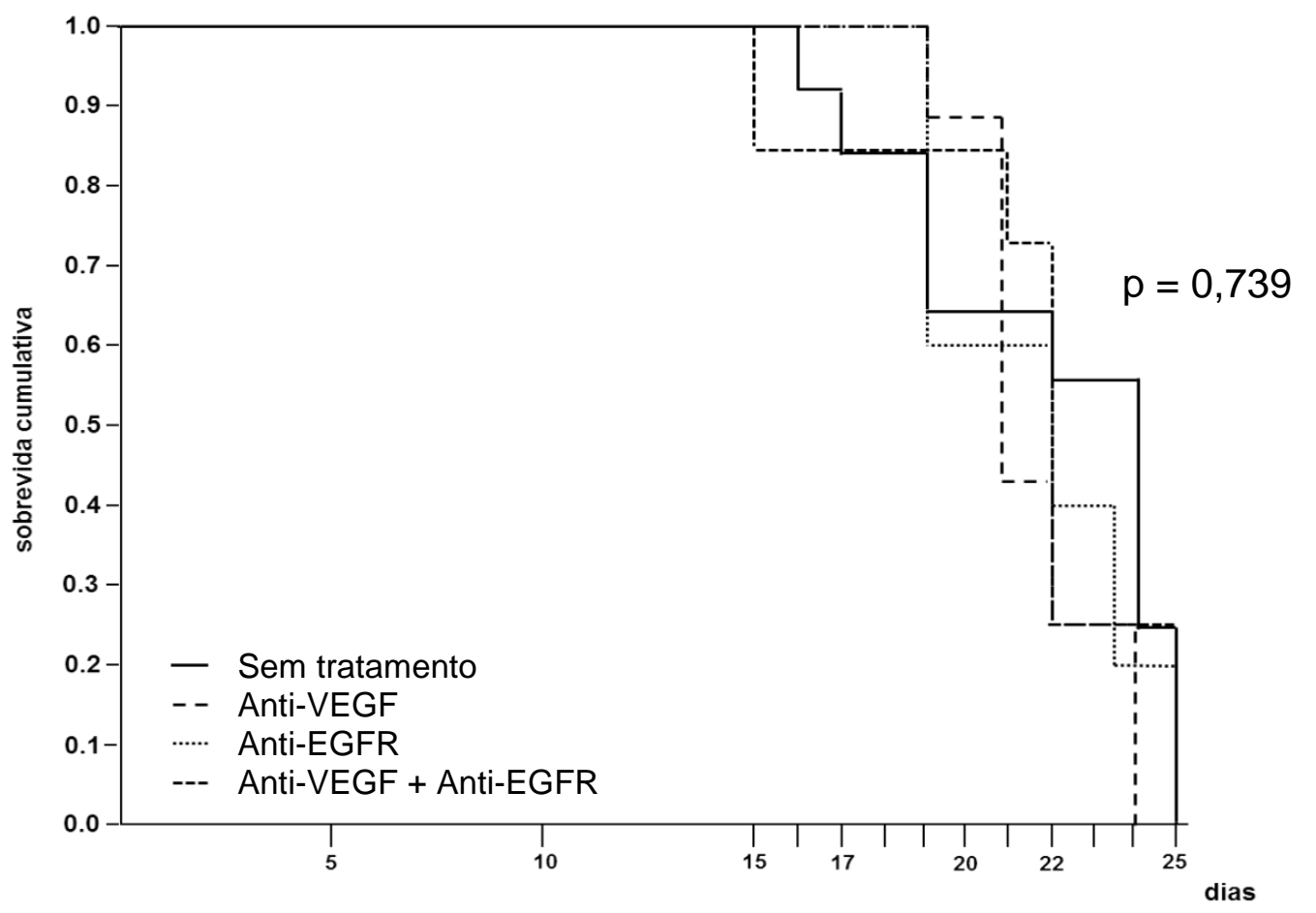

Figura 9 - Curva de sobrevida comparativa de camundongos com doença pleural maligna não tratados e tratados 
Todos os animais desenvolveram neoplasia pleural, com massas e derrame pleural evidentes a partir do $14^{\circ}$ dia de evolução (Figura 6 ).

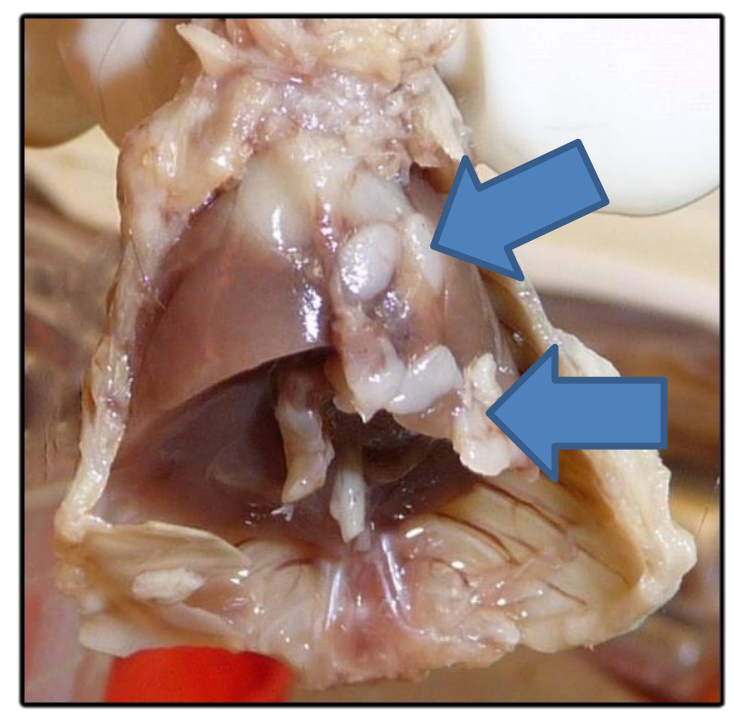

Figura 10 - Tórax em bloco de camundongo com neoplasia pleural maligna, evidenciando implantes tumorais / massas (setas) em pleura visceral

$\mathrm{Na}$ avaliação temporal observou-se aumento progressivo do volume de líquido pleural em todos os grupos. No entanto, o volume de líquido pleural foi significativamente menor em todos os animais que receberam algum tratamento (Tabela 8).

Tabela 8 - Avaliação do volume $(\mu \mathrm{L})$ de líquido pleural

\begin{tabular}{cccccc}
\hline \multirow{2}{*}{ Tempo } & Sem & \multicolumn{3}{c}{ Com tratamento } & \multirow{2}{*}{$\mathbf{p}$} \\
\cline { 3 - 5 } & tratamento & Anti-VEGF (A) & Anti-EGFR (E) & (A) +(E) & \\
\hline 07 dias & $68 \pm 10^{+}$ & $52 \pm 15$ & $53 \pm 5$ & $45 \pm 10$ & 0,008 \\
10 dias & $200 \pm 100^{*+}$ & $67 \pm 29$ & $63 \pm 25$ & $58 \pm 30$ & 0,010 \\
$\mathbf{1 4}$ dias & $475 \pm 89^{\star+}$ & $413 \pm 83^{*}$ & $417 \pm 133^{*}$ & $375 \pm 50^{*}$ & 0,046 \\
$\mathbf{2 1}$ dias & $671 \pm 61^{*+}$ & $424 \pm 157^{*}$ & $425 \pm 96^{*}$ & $350 \pm 64^{*}$ & 0,029 \\
\hline $\mathbf{P}$ & $<0,001$ & $<0,001$ & $<0,001$ & $<0,001$ & \\
\hline
\end{tabular}

* diferença entre os tempos ${ }^{+}$diferença entre os grupos 
Não observamos alterações significativas ou relevantes na avaliação sérica em todos os grupos. No líquido pleural observou-se um aumento progressivo da celularidade e dos níveis de desidrogenase láctica e de proteínas totais, conforme a evolução da doença pleural maligna (Tabelas 9 a 15).

Em todos os grupos de animais tratados a análise citológica evidenciou celularidade total significativamente menor do que no grupo de animais sem tratamento, em todos os tempos analisados (Tabela 9).

Tabela 9 - Total de células nucleadas $\left(\mathrm{mm}^{3}\right)$ no líquido pleural

\begin{tabular}{|c|c|c|c|c|c|}
\hline \multirow{2}{*}{ Tempo } & \multirow{2}{*}{$\begin{array}{c}\text { Sem } \\
\text { tratamento }\end{array}$} & \multicolumn{3}{|c|}{ Com tratamento } & \multirow{2}{*}{$\mathbf{p}$} \\
\hline & & Anti-VEGF (A) & Anti-EGFR (E) & $(A)+(E)$ & \\
\hline 07 dias & $3.020 \pm 404^{+}$ & $2.148 \pm 811$ & $1.750 \pm 900$ & $1.650 \pm 915$ & 0,035 \\
\hline 10 dias & $\begin{array}{c}10.200 \pm \\
5.150^{\star+}\end{array}$ & $\begin{array}{c}6.630 \pm \\
3.023^{\star}\end{array}$ & $\begin{array}{l}8.300 \pm \\
2.224^{*+}\end{array}$ & $\begin{array}{c}4.650 \pm \\
3.226^{\star}\end{array}$ & 0,026 \\
\hline 14 dias & $\begin{array}{c}19.400 \pm \\
9.297^{\star+}\end{array}$ & $\begin{array}{c}16.388 \pm \\
8.453^{+\star}\end{array}$ & $\begin{array}{c}14.400 \pm \\
7.826^{\star}\end{array}$ & $\begin{array}{c}14.900 \pm \\
2.458^{\star}\end{array}$ & 0,032 \\
\hline 21 dias & $\begin{array}{l}23.565 \pm \\
22.576^{\star+}\end{array}$ & $\begin{array}{c}14.222 \pm \\
7.601^{*}\end{array}$ & $\begin{array}{c}13.687 \pm \\
4.898^{\star}\end{array}$ & $\begin{array}{c}15.900 \pm \\
10.524^{*}\end{array}$ & 0,033 \\
\hline $\mathbf{p}$ & $<0,001$ & $<0,001$ & $<0,001$ & $<0,001$ & \\
\hline
\end{tabular}

No $14^{\circ}$ dia do experimento verificou-se menor proporção de leucócitos no líquido pleural dos camundongos tratados com anti-VEGF + anti-EGFR (Tabela 10). E, exceto por queda isolada de leucócitos e aumento isolado de macrófagos no líquido pleural dos animais sem tratamento no $21^{\circ}$ dia, não houve outras diferenças significativas na análise citológica diferencial (Tabelas 10 a 13). 
Tabela 10 - Contagem de leucócitos (\%) no líquido pleural

\begin{tabular}{cccccc}
\hline \multirow{2}{*}{ Tempo } & \multirow{2}{*}{ Sem } & \multicolumn{3}{c}{ Com tratamento } & \multirow{2}{*}{$\mathbf{p}$} \\
\cline { 3 - 5 } & tratamento & Anti-VEGF (A) & Anti-EGFR (E) & $(\mathrm{A})+(\mathrm{E})$ & \\
\hline 07 dias & $61 \pm 1,0$ & $46 \pm 3,6$ & $64 \pm 4,5$ & $72 \pm 8,1$ & 0,041 \\
10 dias & $59 \pm 8,5$ & $54 \pm 8,6$ & $61 \pm 7,2$ & $63 \pm 2,8$ & 0,111 \\
14 dias & $55 \pm 9,0$ & $63 \pm 13,1$ & $63 \pm 4,5$ & $42 \pm 23,3^{\star+}$ & 0,014 \\
21 dias & $40 \pm 7,0^{*+}$ & $64 \pm 6,1$ & $72 \pm 5,7$ & $65 \pm 4,8$ & 0,001 \\
\hline $\mathbf{p}$ & 0,038 & 0,124 & 0,237 & 0,063 & \\
\hline
\end{tabular}

${ }^{*}$ diferença entre os tempos ${ }^{+}$diferença entre os grupos

Tabela 11 - Contagem diferencial de macrófagos (\%) no líquido pleural

\begin{tabular}{cccccc}
\hline \multirow{2}{*}{ Tempo } & \multirow{2}{*}{$\begin{array}{c}\text { Sem } \\
\text { tratamento }\end{array}$} & \multicolumn{3}{c}{ Com tratamento } & \multirow{2}{*}{$\mathbf{p}$} \\
\cline { 3 - 5 } & & Anti-VEGF (A) & Anti-EGFR (E) & (A) +(E) & \\
\hline 07 dias & $39 \pm 1,0$ & $54 \pm 3,6$ & $36 \pm 4,5$ & $28 \pm 8,1$ & 0,151 \\
10 dias & $40 \pm 9,6$ & $43 \pm 5,7$ & $38 \pm 6,1$ & $34 \pm 4,9$ & 0,300 \\
14 dias & $42 \pm 6,1$ & $39 \pm 11$ & $40 \pm 7,1$ & $54 \pm 19,8$ & 0,722 \\
21 dias & $58 \pm 7,7^{*+}$ & $35 \pm 6,1$ & $27,3 \pm 5,7$ & $32 \pm 1,8$ & $<0,001$ \\
\hline $\mathbf{p}$ & 0,038 & 0,237 & 0,132 & 0,055 & \\
\hline
\end{tabular}

* diferença entre os tempos ${ }^{+}$diferença entre os grupos

Tabela 12 - Contagem diferencial de neutrófilos (\%) no líquido pleural

\begin{tabular}{cccccc}
\hline \multirow{2}{*}{ Tempo } & Sem & \multicolumn{3}{c}{ Com tratamento } & \multirow{2}{*}{ p } \\
\cline { 3 - 5 } & tratamento & Anti-VEGF (A) & Anti-EGFR (E) & $(\mathrm{A})+(\mathrm{E})$ & \\
\hline 07 dias & $21 \pm 5,3$ & $25 \pm 15,6$ & $26,8 \pm 18,1$ & $30 \pm 5,6$ & 0,053 \\
10 dias & $35 \pm 10,4$ & $52 \pm 13,5$ & $46 \pm 12,5$ & $48 \pm 20,5$ & 0,465 \\
14 dias & $65 \pm 7,9$ & $61 \pm 8,6$ & $59 \pm 10,0$ & $67 \pm 5,6$ & 0,430 \\
21 dias & $59 \pm 0,7$ & $62 \pm 10,3$ & $66 \pm 6,6$ & $64 \pm 7,2$ & 0,983 \\
\hline $\mathbf{p}$ & 0,052 & 0,156 & 0,325 & 0,458 & \\
\hline
\end{tabular}


Tabela 13 - Contagem diferencial de linfócitos (\%) no líquido pleural

\begin{tabular}{|c|c|c|c|c|c|}
\hline \multirow{2}{*}{ Tempo } & \multirow{2}{*}{$\begin{array}{c}\text { Sem } \\
\text { tratamento }\end{array}$} & \multicolumn{3}{|c|}{ Com tratamento } & \multirow{2}{*}{$\mathbf{p}$} \\
\hline & & $\overline{\text { Anti-VEGF (A) }}$ & Anti-EGFR (E) & $(A)+(E)$ & \\
\hline 07 dias & $67 \pm 6,1$ & $53 \pm 23,3$ & $53 \pm 16,5$ & $61 \pm 14,8$ & 0,488 \\
\hline 10 dias & $54 \pm 12,2$ & $39 \pm 15,2$ & $40 \pm 13,7$ & $41 \pm 21,1$ & 0,736 \\
\hline 14 dias & $22 \pm 7,4$ & $20 \pm 9,4$ & $28 \pm 7,6$ & $21 \pm 14,3$ & 0,500 \\
\hline 21 dias & $39 \pm 0,7$ & $28 \pm 5,1$ & $24 \pm 5,1$ & $28 \pm 15,8$ & 0,277 \\
\hline$p$ & 0,068 & 0,158 & 0,256 & 0,137 & \\
\hline
\end{tabular}

Conforme a evolução da doença pleural maligna, houve aumento significativamente progressivo dos níveis de DHL, proteínas, VEGF e IL-6 no líquido pleural de todos os animais, bem como redução progressiva dos níveis de TNF- $\alpha$ (Tabelas 14 a 19).

Com exceção do $7^{\circ}$ dia, os níveis de DHL foram significativamente menores em todos os animais tratados, mas não foram observadas diferenças dos níveis de proteínas entre os grupos (Tabelas 14 e 15).

Tabela 14 - Dosagem de desidrogenase láctica (UI/L) no líquido pleural

\begin{tabular}{cccccc}
\hline \multirow{2}{*}{ Tempo } & Sem & \multicolumn{3}{c}{ Com tratamento } & \multirow{2}{*}{$\mathbf{p}$} \\
\cline { 3 - 5 } & tratamento & Anti-VEGF (A) & Anti-EGFR (E) & $(\mathbf{A})+(\mathrm{E})$ & \\
\hline $\mathbf{0 7}$ dias & $1.400 \pm 220$ & $935 \pm 410$ & $1.076 \pm 519$ & $1.046 \pm 146$ & 0,143 \\
$\mathbf{1 0}$ dias & $4.275 \pm 460^{\star+}$ & $985 \pm 450$ & $956 \pm 893$ & $902 \pm 366$ & 0,034 \\
$\mathbf{1 4}$ dias & $16.220 \pm 780^{\star+}$ & $12.650 \pm 784$ & $11.029 \pm 850$ & $9.940 \pm 3.440$ & 0,042 \\
$\mathbf{2 1}$ dias & $24.000 \pm 660^{+}$ & $17.080 \pm 828$ & $7.755 \pm 633$ & $11.403 \pm 931$ & $<0,001$ \\
\hline $\mathbf{p}$ & $<0,001$ & $<0,001$ & $<0,001$ & $<0,001$ & \\
\hline
\end{tabular}

* diferença entre os tempos ${ }^{+}$diferença entre os grupos

Quanto às citocinas do líquido pleural, os níveis de VEGF e IL-6 foram significativamente maiores no $21^{\circ}$ dia de estudo dos animais sem tratamento, assim como o EGF no $7^{\circ}$ dia (Tabelas 16 e 17). Não foram observadas outras diferenças significativas (Tabelas 16 a 19). 
Tabela 15 - Dosagem de proteínas totais $(\mathrm{g} / \mathrm{dL})$ no líquido pleural

\begin{tabular}{cccccc}
\hline \multirow{2}{*}{ Tempo } & \multirow{2}{*}{$\begin{array}{c}\text { Sem } \\
\text { tratamento }\end{array}$} & \multicolumn{3}{c}{ Com tratamento } & \multirow{2}{*}{$\mathbf{p}$} \\
\cline { 3 - 5 } & & Anti-VEGF (A) & Anti-EGFR (E) & (A) +(E) & \\
\hline $\mathbf{0 7}$ dias & $2,3 \pm 0,6$ & $2,1 \pm 0,7$ & $2,0 \pm 0,1$ & $2,1 \pm 0,1$ & 0,220 \\
$\mathbf{1 0}$ dias & $2,8 \pm 1,2$ & $2,9 \pm 1,1$ & $2,2 \pm 0,1$ & $2,3 \pm 0,2$ & 0,070 \\
$\mathbf{1 4}$ dias & $4,4 \pm 1,8^{\star}$ & $4,3 \pm 1,2^{\star}$ & $4,3 \pm 2,5^{\star}$ & $4,4 \pm 1,6^{\star}$ & 0,998 \\
$\mathbf{2 1}$ dias & $4,2 \pm 1,5^{\star}$ & $4,4 \pm 1,7^{\star}$ & $4,1 \pm 1,3^{\star}$ & $4,0 \pm 1,6^{\star}$ & 0,878 \\
\hline $\mathbf{p}$ & $<0,001$ & $<0,001$ & $<0,001$ & $<0,001$ & \\
\hline
\end{tabular}

* diferença entre os tempos

Tabela 16 - Dosagem de VEGF (pg/mL) no líquido pleural

\begin{tabular}{cccccc}
\hline \multirow{2}{*}{ Tempo } & \multirow{2}{*}{$\begin{array}{c}\text { Sem } \\
\text { tratamento }\end{array}$} & \multicolumn{3}{c}{ Com tratamento } & \multirow{2}{*}{ p } \\
\cline { 3 - 5 } & & Anti-VEGF (A) & Anti-EGFR (E) & $(\mathbf{A})+(\mathrm{E})$ & \\
\hline $\mathbf{0 7}$ dias & $<15,6$ & $<15,6$ & $<15,6$ & $<15,6$ & 1,000 \\
$\mathbf{1 0}$ dias & $110,8 \pm 35,7$ & $79,2 \pm 50,4$ & $90,1 \pm 23,9$ & $82,6 \pm 56,8$ & 0,970 \\
$\mathbf{1 4}$ dias & $417,7 \pm 66,7^{\star}$ & $346,5 \pm 75,8^{*}$ & $330,2 \pm 181,1^{*}$ & $369,8 \pm 48,6^{*}$ & 0,238 \\
$\mathbf{2 1}$ dias & $2277 \pm 143^{\star+}$ & $978 \pm 277^{\star}$ & $870 \pm 220^{*}$ & $685 \pm 211^{\star}$ & $<0,001$ \\
\hline $\mathbf{p}$ & $<0,001$ & $<0,001$ & $<0,001$ & $<0,001$ & \\
\hline
\end{tabular}

* diferença entre os tempos ${ }^{+}$diferença entre os grupos

Tabela 17 - Dosagem de EGF (pg/mL) no líquido pleural

\begin{tabular}{cccccc}
\hline \multirow{2}{*}{ Tempo } & Sem & \multicolumn{3}{c}{ Com tratamento } & \multirow{2}{*}{ p } \\
\cline { 3 - 5 } & tratamento & Anti-VEGF (A) & Anti-EGFR (E) & $(\mathbf{A})+(\mathrm{E})$ & \\
\hline 07 dias & $5,7 \pm 1,0^{+}$ & $4,1 \pm 0,6$ & $4,9 \pm 0,5$ & $4,5 \pm 0,2$ & 0,004 \\
$\mathbf{1 0}$ dias & $4,3 \pm 0,2$ & $4,1 \pm 0,4$ & $4,2 \pm 0,2$ & $4,6 \pm 0,3$ & 0,206 \\
$\mathbf{1 4}$ dias & $8,1 \pm 9,0$ & $5,1 \pm 2,0$ & $4,9 \pm 0,9$ & $4,3 \pm 0,1$ & 0,128 \\
$\mathbf{2 1}$ dias & $8,5 \pm 10,2$ & $6,2 \pm 3,5$ & $5,3 \pm 3,2$ & $5,3 \pm 2,2$ & 0,245 \\
\hline p & 0,098 & 0,545 & 0,985 & 0,857 & \\
\hline
\end{tabular}

${ }^{+}$diferença entre os grupos 
Tabela 18 - Dosagem de TNF- $\alpha$ (pg/mL) no líquido pleural

\begin{tabular}{cccccc}
\hline \multirow{2}{*}{ Tempo } & Sem & \multicolumn{3}{c}{ Com tratamento } & \multirow{2}{*}{ p } \\
\cline { 3 - 5 } & tratamento & Anti-VEGF (A) & Anti-EGFR (E) & (A) +(E) & \\
\hline 07 dias & $158,8 \pm 77,4^{*}$ & $190,5 \pm 55,5^{*}$ & $149,6 \pm 110^{*}$ & $136,72 \pm 108^{*}$ & 0,123 \\
10 dias & $56,8 \pm 0,8$ & $41,2 \pm 15,6$ & $48,4 \pm 23,1$ & $51,3 \pm 25,7$ & 0,856 \\
14 dias & $40,4 \pm 14,3$ & $47,0 \pm 13,1$ & $41,3 \pm 22,2$ & $40,9 \pm 32,5$ & 0,832 \\
21 dias & $47,2 \pm 15,3$ & $48,1 \pm 12,1$ & $45,3 \pm 21,4$ & $41,2 \pm 22,4$ & 0,972 \\
\hline $\mathbf{p}$ & 0,023 & $<0,001$ & 0,032 & 0,048 & \\
\hline
\end{tabular}

${ }^{*}$ diferença entre os tempos

Tabela 19 - Dosagem de IL-6 (pg/mL) no líquido pleural

\begin{tabular}{cccccc}
\hline \multirow{2}{*}{ Tempo } & Sem & \multicolumn{3}{c}{ Com tratamento } & p \\
\cline { 3 - 5 } & tratamento & Anti-VEGF (A) & Anti-EGFR (E) & $(\mathbf{A})+(\mathrm{E})$ & \\
\hline $\mathbf{0 7}$ dias & $<15,6$ & $<15,6$ & $<15,6$ & $<15,6$ & 1,000 \\
$\mathbf{1 0}$ dias & $76,0 \pm 112,3$ & $37,1 \pm 30$ & $44 \pm 10$ & $53 \pm 36$ & 0,659 \\
$\mathbf{1 4}$ dias & $188 \pm 127^{*}$ & $149,8 \pm 96,7^{*}$ & $162 \pm 69^{*}$ & $150 \pm 62^{*}$ & 0,895 \\
$\mathbf{2 1}$ dias & $1204 \pm 319^{*+}$ & $145 \pm 111^{*}$ & $164 \pm 77^{*}$ & $142 \pm 82^{*}$ & $<0,001$ \\
\hline $\mathbf{p}$ & $<0,001$ & $<0,001$ & $<0,001$ & $<0,001$ & \\
\hline${ }^{*}$ diferença entre os tempos & ${ }^{+}$diferença entre os grupos &
\end{tabular}

\section{Avaliação Histológica}

A implantação tumoral em pleura foi observada em todos os grupos de forma mais evidente a partir do 14ำ dia. Com exceção deste tempo, não houve diferença significativa entre os animas não tratados e tratados (Tabela 20).

No $21^{\circ}$ dia todos os camundongos sem tratamento apresentaram o máximo grau de disseminação e severidade metastática em pleura. No entanto, somente alguns animais apresentaram infiltração neoplásica em parênquima pulmonar. 
Tabela 20 - Tumor em pleura visceral e/ou parietal (extensão x severidade)

\begin{tabular}{cccccc}
\hline \multirow{2}{*}{ Tempo } & Sem & \multicolumn{3}{c}{ Com tratamento } & \multirow{2}{*}{$\mathbf{p}$} \\
\cline { 3 - 5 } & tratamento & Anti-VEGF (A) & Anti-EGFR (E) & $(\mathbf{A})+(\mathrm{E})$ & \\
\hline $\mathbf{0 7}$ dias & $1,0 \pm 0,8$ & $1,3 \pm 1,0$ & $1,2 \pm 0,8$ & $0,8 \pm 1,5$ & 0,720 \\
$\mathbf{1 0}$ dias & $1,3 \pm 1,5$ & $1,0 \pm 0,0$ & $2,5 \pm 3,8$ & $1,5 \pm 1,3$ & 0,957 \\
$\mathbf{1 4}$ dias & $14,8 \pm 2,9^{*+}$ & $7,2 \pm 5,7^{*}$ & $6,0 \pm 6,0^{*}$ & $8,5 \pm 6,6^{*}$ & 0,001 \\
$\mathbf{2 1}$ dias & $16,0 \pm 0,0^{*}$ & $13,7 \pm 2,1^{*}$ & $14,3 \pm 3,5^{*}$ & $14,0 \pm 4,0^{*}$ & 0,198 \\
\hline $\mathbf{p}$ & $<0,001$ & $<0,001$ & $<0,001$ & $<0,001$ & \\
\hline
\end{tabular}

${ }^{*}$ diferença entre os tempos ${ }^{+}$diferença entre os grupos

Foram observados implantes tumorais no coração (músculo cardíaco e pericárdio), principalmente no $21^{\circ}$ dia no grupo sem tratamento (Tabela 21).

Tabela 21 - Tumor em pericárdio e/ou músculo cardíaco (extensão x severidade)

\begin{tabular}{cccccc}
\hline \multirow{2}{*}{ Tempo } & Sem & \multicolumn{3}{c}{ Com tratamento } & \multirow{2}{*}{$\mathbf{p}$} \\
\cline { 3 - 5 } & tratamento & Anti-VEGF (A) & Anti-EGFR (E) & $(\mathbf{A})+(\mathrm{E})$ & \\
\hline $\mathbf{0 7}$ dias & $0,0 \pm 0,0$ & $0,0 \pm 0,0$ & $0,0 \pm 0,0$ & $0,0 \pm 0,0$ & 1,000 \\
$\mathbf{1 0}$ dias & $0,3 \pm 0,6$ & $0,0 \pm 0,0$ & $0,0 \pm 0,0$ & $0,3 \pm 0,5$ & 0,254 \\
$\mathbf{1 4}$ dias & $0,6 \pm 0,8$ & $0,6 \pm 0,4$ & $0,3 \pm 0,6$ & $0,8 \pm 0,5$ & 0,298 \\
$\mathbf{2 1}$ dias & $2,5 \pm 1,6^{\star+}$ & $0,8 \pm 0,8$ & $0,8 \pm 0,6$ & $1,3 \pm 1,0^{*}$ & 0,020 \\
\hline $\mathbf{p}$ & 0,005 & 0,049 & 0,048 & 0,003 & \\
\hline * diferença entre os tempos & ${ }^{+}$diferença entre os grupos &
\end{tabular}

Com exceção do $21^{\circ}$ dia no grupo sem tratamento, houve discreto infiltrado inflamatório em parênquima pulmonar, em todos os grupos, e mínimas alterações hepáticas, renais e esplênicas (Tabelas 22 a 28). As alterações hepáticas e esplênicas aumentaram com a progressão da doença, atingindo 0 escore máximo aos 21 dias nos animais não tratados, significativamente mais evidentes do que nos animais tratados. Não foi notada a presença de metástase em rins, baço e fígado. 
Tabela 22 - Infiltrado inflamatório em parênquima pulmonar

\begin{tabular}{cccccc}
\hline \multirow{2}{*}{ Tempo } & \multirow{2}{*}{$\begin{array}{c}\text { Sem } \\
\text { tratamento }\end{array}$} & \multicolumn{3}{c}{ Com tratamento } & \multirow{2}{*}{$\mathbf{p}$} \\
\cline { 3 - 5 } & & Anti-VEGF (A) & Anti-EGFR (E) & (A) +(E) & \\
\hline 07 dias & $1,6 \pm 0,5^{+}$ & $0,8 \pm 0,5$ & $0,8 \pm 0,4$ & $0,3 \pm 0,5$ & $<0,001$ \\
10 dias & $0,7 \pm 0,6$ & $0,3 \pm 0,6$ & $0,3 \pm 0,5$ & $0,3 \pm 0,5$ & 0,362 \\
14 dias & $1,3 \pm 1,6$ & $1,0 \pm 0,6$ & $0,7 \pm 1,2$ & $0,5 \pm 1,0$ & 0,347 \\
$\mathbf{2 1}$ dias & $1,5 \pm 0,7^{+}$ & $1,6 \pm 1,0^{*+}$ & $0,5 \pm 0,6$ & $0,8 \pm 1,0$ & 0,015 \\
\hline $\mathbf{p}$ & 0,096 & 0,010 & 0,221 & 0,560 & \\
\hline
\end{tabular}

* diferença entre os tempos ${ }^{+}$diferença entre os grupos

Tabela 23 - Degeneração hidrópica no fígado (extensão x severidade)

\begin{tabular}{cccccc}
\hline \multirow{2}{*}{ Tempo } & Sem & \multicolumn{3}{c}{ Com tratamento } & \multirow{2}{*}{ p } \\
\cline { 3 - 5 } & tratamento & Anti-VEGF (A) & Anti-EGFR (E) & $(\mathbf{A})+(\mathrm{E})$ & \\
\hline $\mathbf{0 7}$ dias & $2,5 \pm 2,1$ & $4,8 \pm 3,5$ & $4,6 \pm 3,5^{\star}$ & $3,3 \pm 3,9$ & 0,468 \\
$\mathbf{1 0}$ dias & $1,7 \pm 2,1$ & $5,7 \pm 2,9^{+}$ & $1,5 \pm 1,7$ & $3,3 \pm 1,5$ & 0,008 \\
$\mathbf{1 4}$ dias & $2,7 \pm 1,7$ & $2,7 \pm 3,0$ & $1,0 \pm 1,0$ & $2,5 \pm 1,9$ & 0,201 \\
$\mathbf{2 1}$ dias & $6,3 \pm 2,5^{\star+}$ & $1,9 \pm 3,3^{*}$ & $1,0 \pm 1,0$ & $1,0 \pm 0,8$ & 0,007 \\
\hline $\mathbf{p}$ & 0,003 & 0,021 & 0,005 & 0,072 & \\
\hline
\end{tabular}

${ }^{*}$ diferença entre os tempos ${ }^{+}$diferença entre os grupos

Tabela 24 - Esteatose microgoticular no fígado (extensão x severidade)

\begin{tabular}{cccccc}
\hline \multirow{2}{*}{ Tempo } & Sem & \multicolumn{3}{c}{ Com tratamento } & \multirow{2}{*}{$\mathbf{p}$} \\
\cline { 3 - 5 } & tratamento & Anti-VEGF (A) & Anti-EGFR (E) & $(\mathbf{A})+(\mathrm{E})$ & \\
\hline $\mathbf{0 7}$ dias & $1,0 \pm 0,0$ & $2,6 \pm 2,6$ & $1,2 \pm 1,1$ & $1,3 \pm 1,9$ & 0,559 \\
$\mathbf{1 0}$ dias & $1,3 \pm 0,6$ & $1,0 \pm 1,7$ & $1,0 \pm 2,0$ & $1,3 \pm 1,9$ & 0,404 \\
$\mathbf{1 4}$ dias & $2,2 \pm 1,5$ & $1,0 \pm 1,7$ & $0,7 \pm 0,6$ & $1,0 \pm 2,0$ & 0,124 \\
$\mathbf{2 1}$ dias & $6,3 \pm 2,5^{\star+}$ & $0,7 \pm 1,5$ & $0,7 \pm 0,6$ & $0,8 \pm 1,0$ & $<0,001$ \\
\hline $\mathbf{p}$ & $<0,001$ & 0,168 & 0,437 & 0,879 & \\
\hline
\end{tabular}

* diferença entre os tempos ${ }^{+}$diferença entre os grupos 
Tabela 25 - Infiltrado sinusoidal no fígado (extensão x severidade)

\begin{tabular}{cccccc}
\hline \multirow{2}{*}{ Tempo } & \multirow{2}{*}{$\begin{array}{c}\text { Sem } \\
\text { tratamento }\end{array}$} & \multicolumn{3}{c}{ Com tratamento } & \multirow{2}{*}{$\mathbf{p}$} \\
\cline { 3 - 5 } & & Anti-VEGF (A) & Anti-EGFR (E) & $(\mathbf{A})+(\mathrm{E})$ & \\
\hline $\mathbf{0 7}$ dias & $0,3 \pm 0,6$ & $0,5 \pm 0,6$ & $0,6 \pm 0,9$ & $0,8 \pm 0,5$ & 0,753 \\
$\mathbf{1 0}$ dias & $0,3 \pm 0,6$ & $0,3 \pm 0,6$ & $1,0 \pm 0,8$ & $0,3 \pm 0,5$ & 0,109 \\
$\mathbf{1 4}$ dias & $1,9 \pm 1,6^{+}$ & $1,8 \pm 1,8^{+}$ & $0,7 \pm 1,2$ & $0,5 \pm 1,0$ & 0,027 \\
$\mathbf{2 1}$ dias & $3,3 \pm 3,1^{*+}$ & $1,3 \pm 2,4$ & $2,7 \pm 0,6^{*}$ & $0,8 \pm 1,0$ & 0,045 \\
\hline $\mathbf{p}$ & $<0,001$ & 0,233 & 0,003 & 0,318 & \\
\hline
\end{tabular}

${ }^{*}$ diferença entre os tempos ${ }^{+}$diferença entre os grupos

Tabela 26 - Degeneração hidrópica renal (extensão x severidade)

\begin{tabular}{cccccc}
\hline \multirow{2}{*}{ Tempo } & \multirow{2}{*}{ Sem } & \multicolumn{3}{c}{ Com tratamento } & \multirow{2}{*}{$\mathbf{p}$} \\
\cline { 3 - 5 } & tratamento & Anti-VEGF (A) & Anti-EGFR (E) & (A) +(E) & \\
\hline $\mathbf{0 7}$ dias & $0,8 \pm 0,8$ & $1,0 \pm 0,0$ & $1,8 \pm 1,1$ & $1,3 \pm 1,9$ & 0,116 \\
$\mathbf{1 0}$ dias & $1,7 \pm 0,6$ & $2,0 \pm 1,0^{*}$ & $1,3 \pm 1,9$ & $2,0 \pm 1,4$ & 0,338 \\
$\mathbf{1 4}$ dias & $1,6 \pm 1,7$ & $0,8 \pm 0,5$ & $0,7 \pm 0,6$ & $1,0 \pm 1,0$ & 0,735 \\
$\mathbf{2 1}$ dias & $4,3 \pm 2,9^{*+}$ & $0,5 \pm 0,6$ & $0,7 \pm 0,6$ & $0,5 \pm 0,6$ & 0,010 \\
\hline $\mathbf{p}$ & $<0,001$ & 0,002 & 0,115 & 0,080 & \\
\hline${ }^{*}$ diferença entre os tempos & + diferença entre os grupos &
\end{tabular}

Tabela 27 - Esteatose renal (extensão x severidade)

\begin{tabular}{cccccc}
\hline \multirow{2}{*}{ Tempo } & Sem & \multicolumn{3}{c}{ Com tratamento } & \multirow{2}{*}{ p } \\
\cline { 3 - 5 } & tratamento & Anti-VEGF (A) & Anti-EGFR (E) & $(\mathbf{A})+(\mathrm{E})$ & \\
\hline $\mathbf{0 7}$ dias & $0,4 \pm 0,5$ & $0,3 \pm 0,5$ & $1,2 \pm 1,1$ & $0,8 \pm 1,0$ & 0,135 \\
$\mathbf{1 0}$ dias & $1,3 \pm 0,6$ & $0,3 \pm 0,6$ & $0,5 \pm 0,6$ & $0,5 \pm 1,0$ & 0,055 \\
$\mathbf{1 4}$ dias & $1,1 \pm 1,3$ & $0,3 \pm 0,5$ & $0,3 \pm 0,6$ & $0,7 \pm 0,6$ & 0,119 \\
$\mathbf{2 1}$ dias & $3,7 \pm 2,5^{\star+}$ & $0,3 \pm 0,5$ & $0,5 \pm 0,6$ & $0,5 \pm 0,6$ & 0,002 \\
\hline $\mathbf{p}$ & 0,002 & 0,978 & 0,217 & 0,800 & \\
\hline
\end{tabular}

${ }^{*}$ diferença entre os tempos ${ }^{+}$diferença entre os grupos 
Tabela 28 - Hiperplasia de polpa branca do baço (extensão x severidade)

\begin{tabular}{cccccc}
\hline \multirow{2}{*}{ Tempo } & Sem & \multicolumn{3}{c}{ Com tratamento } & \multirow{2}{*}{$\mathbf{p}$} \\
\cline { 3 - 5 } & tratamento & Anti-VEGF (A) & Anti-EGFR (E) & $(\mathbf{A})+(\mathrm{E})$ & \\
\hline $\mathbf{0 7}$ dias & $1,8 \pm 1,3$ & $2,3 \pm 1,5$ & $1,8 \pm 1,3$ & $2,5 \pm 1,7$ & 0,580 \\
$\mathbf{1 0}$ dias & $1,3 \pm 0,6$ & $2,3 \pm 1,5$ & $1,3 \pm 0,5$ & $1,3 \pm 0,5$ & 0,202 \\
$\mathbf{1 4}$ dias & $1,9 \pm 1,1$ & $1,2 \pm 0,4$ & $1,3 \pm 0,6$ & $1,3 \pm 0,5$ & 0,124 \\
$\mathbf{2 1}$ dias & $9,0 \pm 3,0^{\star+}$ & $1,4 \pm 0,5$ & $1,3 \pm 0,5$ & $1,3 \pm 0,5$ & $<0,001$ \\
\hline $\mathbf{p}$ & $<0,001$ & 0,022 & 0,772 & 0,298 & \\
\hline
\end{tabular}

${ }^{*}$ diferença entre os tempos ${ }^{+}$diferença entre os grupos

\subsection{ANÁLISE IMUNOHISTOQUÍMICA EM NEOPLASIA PLEURAL EXPERIMENTALMENTE INDUZIDA}

A análise imunohistoquímica de amostras representativas de tumores pleurais evidenciou aumento progressivo do EGFR, de acordo com o tempo de doença. Sua expressão foi significativamente menor no $14^{\circ}$ dia nos animais que receberam tratamento. Já o VEGFR foi significativamente menor nos animais tratados com anti-VEGF + anti-EGFR, em comparação com outros tempos e outros grupos (Tabelas 29 e 30).

Tabela 29 - Fração de área de células tumorais positivas para expressão do EGFR

\begin{tabular}{cccccc}
\hline \multirow{2}{*}{ Tempo } & Sem & \multicolumn{3}{c}{ Com tratamento } & \multirow{2}{*}{ p } \\
\cline { 3 - 5 } & tratamento & Anti-VEGF (A) & Anti-EGFR (E) & (A) +(E) & \\
\hline 07 dias & $25,0 \pm 7,6^{*}$ & $23,8 \pm 7,5$ & $21,4 \pm 6,5$ & $23,3 \pm 10,5$ & 0,985 \\
10 dias & $33,8 \pm 8,4$ & $38,2 \pm 10,4$ & $29,2 \pm 9,1$ & $30,6 \pm 8,3$ & 0,935 \\
14 dias & $55,6 \pm 4,3^{+}$ & $29,5 \pm 5,1$ & $28,7 \pm 11,1$ & $31,8 \pm 6,3$ & 0,008 \\
21 dias & $50,7 \pm 11,1$ & $43,3 \pm 4,9$ & $38,8 \pm 9,8$ & $35,0 \pm 8,1$ & 0,598 \\
\hline $\mathbf{p}$ & 0,011 & 0,207 & 0,537 & 0,783 & \\
\hline
\end{tabular}

${ }^{*}$ diferença entre os tempos ${ }^{+}$diferença entre os grupos 
Tabela 30 - Fração de área de células tumorais positivas para expressão do VEGFR

\begin{tabular}{cccccc}
\hline \multirow{2}{*}{ Tempo } & \multirow{2}{*}{$\begin{array}{c}\text { Sem } \\
\text { tratamento }\end{array}$} & \multicolumn{3}{c}{ Com tratamento } & \multirow{2}{*}{$\mathbf{p}$} \\
\cline { 3 - 5 } & & Anti-VEGF (A) & Anti-EGFR (E) & (A) +(E) & \\
\hline 07 dias & $58,3 \pm 20,2$ & $59,1 \pm 11,5$ & $54,0 \pm 12,3$ & $57, \pm 19,8$ & 0,874 \\
10 dias & $57,2 \pm 11,0$ & $53,3 \pm 14,3$ & $46,5 \pm 14,3$ & $50,6 \pm 21,7$ & 0,404 \\
14 dias & $57,2 \pm 17,1$ & $50,4 \pm 18,5$ & $52,5 \pm 14,7$ & $36,4 \pm 12,0^{*}$ & 0,015 \\
21 dias & $58,3 \pm 13,3$ & $56,9 \pm 17,3$ & $55,0 \pm 20,1$ & $53,5 \pm 16,1$ & 0,834 \\
\hline $\mathbf{p}$ & 0,989 & 0,326 & 0,549 & 0,049 & \\
\hline
\end{tabular}

* diferença entre os tempos ${ }^{+}$diferença entre os grupos

Tabela 31 - Índices de apoptose em tecido tumoral

\begin{tabular}{cccccc}
\hline \multirow{2}{*}{ Tempo } & \multirow{2}{*}{$\begin{array}{c}\text { Sem } \\
\text { tratamento }\end{array}$} & \multicolumn{3}{c}{ Com tratamento } & \multirow{2}{*}{ p } \\
\cline { 3 - 5 } & & Anti-VEGF (A) & Anti-EGFR (E) & (A) + (E) & \\
\hline 07 dias & $3,3 \pm 1,2^{*}$ & $0,3 \pm 0,5^{+}$ & $6,3 \pm 2,5^{*}$ & $2,0 \pm 0,0$ & $<0,001$ \\
$\mathbf{1 0}$ dias & $0,7 \pm 0,6^{+}$ & $5,3 \pm 4,0^{*}$ & $1,5 \pm 0,7$ & $5,7 \pm 3,5^{\star}$ & 0,002 \\
$\mathbf{1 4}$ dias & $0,8 \pm 0,5^{+}$ & $1,7 \pm 2,2^{+}$ & $5,3 \pm 1,2$ & $5,8 \pm 2,4^{*}$ & $<0,001$ \\
$\mathbf{2 1}$ dias & $2,0 \pm 0,0$ & $2,9 \pm 1,9$ & $7,0 \pm 2,4^{\star+}$ & $5,0 \pm 1,2^{++}$ & $<0,001$ \\
\hline $\mathbf{p}$ & $<0,001$ & $<0,001$ & $<0,001$ & 0,001 & \\
\hline
\end{tabular}

* diferença entre os tempos ${ }^{+}$diferença entre os grupos

Tabela 32 - Determinação de atividade mitótica (PCNA)

\begin{tabular}{cccccc}
\hline \multirow{2}{*}{ Tempo } & Sem & \multicolumn{3}{c}{ Com tratamento } & \multirow{2}{*}{ p } \\
\cline { 3 - 5 } & tratamento & Anti-VEGF (A) & Anti-EGFR (E) & (A) +(E) & \\
\hline $\mathbf{0 7}$ dias & $14,0 \pm 2,8^{*+}$ & $6,0 \pm 0,0^{+}$ & $1,4 \pm 0,0$ & $2,3 \pm 3,2$ & $<0,001$ \\
$\mathbf{1 0}$ dias & $2,0 \pm 0,0$ & $2,5 \pm 1,6$ & $4,5 \pm 6,4$ & $4,0 \pm 4,2$ & 0,890 \\
$\mathbf{1 4}$ dias & $6,5 \pm 3,5$ & $2,5 \pm 2,1$ & $5,3 \pm 4,0$ & $4,0 \pm 0,0$ & 0,243 \\
$\mathbf{2 1}$ dias & $16,0 \pm 0,0^{*+}$ & $5,6 \pm 3,2$ & $7,8 \pm 2,5$ & $6,5 \pm 2,9$ & 0,015 \\
\hline $\mathbf{p}$ & 0,003 & 0,125 & 0,334 & 0,435 & \\
\hline
\end{tabular}

${ }^{*}$ diferença entre os tempos ${ }^{+}$diferença entre os grupos 
Nos grupos tratados com anti-EGFR e com a combinação anti-VEGF + anti-EGFR foram observados maiores escores de apoptose em amostras de tumores pleurais (TUNEL), e baixos escores de proliferação tumoral (PCNA), conforme Tabelas 31 e 32.

\subsection{MICROSCOPIA ELETRÔNICA}

$\mathrm{Na}$ análise tumoral através de microscopia eletrônica, foram observadas células claras e células escuras intimamente coesas (com escasso estroma), caracterizadas respectivamente por núcleos vesiculares e irregulares ou núcleos hipercromáticos com nucléolos evidentes (Figuras 11, 12 e 13).

Nas tumorações provenientes de camundongos sem tratamento, foram observadas células com núcleos reduzidos, mitocôndrias disformes e retículo endoplasmático dilatado e irregular.

De forma semelhante, os animais tratados com anti-VEGF + anti-EGFR apresentaram tumorações com células escuras com mitocôndrias disformes e retículo endoplasmático dilatado e irregular concentrado em um dos polos da célula, além de células claras e neutrófilos.

Os camundongos submetidos a tratamento com anti-EGFR apresentaram tumores com capilares de paredes pouco nítidas e grande número de células escuras contendo núcleos em apoptose e mitocôndrias e retículo endoplasmático concentrados em um dos polos da célula.

Já nas tumorações provenientes de animais tratados com anti-VEGF, foram observados núcleos em apoptose, com número reduzido de mitocôndrias e retículo endoplasmático, principalmente nas células escuras. 


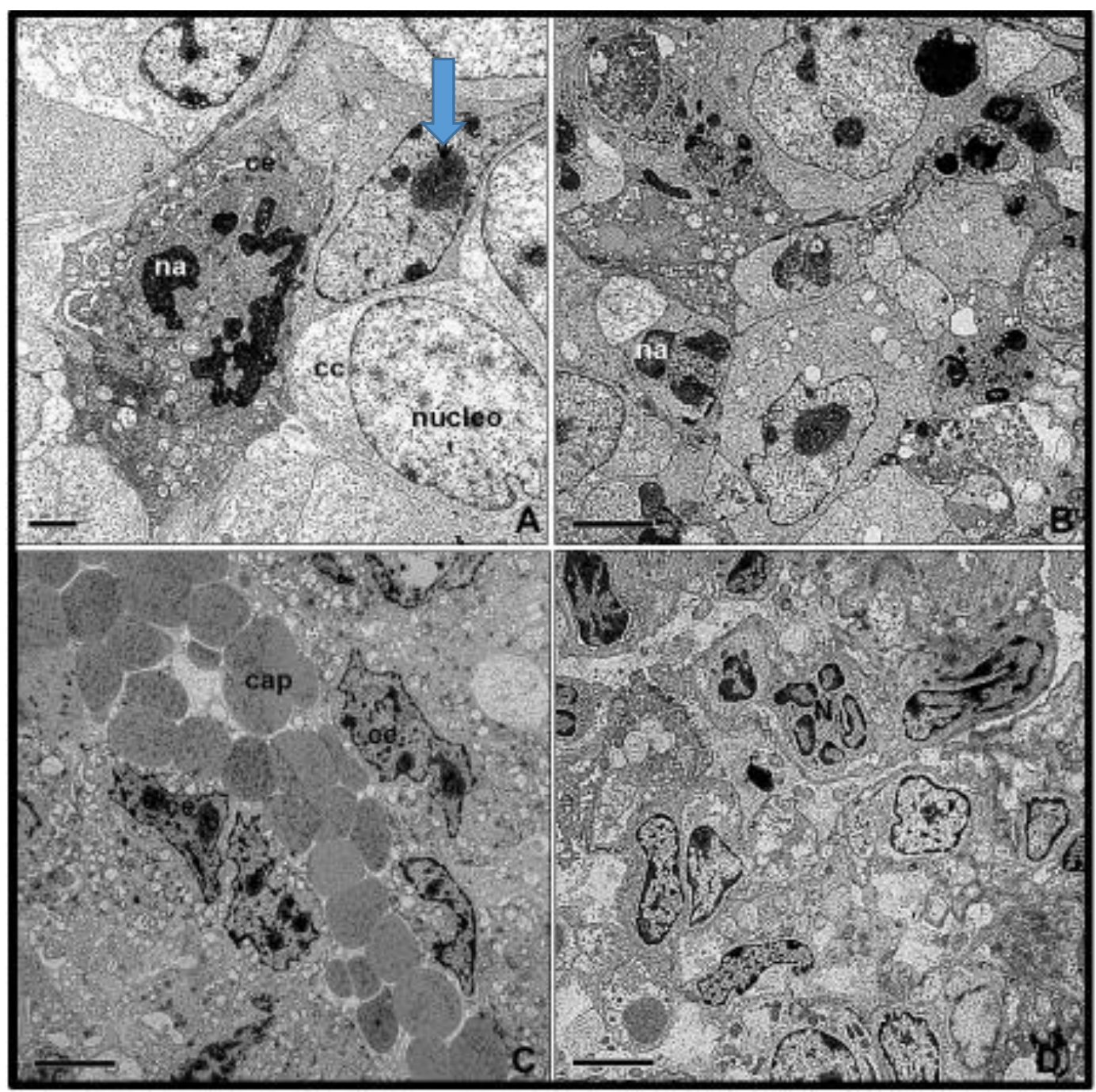

Figura 11 - Microscopia eletrônica de tumorações de camundongos expostos a células LLC (Aumento de 4.000X): (A) Não tratados, com células claras e escuras intimamente coesas, caracterizadas por núcleos vesiculares com nucléolos evidentes (seta) e núcleos irregulares hipercromáticos e em apoptose, respectivamente; (B) Tratados com anti-VEGF, demonstrando núcleos em apoptose e escasso estroma entre as células; (C) Tratados com anti-EGFR, apresentando diversas células escuras e capilar com paredes pouco nítidas; (D) Tratados com anti-VEGF + anti-EGFR, com neutrófilos e células claras e escuras $(c c$ = célula clara; $c e$ = célula escura; na = apoptose; cap = capilar) 


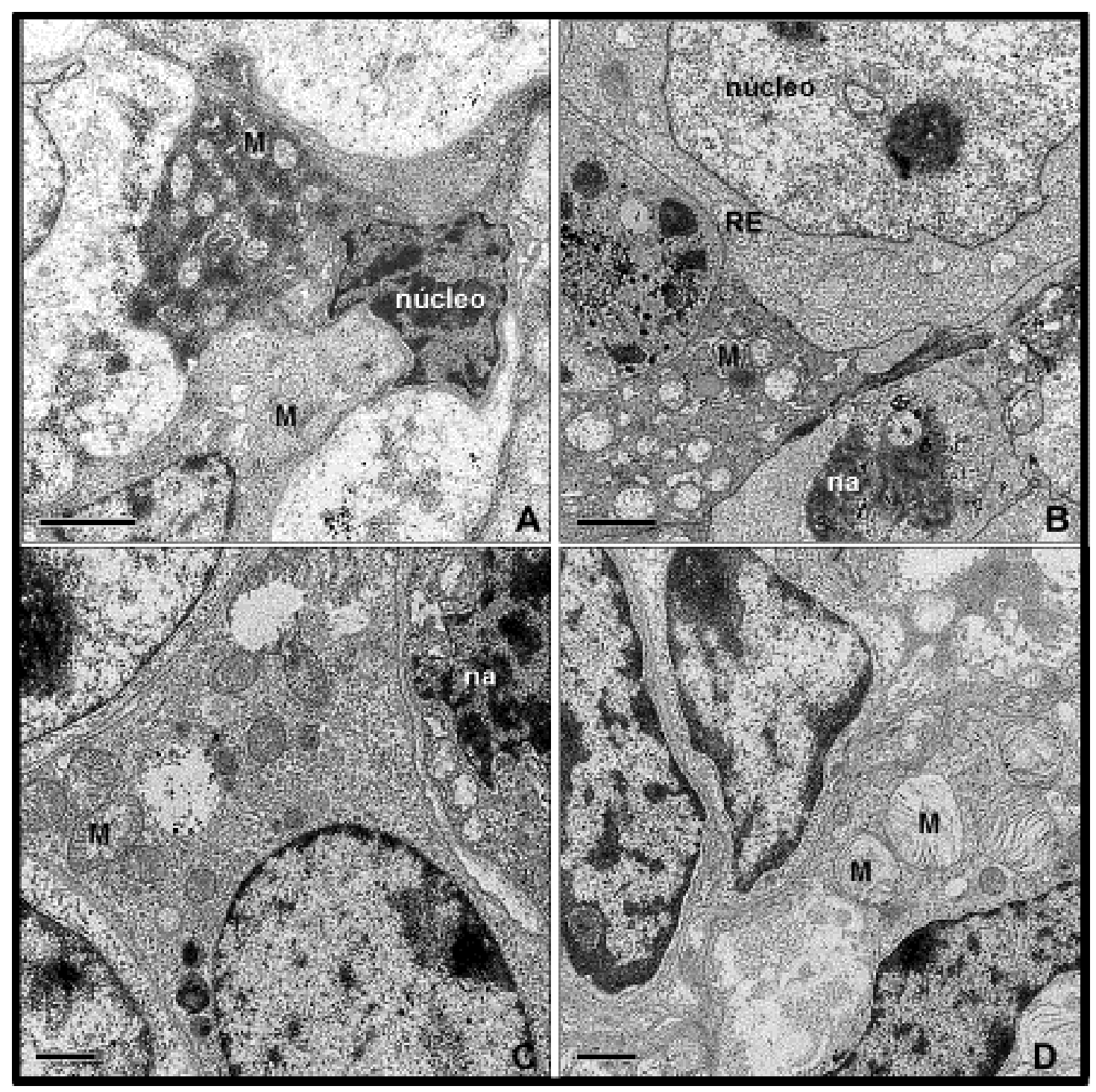

Figura 12 - Microscopia eletrônica de tumorações de camundongos expostos a células LLC (Aumento de 15.000X): (A) Não tratados, demonstrando núcleo reduzido, com mitocôndrias disformes e reticulo endoplasmático dilatado e irregular; (B) Tratados com anti-VEGF, demonstrando células escuras em apoptose e reduzido número de mitocôndrias e retículo endoplasmático; (C) Tratados com anti-EGFR, apresentando células escuras em apoptose e baixo número de mitocôndrias, concentradas em um dos polos da célula; (D) Tratados com anti-VEGF + anti-EGFR, com cristas mitocondriais irregulares e disformes em um dos polos da célula ( $\mathrm{M}=$ mitocôndrias; $\mathrm{RE}=$ retículo endoplasmático; na = apoptose) 


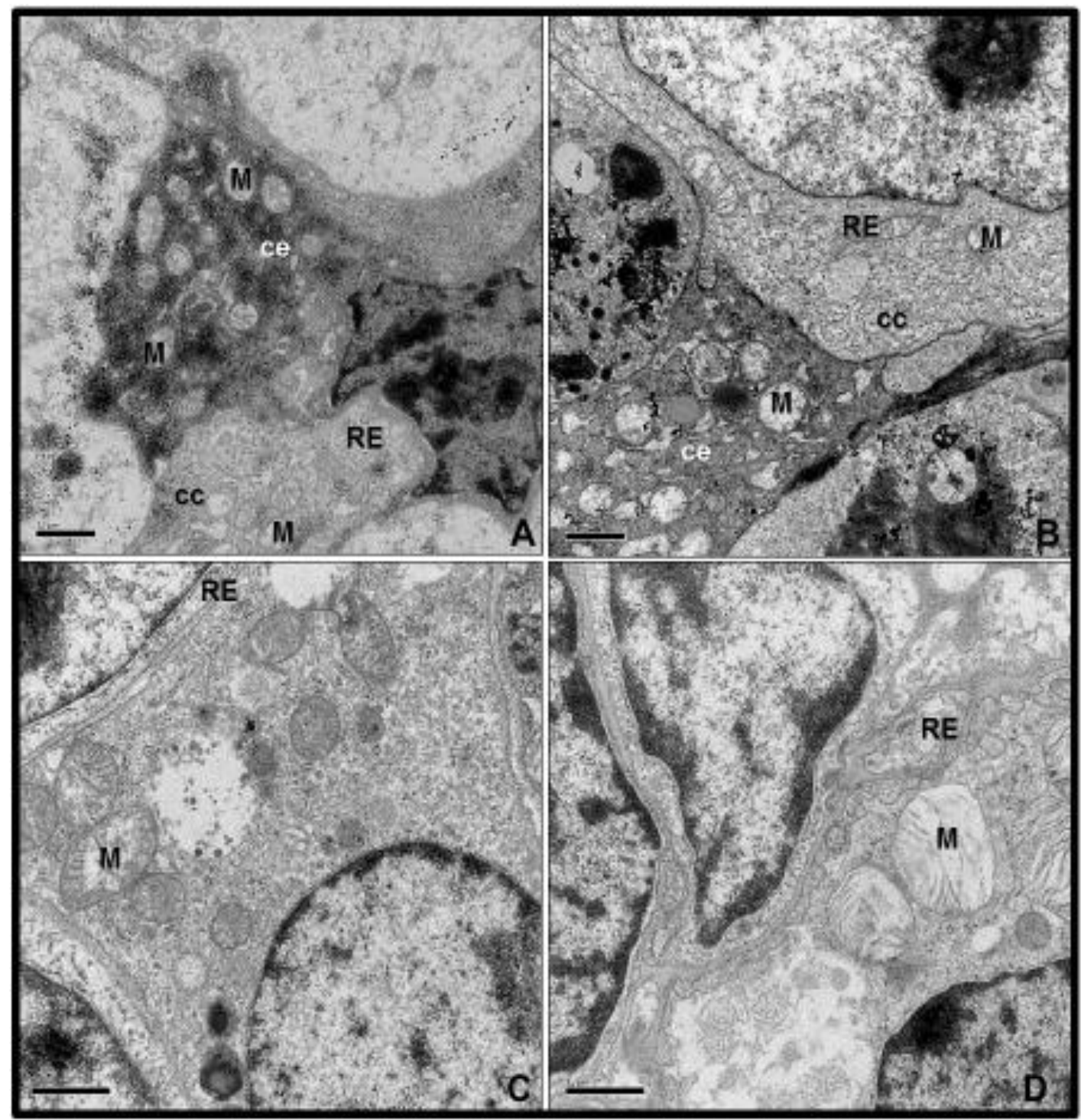

Figura 13 - Microscopia eletrônica de tumorações de camundongos expostos a células LLC (Aumento de 20.000X): (A) Não tratados, demonstrando célula escura com mitocôndrias disformes e célula clara com mitocôndrias disformes e retículo endoplasmático dilatado e irregular; (B) Tratados com anti-VEGF, demonstrando células escuras e claras com número reduzido de mitocôndrias e retículo endoplasmático; (C) Tratados com anti-EGFR, com mitocôndrias e retículo endoplástico concentrados em um dos polos da célula; (D) Tratados com anti-VEGF + anti-EGFR, com cristas mitocondriais irregulares e disformes e retículo endoplasmático dilatado e concentrado em um dos polos da célula (ce = célula escura; $c c=$ célula clara; $M$ = mitocôndrias; $\mathrm{RE}$ = retículo endoplasmático) 


\subsection{AVALIAÇÃO DA EXPRESSÃO GÊNICA DE VEGF, EGFR, KRAS E}

ALK EM MODELO EXPERIMENTAL DE NEOPLASIA PLEURAL

$\mathrm{Na}$ avaliação da expressão gênica de VEGF, EGFR, KRAS e ALK nos implantes tumorais dos animais não tratados e dos animais tratados verificouse superexpressão do VEGF - aproximadamente $30 \%$ maior do que no pulmão dos camundongos não submetidos à indução de neoplasia (controle) - porém sem diferenças entre os grupos com ou sem tratamento (Figura 14).

A

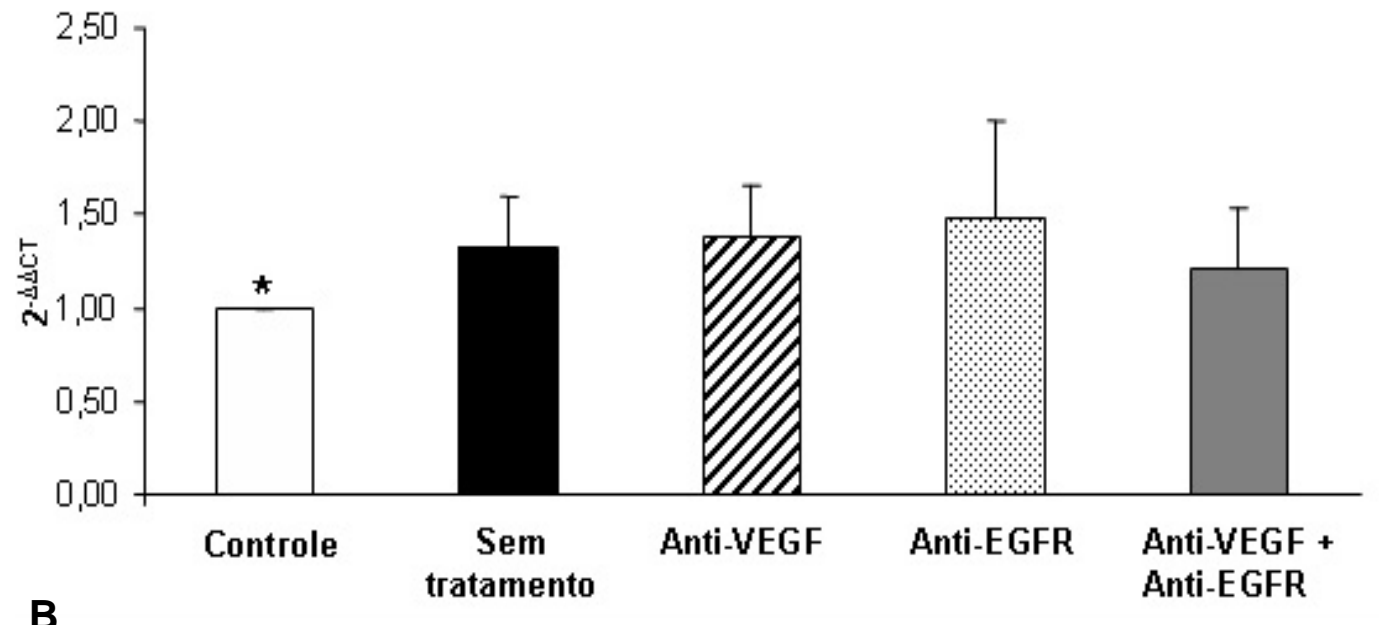

B

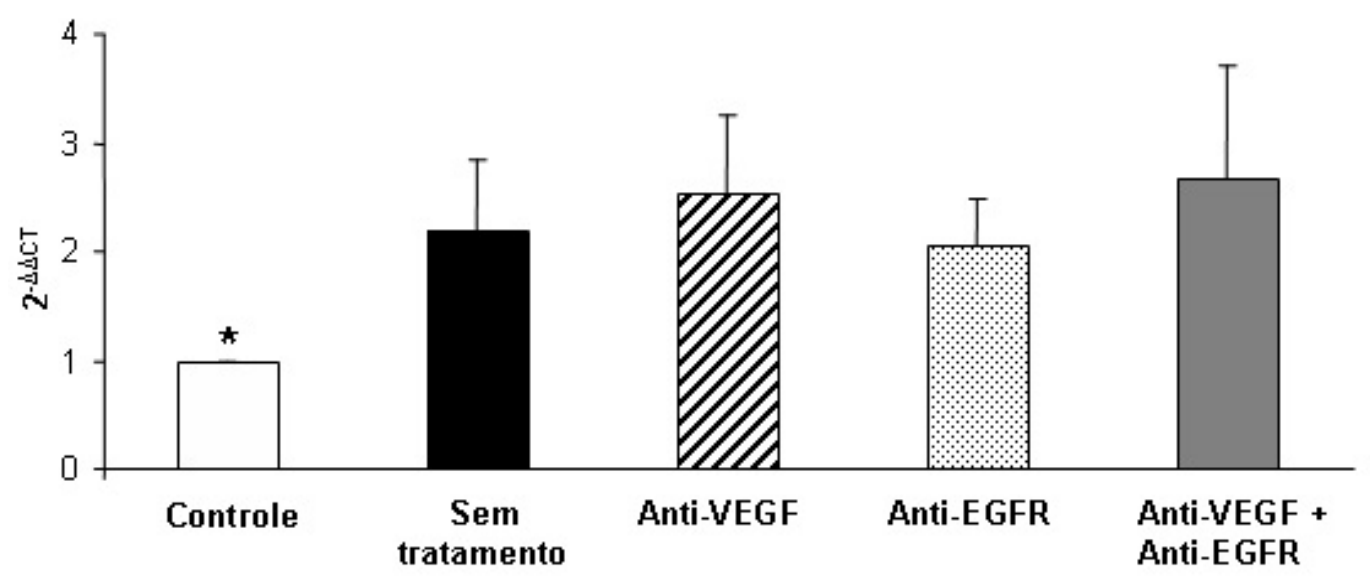

Figura 14 - Expressão de VEGF (A) e de EGFR (B) 
De forma semelhante verificou-se superexpressão do EGFR e do KRAS, tanto nos tumores dos animais não tratados quanto nos tratados, sem diferenças entre os grupos (Figuras 14 e 15), com expressão do EGFR aproximadamente 2 vezes maior e do KRAS aproximadamente 5 vezes maior do que nos camundongos não submetidos à indução de neoplasia (controle).

Já na avaliação gênica do ALK verificou-se sua subexpressão nos implantes tumorais dos animais com neoplasia pleural, sem diferenças entre os animais não tratados e os tratados (Figura 16).

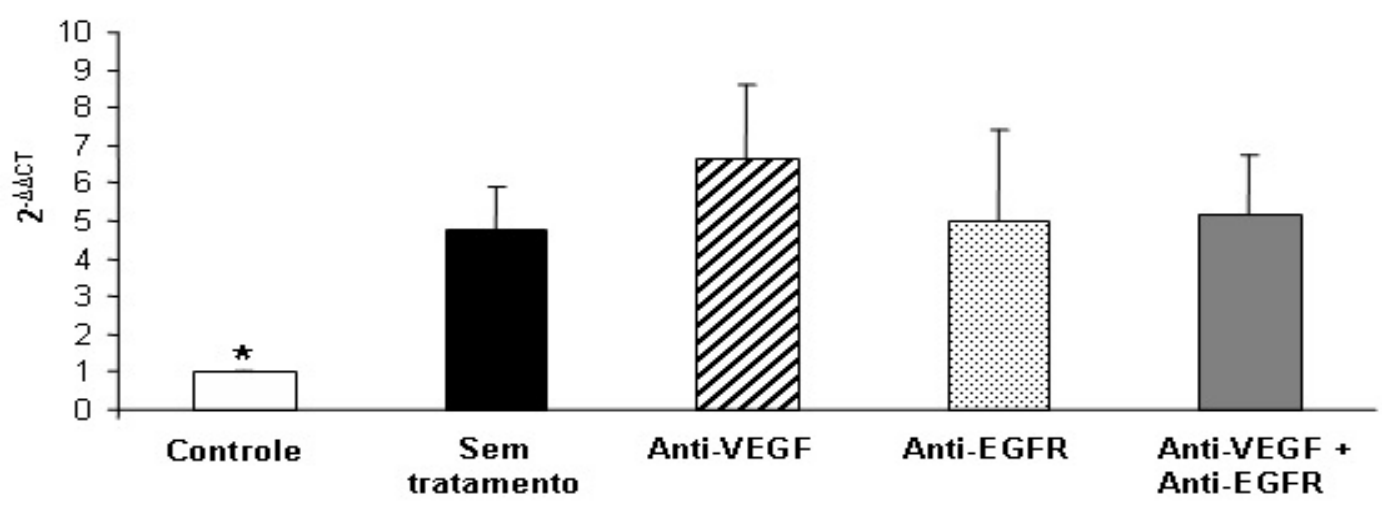

Figura 15 - Expressão do KRAS

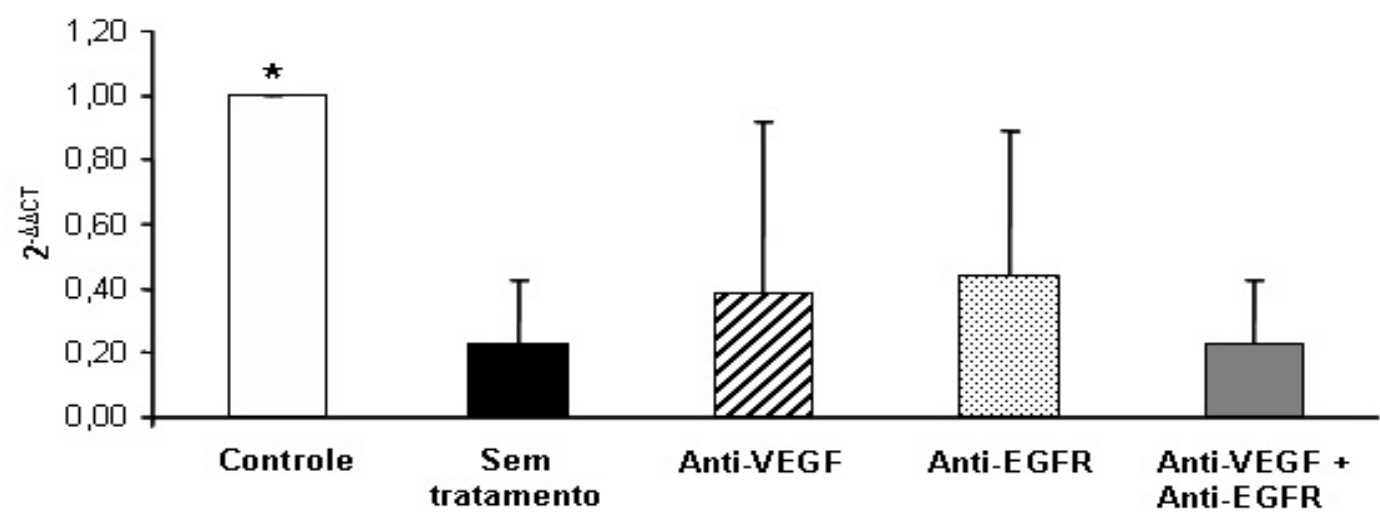

Figura 16 - Expressão de ALK 


\subsection{AVALIAÇÃO DA FREQUÊNCIA DE MUTAÇÕES DO EGFR E DO KRAS EM MODELO EXPERIMENTAL DE NEOPLASIA PLEURAL}

Para avaliação de mutações de EGFR e KRAS, foram analisados tecidos adjacentes aos implantes, células LLC em cultura e implantes tumorais 14 dias após a indução da neoplasia pleural com células de Lewis.

Nos tecidos adjacentes não foram observadas mutações tanto nos éxons 18 a 22 do gene EGFR quanto no éxon 2 do gene KRAS.

Também não foram observadas mutações no sequenciamento para os éxons 18 a 22 do EGFR no tecido tumoral e nas células em cultura (Figura 17).

Quando avaliado o éxon 2 do gene KRAS identificou-se a mutação p.Gly12Cys em heterozigose, tanto em células LLC em cultura quanto no tumor extraído dos camundongos 14 dias após a indução da neoplasia pleural com células de Lewis (Figura 18). 


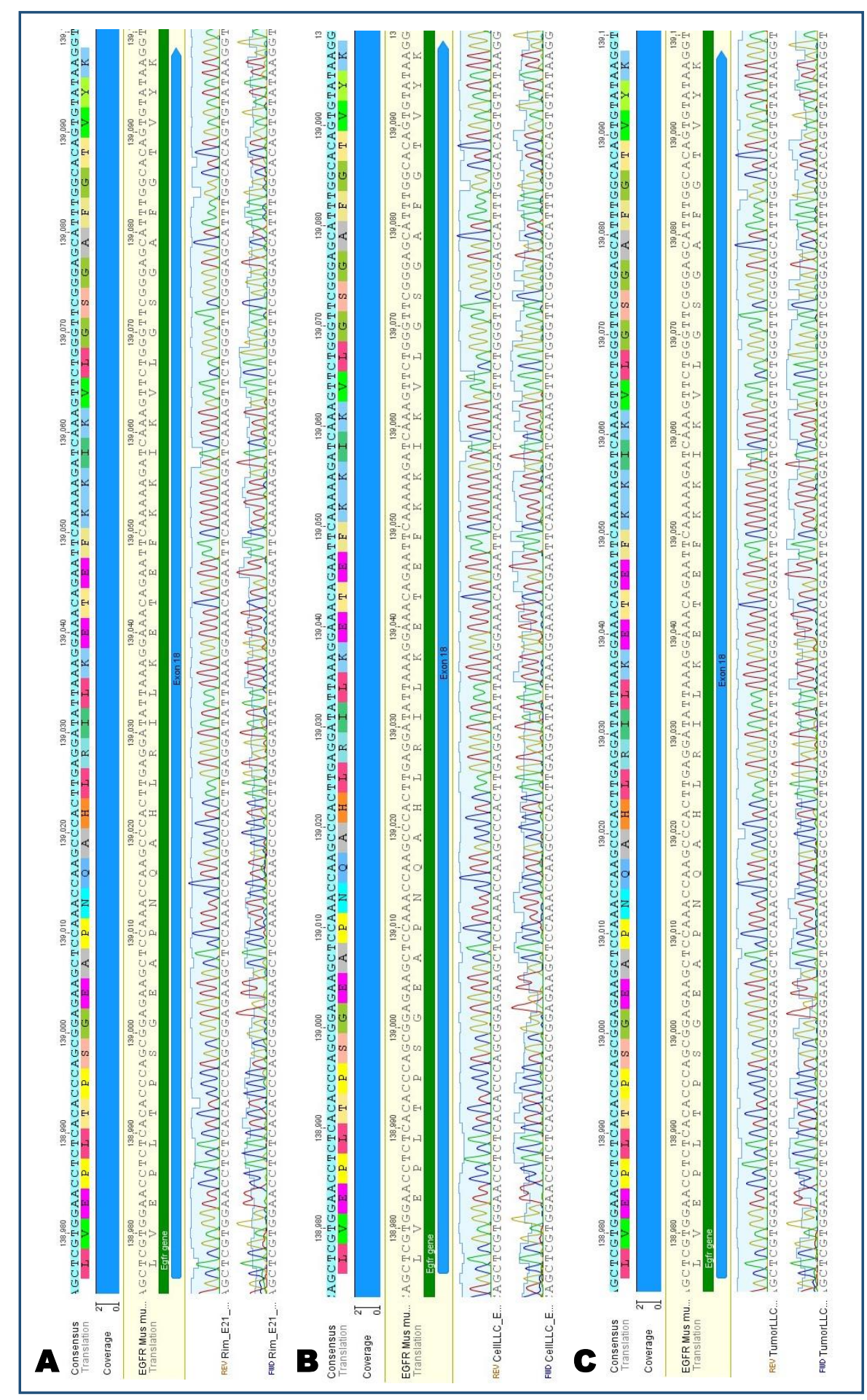

Figura 17 - Exemplo de sequenciamento em rim de camundongo para avaliação do éxon 18 do gene EGFR (A) e sequenciamento dos éxons 18 e 19 do gene EGFR em cultura de células LLC (B) e em tecido tumoral de camundongos 14 dias após implante de células LLC (C) 


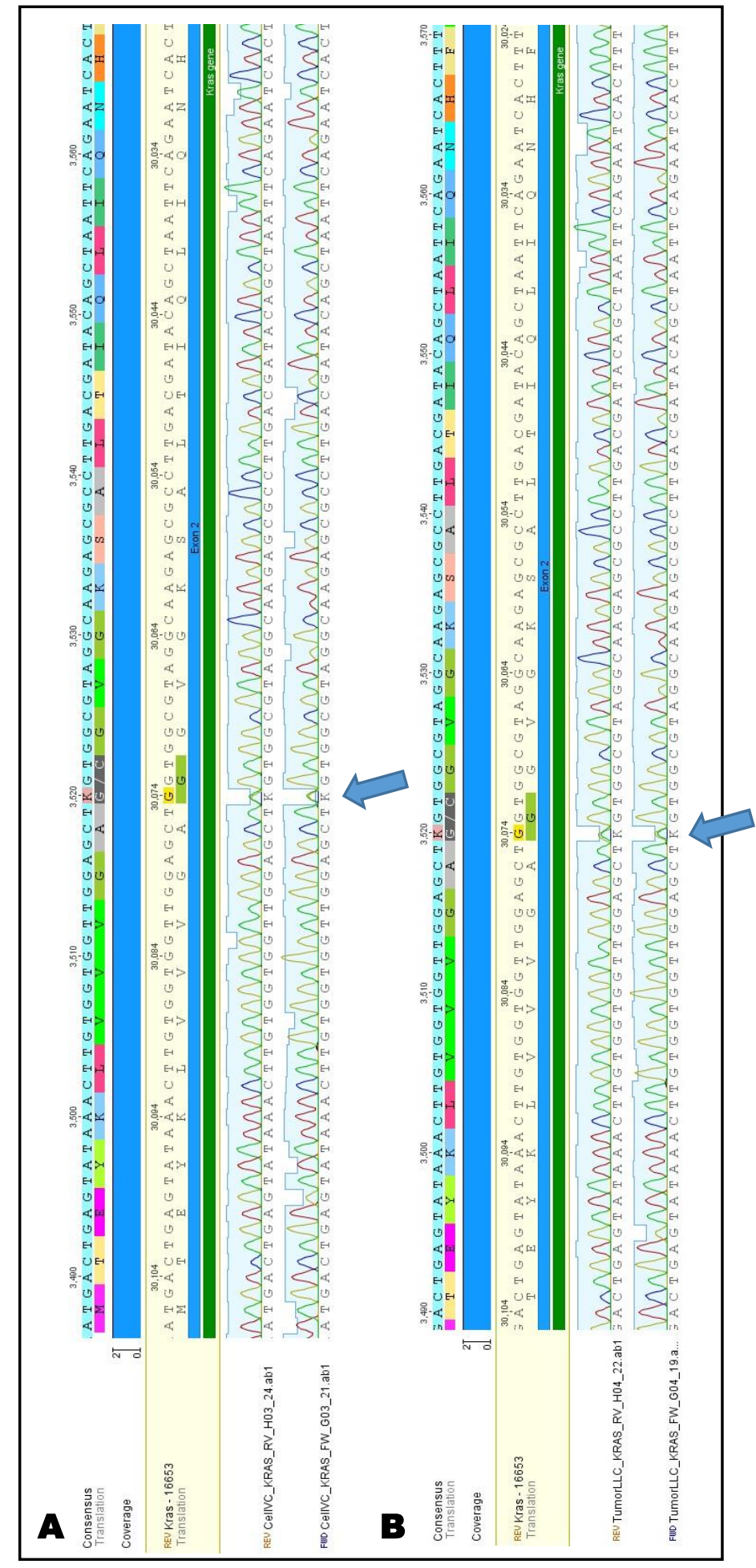

Figura 18 - Mutação (setas) em sequenciamento do éxon 2 do gene KRAS em cultura de células LLC (A) e em tecido tumoral de camundongos 14 dias após implante de células LLC (B) 
DISCUSSÃO 


\section{DISCUSSÃO}

O câncer de pulmão é uma importante causa de mortalidade em todo o mundo, responsável por mais de um milhão de mortes por câncer a cada ano, sobretudo pelo adenocarcinoma, seu subtipo histológico mais comum. ${ }^{1-4}$

Neste contexto, o derrame pleural maligno resultante de metástases pleurais de adenocarcinomas de pulmão tem grande relevância. ${ }^{5-7}$ Seu surgimento sinaliza doença em estágio avançado, com alta mortalidade e grande comprometimento de qualidade de vida, sobretudo por dispneia debilitante na maioria dos casos. ${ }^{5-8,17} \mathrm{E}$, apesar dos avanços no conhecimento e no tratamento do câncer de pulmão desde os esquemas baseados em platina, não houve modificações significativas nesta evolução para a maioria dos pacientes. ${ }^{8,12,19}$ Sobretudo, os procedimentos mais utilizados na maior parte do mundo para tratamento específico do derrame pleural maligno pleurodese e cateteres de longa permanência - não beneficiam todos os pacientes e não modificam a evolução da doença. ${ }^{5,15}$

São necessárias mudanças significativas para melhorar o controle local, diminuir a disseminação do câncer e, possivelmente, modificar as curvas de sobrevida. ${ }^{17}$ Porém, para mudanças estratégicas, é necessário um melhor entendimento sobre a patogênese do derrame pleural neoplásico secundário ao adenocarcinoma de pulmão. ${ }^{23}$

Até há algum tempo, havia poucos modelos experimentais para o seu estudo, a maioria utilizando animais com pleura normal. ${ }^{90-92}$ Entretanto, na ausência de doença pleural maligna, não era possível avaliar a evolução natural do câncer, as interações neoplasia-hospedeiro e possíveis respostas a diferentes estratégias. ${ }^{23-25}$

Em 2006, Stathopoulos e colaboradores caracterizaram um novo modelo experimental de derrame pleural maligno, através da injeção de $1,5 \times 10^{5}$ células LLC em camundongos imunocompetentes. ${ }^{24}$ Sendo um modelo que mimetiza a condição humana, vem sendo utilizado para estudar a fisiopatologia do derrame pleural maligno, como a expressão e a interação de mediadores inflamatórios e vasoativos que contribuem para o seu desenvolvimento. ${ }^{23-25}$ 
Com este modelo experimental diversos estudos foram realizados, demonstrando inclusive a possibilidade de se avaliar o controle do derrame pleural maligno com a utilização de agentes quimioterápicos e terapias-alvo administradas na primeira evidência de doença pleural maligna. ${ }^{23-32}$

No entanto, a sobrevida máxima dos animais nestes estudos foi de apenas 17 dias, o que pode não ser suficiente para a avaliação de parâmetros fisiopatológicos e terapêuticos. ${ }^{23-32}$

Nosso estudo avaliou inicialmente a curva de sobrevida e os aspectos laboratoriais e histológicos deste modelo experimental murino de derrame pleural maligno, utilizando diferentes concentrações de células de Lewis (Apêndice). ${ }^{96}$

Foram observados implantes tumorais em pleura em todos os grupos proporcionais à concentração e ao tempo de injeção das células LLC, permitindo a observação de passos fundamentais na patogênese do derrame pleural maligno, como a angiogênese, o aumento da permeabilidade vascular e o influxo de líquido e células inflamatórias na cavidade pleural. Da mesma forma foi possível avaliar a disseminação da doença por metástases pericárdicas, mais evidentes no grupo que recebeu concentração mais elevada de células LLC, bem como alterações inflamatórias em parênquima pulmonar e alterações histológicas em fígado, rins e baço.

De forma geral, observou-se que a indução de neoplasia pleural com uma menor concentração de células LLC $\left(0,5 \times 10^{5}\right)$ cursa com melhores condições gerais dos camundongos (peso e atividade) até o 14\% dia e maior sobrevida, permitindo uma melhor avaliação dos desfechos, sobretudo de possíveis respostas a diferentes tratamentos. Houve ganho de 6 dias sobre os camundongos que receberam a concentração utilizada na literatura $\left(1,5 \times 10^{5}\right.$ células LLC), mantendo as características do modelo de Stathophoulous e colaboradores. ${ }^{24}$ Além disso, observou-se a formação de derrame pleural com menor número de focos tumorais nas pleuras parietal e visceral, com melhor mimetismo da evolução em seres humanos.

Com base nestes resultados, estipulamos que a melhor concentração para a segunda fase do nosso estudo seria a de $0,5 \times 10^{5}$ células LLC. ${ }^{96}$ 
$\mathrm{Na}$ segunda etapa do projeto, avaliou-se o impacto de terapias-alvo (anti-VEGF e anti-EGFR) administradas de forma isolada ou combinadas por via intrapleural no modelo modificado. Neste estudo, a carcinomatose pleural foi letal em todos os grupos, com mortalidade de $100 \%$ até o $25^{\circ}$ dia do experimento, sem diferença de sobrevida entre os animais não tratados e tratados.

Conforme a evolução da doença pleural maligna houve emagrecimento e redução de atividade, porém os animais tratados com anti-EGFR ou com antiVEGF + anti-EGFR estavam significativamente mais ativos no $10^{\circ}$ e no $14^{\circ}$ dia.

Houve aumento progressivo do volume de líquido pleural, evidente em todos os animais a partir do $14^{\circ}$ dia de evolução, com celularidade, DHL, proteínas totais, VEGF e IL-6 crescentes e menores níveis de TNF- $\alpha$. No entanto, todos os animais que receberam tratamento apresentaram derrame pleural significativamente menor, com menos células, menores níveis de DHL e, no $21^{\circ}$ dia do estudo, menores níveis de VEGF e IL-6 em relação aos não tratados.

O VEGF é uma glicoproteína que age sobre células endoteliais, estimulando a angiogênese e o aumento da permeabilidade vascular. É considerado o fator angiogênico conhecido mais potente, diretamente relacionado ao desenvolvimento do derrame pleural maligno. ${ }^{97-101}$

Quando elevado no sangue e principalmente no líquido dos pacientes com derrame pleural maligno secundário ao câncer de pulmão, vem sendo citado como um marcador de pior prognóstico, podendo prever uma pobre resposta ao tratamento e menor sobrevida. ${ }^{97-101}$

Em nosso estudo, verificou-se uma boa resposta do anti-VEGF intrapleural sobre o volume de líquido pleural, porém sem diferença dos outros grupos tratados e sem impacto significativo no controle da disseminação tumoral e sobrevida. Isto estaria relacionado ao pior prognóstico desta neoplasia, confirmado pela superexpressão gênica do VEGF nos implantes tumorais, pelos níveis progressivamente maiores de VEGF no líquido pleural e também em amostras tumorais.

Outra via molecular bem definida na carcinogênese de pulmão é a da tirosina-quinase, envolvendo o EGF e o EGFR. ${ }^{97-101}$ O EGF é um fator de 
crescimento que regula fisiologicamente aspectos de proliferação e sobrevida de vários tipos de células, controlando o crescimento, a diferenciação e a apoptose. Atua através da ligação com alta afinidade ao seu receptor (EGFR), desencadeando uma série de alterações intracelulares por ação da tirosinaquinase..$^{20,31,40,101}$ Quando alterado, seja por hiperexpressão, amplificação ou mutações, O EGFR é considerado oncogênico, por ativação de múltiplas cascatas de eventos intracelulares, que cursam com crescimento descontrolado ou fenótipo maligno. ${ }^{20,31,40,101}$

Os genes KRAS também são elementos fundamentais nesta via de sinalização mediada pelo EGF, regulando conjuntamente crescimento celular, diferenciação e apoptose através da interação com múltiplos efetores. ${ }^{52,101}$ Suas mutações são um mau prognóstico, pois estão relacionadas a uma menor resposta aos medicamentos inibidores do EGFR, tanto de efeito em sua porção extracelular (cetuximabe) quanto em seu domínio tirosina-quinase (erlotinibe e gefitinibe). ${ }^{20,55,58,101}$

Neste estudo, o anti-EGFR e a combinação anti-VEGF + anti-EGFR foram associados a manutenção da atividade dos animais no $10^{\circ}$ e no $14^{\circ}$ dias, em comparação com os outros grupos, e também a maiores escores de apoptose e baixos escores de proliferação tumoral em amostras de tumores pleurais. Entretanto, não houve impacto sobre a disseminação tumoral, nem modificação de sobrevida.

O volume de líquido pleural e os níveis de DHL no líquido pleural foram significativamente menores no grupo tratado com anti-EGFR ou a combinação de tratamentos do que no grupo não tratado, porém não houve diferença dos animais tratados somente com anti-VEGF. Os níveis do EGF no líquido pleural também não apresentaram diferenças entre os grupos, embora a análise imunohistoquímica tenha evidenciado o aumento progressivo do EGFR em amostras tumorais, de acordo com o tempo de doença.

Isto sugere uma atuação parcial do anti-EGFR intrapleural, com boa resposta sobre o volume de líquido pleural, porém sem controle tumoral.

Analisamos também a frequência de mutações de EGFR e KRAS nesta linhagem tumoral de adenocarcinoma utilizada em modelos experimentais, com achado de mutação do gene KRAS, tanto em cultura de células LLC quanto 
nos implantes tumorais extraídos dos camundongos. E, apesar de não se evidenciarem mutações de EGFR, houve expressão gênica tumoral aproximadamente 2 vezes maior do EGFR, assim como do KRAS que foi aproximadamente 5 vezes maior do que nos pulmões de camundongos normais.

Nossos achados indicam uma linhagem tumoral de fenótipo maligno mais agressivo, com crescimento descontrolado e perda de apoptose, associado a um pior prognóstico e a uma menor resposta aos medicamentos inibidores do EGFR como, por exemplo, o cetuximabe (anti-EGFR) utilizado no estudo. Isto corrobora com os achados clínicos de Johnson et al., que evidenciaram aumento da sobrevida livre de doença com a associação do antiEGFR ao anti-VEGF, porém sem aumento da sobrevida global. ${ }^{100}$

Os medicamentos administrados por via intrapleural tanto em modelo de neoplasia como em estudos com pleura normal, reduziram significativamente 0 volume de líquido pleural e os mediadores inflamatórios. ${ }^{26,27,90-92} \mathrm{~A}$ combinação do anti-VEGF ao anti-EGFR melhorou a morbidade, com animais significativamente mais ativos no $10^{\circ}$ e no $14^{\circ}$ dia. Contudo, conforme demostrado em estudos clínicos, não modifica a sobrevida global e não tem impacto sobre os implantes tumorais. ${ }^{100}$

O presente estudo demonstrou que as terapias-alvo por via intrapleural reduzem significativamente $\mathrm{o}$ derrame pleural, morbidade e parâmetros histológicos, embora sem impacto na sobrevida dos animais neste modelo experimental. Esses achados indicam que a linhagem tumoral LLC possui um fenótipo tumoral agressivo demonstrado através da mutação do KRAS e superexpressão do EGFR, o que pode estar associado ao pior prognóstico e menor resposta terapêutica.

Mimetizando-se a condição humana, pelo efeito demonstrado sobre o volume de líquido pleural, as terapias-alvo intrapleurais poderiam ser uma opção à pleurodese e aos cateteres pleurais no tratamento específico do derrame pleural secundário ao adenocarcinoma de pulmão. 
CONCLUSÕES 


\section{CONCLUSÕES}

Este estudo demonstrou a possibilidade de indução de doença pleural maligna com uma menor concentração de células LLC $\left(0,5 \times 10^{5}\right)$, mantendo as características do modelo de Stathophoulous e colaboradores.

Com esta concentração, obteve-se um modelo com maior sobrevida, que permite o acompanhamento dos animais doentes por mais tempo e uma melhor compreensão dos mecanismos fisiopatológicos envolvidos no desenvolvimento do derrame pleural maligno.

As terapias-alvo intrapleurais, embora tenham melhorado morbidade (peso e atividade), volume de líquido pleural e parâmetros bioquímicos, imunológicos e histológicos nas fases iniciais e intermediárias, não reduziram a carcinomatose pleural e a disseminação da doença, sem ganho de sobrevida.

As terapias-alvo induziram altos índices de apoptose e menores índices de proliferação tumoral. A análise imunohistoquímica evidenciou aumento progressivo do EGFR em amostras tumorais, de acordo com o tempo de doença, sugerindo uma atuação parcial do anti-EGFR intrapleural, porém sem controle tumoral.

Houve superexpressão gênica tumoral do EGFR e do KRAS e mutação do gene KRAS indicando que a linhagem tumoral LLC possui um fenótipo tumoral agressivo possivelmente associado ao pior prognóstico e menor resposta terapêutica. 
ANEXO 


\section{ANEXO}

Tabela 1 - Concentrações dos anticorpos utilizados no método ELISA

\begin{tabular}{cccc}
\hline Citocinas & $\begin{array}{c}\text { Anticorpo de captura / } \\
\text { sensibilização }(\mu \mathbf{g} / \mathbf{m L})\end{array}$ & $\begin{array}{c}\text { Padrões } \\
(\mathbf{p g} / \mathbf{m L})\end{array}$ & $\begin{array}{c}\text { Anticorpo de } \\
\text { detecção }(\mathbf{n g} / \mathbf{m L})\end{array}$ \\
\hline IL-6 & 2 & $15,6-1000$ & 200 \\
TNF- $\alpha$ & 0,8 & $31,2-2000$ & 150 \\
EGF & 4 & $7,8-250$ & 200 \\
VEGF & 0,4 & $15,6-1000$ & 100 \\
\hline
\end{tabular}

Tabela 2 - Primers utilizados para a PCR-RT

\begin{tabular}{ccc}
\hline Gene & Primer forward & Primer reverse \\
\hline EGFR & TTGGCCTATTCATGCGAAGAC & GTCATGAGCCCTTCCACAAT \\
VEGF & TCGGCTGTCCATGAAAGTGA & TTGCAGGCGAGCCATCTT \\
K-RAS & CAAGAGCGCCTTGACGATACA & CCAAGAGACAGGTTTCTCCATC \\
ALK & GCAGTCGATATGGTCTGGAGT & TGCAGAGGTGTTCAGGAGGA \\
\hline
\end{tabular}

Tabela 3 - Primers utilizados para sequenciamento.

\begin{tabular}{|c|c|c|}
\hline Exon & Primer forward & Primer reverse \\
\hline $18^{*}$ & GGAAGTGGGGCTTTCTGTTG & AGTTCTGAGTAAGGATGGCAGT \\
\hline $19^{*}$ & CTACCCAATTTTGAGATCACCGT & AGTAGCCCTTCACACCATGT \\
\hline $20^{*}$ & CATGCAACATCCCAAAGGAGT & TCTCTTAGATCATCCTTGCTGCT \\
\hline $21^{*}$ & TTGGTGTTGAGCAGCCTAGA & ССССАСТСАGАATCTTTGGC \\
\hline $22^{\star}$ & AGTGAGAGGTTCACAGCCTT & TTCAGTAGATGGACACGCTCA \\
\hline $2^{\star \star}$ & CATCTGTAGTCACTGAATTCGGA & CCTTGGAACTAAAGGACATCACA \\
\hline
\end{tabular}


Tabela 4 - Reações utilizadas para sequenciamento.

\begin{tabular}{cc}
\hline PCR mix & Volume para reação \\
\hline 5x Green GoTaq Flexi Buffer & $5 \mu \mathrm{L}$ \\
GoTaq DNA Polimerase & $0,25 \mu \mathrm{L}$ \\
MgCl (25mM) & $2 \mu \mathrm{L}$ \\
dNTP (25mM) & $0,5 \mu \mathrm{L}$ \\
Primer Foward (10uM) & $1 \mu \mathrm{L}$ \\
Primer Reverse (10uM) & $1 \mu \mathrm{L}$ \\
Amostra (gDNA a 50ng/ $\mu \mathrm{L})$ & $1 \mu \mathrm{L}$ \\
Água & $15,25 \mu \mathrm{L}$ \\
\hline
\end{tabular}

Tabela 5 - Reagentes e volumes utilizados para sequenciamento Mix utilizado para sequenciamento Volume para reação

\begin{tabular}{cc}
\hline BigDye $^{\mathrm{TM}}$ Terminator v3.1 Ready Reaction Mix & $1 \mu \mathrm{L}$ \\
BigDye $^{\mathrm{TM}}$ Terminator v3.1 5X Sequencing Buffer & $1,25 \mu \mathrm{L}$ \\
Primer específico $(5 \mu \mathrm{M})$ & $2,5 \mu \mathrm{L}$ \\
Amostra Purificada & $2,5 \mu \mathrm{L}$ \\
Água & $2,5 \mu \mathrm{L}$ \\
\hline
\end{tabular}


REFERÊNCIAS BIBLIOGRÁFICAS 


\section{REFERÊNCIAS BIBLIOGRÁFICAS}

1. Jemal A, Bray F, Center MM, Ferlay J, Ward E, Forman D. Global Cancer statistics. CA Cancer J Clin. 2011; 61: 69-90.

2. Instituto Nacional de Câncer, Ministério da Saúde. Estatísticas do Câncer: Incidência de Câncer no Brasil. Rio de Janeiro: INCA [acesso em 30/08/2016]. Disponível em: <http://www.inca.gov.br/estimativa/2014>.

3. Malta DC, de Moura L, de Souza MFM, Curado MP, Alencar AP, Alencar GP. Lung cancer, cancer of the trachea, and bronchial cancer: mortality trends in Brazil, 1980-2003. J Bras Pneumol. 2007; 33: 536-543.

4. Instituto Nacional de Câncer, Ministério da Saúde. Estatísticas do Câncer: Mortalidade. Rio de Janeiro: INCA [acesso em 30/08/2016]. Disponível em: <http://www1.inca.gov.br/vigilancia/mortalidade.asp>.

5. Sahn SA. Malignant pleural effusion. Eur Respir Mon. 2002; 22: 177-188.

6. Sugiura S, Ando Y, Minami H, Ando M, Sakai S, Shimokata K. Prognostic value of pleural effusion in patients with non-small cell lung cancer. Clin Cancer Res. 1997; 3: 47-50.

7. Naito T, Satoh $H$, Ishikawa $H$, Yamashita $Y T$, Kamma $H$, Takahashi $H$, Ohtsuka M, Hasegawa S. Pleural effusion as a significant prognostic factor in non-small cell lung cancer. Anticancer Res. 1997; 17: 4743-4746.

8. Antony VB, Loddenkemper R, Astoul P, Boutin C, Goldstraw P, Hott J, Rodriguez-Panadero F, Sahn SA. Management of malignant pleural effusions. Eur Respir J. 2001; 18: 402-419.

9. Antunes G, Neville E, Duffy J, Ali N. BTS guidelines for the management of malignant pleural effusions. Thorax. 2003; 58: 29-38.

10. Gary-Lee YC, Light RW. Management of malignant pleural effusions. Respirology. 2004; 9: 148-156.

11. Neragi-Miandoab S. Malignant pleural effusion, current and evolving approaches for its diagnosis and management. Lung Cancer. 2006; 54: 1-9.

12. Heffner JE, Klein JS. Recent advances in the diagnosis and management of malignant pleural effusions. Mayo Clin Proc. 2008; 83: 235-250.

13. Musani Al. Treatment options for malignant pleural effusion. Curr Opin Pulm Med. 2009; 15: 380-387.

14. Uzbeck MH, Almeida FA, Sarkiss MG, Morice RC, Jimenez CA, Eapen GA, Kennedy MP. Management of malignant pleural effusions. Adv Ther. 2010; 27: 334-347.

15. Roberts ME, Neville E, Berrisford RG, Antunes G, Ali NJ. Management of a malignant pleural effusion: British Thoracic Society pleural disease guideline 2010. Thorax. 2010; 65: 32-40. 
16. Lombardi G, Zustovich F, Nicoletto MO, Donach M, Artioli G, Pastorelli D. Diagnosis and treatment of malignant pleural effusion. A systematic literature review and new approaches. Am J Clin Oncol. 2010; 33: 420-423.

17. Morgensztern D, Waqar S, Subramanian J, Trinkaus K, Govindan R. Prognostic Impact of Malignant Pleural Effusion at Presentation in Patients with Metastatic Non-Small-Cell Lung Cancer. J Thorac Oncol. 2012; 7: 1485-1489.

18. Bareschino MA, Schettino C, Rossi A, Maione P, Sacco PC, Zeppa R, Gridelli C. Treatment of advanced non-small cell lung cancer. J Thorac Dis. 2011; 3: 122-133.

19. National Cancer Institute $(\mathrm{NCl})$. Non-small cell lung cancer treatment [acesso em 30/08/2016]. Disponível em: $<$ http://www.cancer.gov/types/lung/hp/non-small-cell-lung-treatmentpdq\#section>.

20. The Cancer Genome Atlas Research Network. Comprehensive molecular profiling of lung adenocarcinoma. Nature. 2014; 511: 543-550.

21. Custodio A, Mendez M, Provencio M. Targeted therapies for advanced nonsmall cell lung cancer: current status and future implications. Cancer Treat Rev. 2012; 38: 36-53.

22. Rossi A, Maione P, Colantuoni G, Ferrara C, Rossi E, Guerriero C, Nicolella D, Falanga M, Palazzolo G, Gridelli C. Recent developments of targeted therapies in the treatment of non-small cell lung cancer. Curr Drug Discov Technol. 2009; 6: 91-102.

23. Stathopoulos GT. Translational advances in pleural malignancies. Respirology. 2011; 16: 53-63.

24. Stathopoulos GT, Kalomenidis I. Animal models of malignant pleural effusion. Curr Opin Pulm Med. 2009; 15: 343-352.

25. Stathopoulos GT e Kalomenidis I. Malignant pleural effusion: tumor-host interactions unleashed. Am J Respir Crit Care Med. 2012; 186: 487-492.

26. Stathopoulos GT, Zhu Z, Everhart MB, Kalomenidis I, Lawson WE, Bilaceroglu S, Peterson TE, Mitchell D, Yull FE, Light RW, Blackwell TS. Nuclear factor-kappa B affects tumor progression in a mouse model of malignant pleural effusion. Am J Respir Cell Mol Biol. 2006; 34: 142-150.

27.Psallidas I, Karabela SP, Moschos C, Sherrill TP, Kollintza A, Magkouta S, Theodoropoulou P, Roussos C, Blackwell TS, Kalomenidis I, Stathopoulos GT. Specific effects of bortezomib against experimental malignant pleural effusion: a preclinical study. Molecular Cancer. 2010; 9: 1-11.

28. Marazioti A, Kairi CA, Spella M, Giannou AD, Magkouta S, Giopanou I, Papaleonidopoulos V, Kalomenidis I, Snyder LA, Kardamakis D, Stathopoulos GT. Beneficial impact of CCL2 and CCL12 neutralization on experimental malignant pleural effusion. PLoS One. 2013; 8: e71207.

29. Giannou AD, Marazioti A, Spella M, Kanellakis NI, Apostolopoulou H, Psallidas I, Prijovich ZM, Vreka M, Zazara DE, Lilis I, Papaleonidopoulos V, 
Kairi CA, Patmanidi AL, Giopanou I, Spiropoulou N, Harokopos V, Aidinis V, Spyratos D, Teliousi S, Papadaki H, Taraviras S, Snyder LA, Eickelberg O, Kardamakis D, Iwakura Y, Feyerabend TB, Rodewald HR, Kalomenidis I, Blackwell TS, Agalioti T, Stathopoulos GT. Mast cells mediate malignant pleural effusion formation. J Clin Invest. 2015; 125: 2317-2334.

30. Lieser EA, Croghan GA, Nevala WK, Bradshaw MJ, Markovic SN, Mansfield AS. Up-regulation of pro-angiogenic factors and establishment of tolerance in malignant pleural effusions. Lung Cancer. 2013; 82: 63-68.

31. Schettino C, Bareschino MA, Sacco PC, Maione P, Rossi A, Casaluce F, Sgambato A, Gridelli C. New molecular targets in the treatment of NSCLC. Curr Pharm Des. 2013; 19: 5333-5343.

32. Vazakidou ME, Magkouta S, Moschos C, Kalomenidis I. Mammalian target of rapamycin (mTOR) inhibition does not prevent lung adenocarcinomainduced malignant pleural effusion. Respirology. 2014; 19: 290-292.

33. Alberg AJ, Samet JM. Epidemiology of lung cancer. Chest. 2003; 123: 2149.

34. Vansteenkiste J, Crinò L, Dooms C, Douillard JY, Faivre-Finn C, Lim E, Rocco G, Senan S, Van Schil P, Veronesi G, Stahel R, Peters S, Felip E, Panel Members. $2^{\text {nd }}$ ESMO Consensus Conference on Lung Cancer: earlystage non-small-cell lung cancer consensus on diagnosis, treatment and follow-up. Ann Oncol. 2014; 25: 1462-1474.

35. Sandler A, Gray R, Perry MC, Brahmer J, Schiller JH, Dowlati A, Lilenbaum $\mathrm{R}$, Johnson DH. Paclitaxel-carboplatin alone or with bevacizumab for nonsmall-cell lung cancer. N Engl J Med. 2006; 355: 2542-2550.

36. Cabebe $\mathrm{E}$, Wakelee $\mathrm{H}$. Role of anti-angiogenesis agents in treating NSCLC: focus on bevacizumab and VEGFR tyrosine kinase inhibitors. Curr Treat Options Oncol. 2007; 8: 15-27.

37. Rossi A, Maione P, Ferrara ML, Sacco PC, Schettino C, Bareschino MA, Gridelli C. Angiogenesis inhibitors and vascular disrupting agents in non-small cell lung cancer. Curr Med Chem. 2009; 16: 3919-3930.

38. Korpanty G, Smyth E, Carney DN. Update on anti-angiogenic therapy in non-small cell lung cancer: Are we making progress? J Thorac Dis. 2011; 3: 19-29.

39. Mok TS, Wu YL, Thongprasert S, Yang CH, Chu DT, Saijo N, Sunpaweravong $\mathrm{P}$, Han $\mathrm{B}$, Margono $\mathrm{B}$, Ichinose $\mathrm{Y}$, Nishiwaki $\mathrm{Y}$, Ohe $\mathrm{Y}$, Yang JJ, Chewaskulyong B, Jiang H, Duffield EL, Watkins CL, Armour AA, Fukuoka M. Gefitinib or paclitaxel-carboplatin in pulmonary adenocarcinoma. N Engl J Med. 2009; 361: 947-957.

40. Gazdar AF. Epidermal growth factor receptor inhibition in lung cancer: the evolving role of individualized therapy. Cancer Metastasis Rev. 2010; 29: 37-48.

41. Pirker R, Pereira JR, Szczesna A, von Pawel J, Krzakowski M, Ramlau R, Vynnychenko I, Park K, Yu CT, Ganul V, Roh JK, Bajetta E, O'Byrne K, de Marinis F, Eberhardt W, Goddemeier T, Emig M, Gatzemeier U. Cetuximab 
plus chemotherapy in patients with advanced non-small-cell lung cancer (FLEX): an open-label randomised phase III trial. Lancet. 2009; 373: 15251531.

42. Casaluce F, Sgambato A, Maione $P$, Rossi A, Ferrara C, Napolitano A, Palazzolo G, Ciardiello F, Gridelli C. ALK inhibitors: a new targeted therapy in the treatment of advanced NSCLC. Target Oncol. 2013; 8: 55-67.

43. Gridelli C, Peters S, Sgambato A, Casaluce F, Adjei AA, Ciardiello F. ALK inhibitors in the treatment of advanced NSCLC. Cancer Treat Rev. 2014; 40: 300-306.

44. Petrelli F, Coinu A, Cabiddu M, Borgonovo K, Ghilardi M, Lonati V, Barni S. Efficacy of fourth-line chemotherapy in advanced non-small-cell lung cancer: a systematic review and pooled analysis of published studies. Anticancer Drugs. 2015 [Epub ahead of print].

45. De Marinis F, Bria E, Baas P, Tiseo M, Camerini A, Favaretto AG, Gridelli C. Treatment of unfit patients with advanced non-small-cell lung cancer: definition criteria according an expert panel. Clinical Lung Cancer. 2015 [Epub ahead of print].

46. Felip E, Gridelli C, Baas P, Rosell R, Stahel R, Panel Members. Metastatic non-small-cell lung cancer: consensus on pathology and molecular tests, first-line, second-line, and third-line therapy. $1^{\text {st }}$ ESMO Consensus Conference in Lung Cancer (Lugano 2010). Annals of Oncology. 2011; 22: 1507-1519.

47. Socinski MA, Evans T, Gettinger S, Hensing TA, Sequist LV, Ireland B, Stinchcombe TE. Treatment of Stage IV Non-small Cell Lung Cancer. In: Diagnosis and Management of Lung Cancer, $3^{\text {rd }}$ ed: American College of Chest Physicians Evidence-Based Clinical Practice Guidelines. Chest. 2013; 143 (Supplement): 341-368.

48. Reck M, Popat S, Reinmuth N, de Ruysscher D, Kerr KM, Peters S, ESMO Guidelines Working Group. Metastatic non-small-cell lung cancer (NSCLC): ESMO Clinical Practice Guidelines for diagnosis, treatment and follow-up. Annals of Oncology. 2014; 25 (Supplement): 27-39.

49. Gazdar AF, Gao B, Minna JD. Lung cancer cell lines: Useless artifacts or invaluable tools for medical science? Lung Cancer. 2010; 68: 309-318.

50. Soda M, Choi YL, Enomoto M, Takada S, Yamashita Y, Ishikawa S, Fujiwara S, Watanabe H, Kurashina K, Hatanaka H, Bando M, Ohno S, Ishikawa $Y$, Aburatani $H$, Niki T, Sohara $Y$, Sugiyama $Y$, Mano $H$. Identification of the transforming EML4-ALK fusion gene in non-small-cell lung cancer. Nature. 2007; 448: 561-566.

51. Sharma SV, Bell DW, Settleman J, Haber DA. Epidermal growth factor receptor mutations in lung cancer. Nat Rev Cancer. 2007; 7: 169-181.

52. Massarelli E, Varella-Garcia M, Tang X, Xavier AC, Ozburn NC, Liu DD, Bekele BN, Herbst RS, Wistuba II. KRAS mutation is an important predictor of resistance to therapy with epidermal growth factor receptor tyrosine 
kinase inhibitors in non-small-cell lung cancer. Clin Cancer Res. 2007; 13: 2890-2896.

53. Koivunen JP, Mermel C, Zejnullahu K, Murphy C, Lifshits E, Holmes AJ, Choi HG, Kim J, Chiang D, Thomas R, Lee J, Richards WG, Sugarbaker DJ, Ducko C, Lindeman N, Marcoux JP, Engelman JA, Gray NS, Lee C, Meyerson M, Jänne PA. EML4-ALK fusion gene and efficacy of an ALK kinase inhibitor in lung cancer. Clin Cancer Res. 2008; 14: 4275-4283.

54. Rosell R, Moran T, Queralt C, Porta R, Cardenal F, Camps C, Majem M, Lopez-Vivanco G, Isla D, Provencio M, Insa A, Massuti B, Gonzalez-Larriba JL, Paz-Ares L, Bover I, Garcia-Campelo R, Moreno MA, Catot S, Rolfo C, Reguart N, Palmero R, Sánchez JM, Bastus R, Mayo C, Bertran-Alamillo J, Molina MA, Sanchez JJ, Taron M (Spanish Lung Cancer Group). Screening for epidermal growth factor receptor mutations in lung cancer. $N$ Engl $J$ Med. 2009; 361: 958-967.

55. Gazdar AF. Activating and resistance mutations of EGFR in non-small-cell lung cancer: role in clinical response to EGFR tyrosine kinase inhibitors. Oncogene. 2009; 28 (Supplement): 24-31.

56. Hirsch FR, Varella-Garcia M, Cappuzzo F. Predictive value of EGFR and HER2 overexpression in advanced non-small-cell lung cancer. Oncogene. 2009; 28 (Supplement): 32-37.

57. John T, Liu G, Tsao MS. Overview of molecular testing in non-small-cell lung cancer: mutational analysis, gene copy number, protein expression and other biomarkers of EGFR for the prediction of response to tyrosine kinase inhibitors. Oncogene. 2009; 28 (Supplement): 14-23.

58. Tanner NT, Pastis NJ, Sherman C, Simon GR, Lewin D, Silvestri GA. The role of molecular analyses in the era of personalized therapy for advanced NSCLC. Lung Cancer. 2012; 76: 131-137.

59. Chernow B, Sahn SA. Carcinomatous involvement of the pleura: an analysis of 96 patients. Am J Med. 1977; 63: 695-702.

60. Rodriguez-Panadero F, Borderas Naranjo F, Lopez-Mejias J. Pleural metastatic tumours and effusions: frequency and pathogenic mechanisms in a post-mortem series. Eur Respir J. 1989; 2: 366-369.

61. Jantz MA, Antony VB. Pathophysiology of the pleura. Respiration. 2008; 75 : 121-133.

62. English JC, Leslie KO. Pathology of the Pleura. Clin Chest Med. 2006; 27 : 157-180.

63. Light RW. Pleural Diseases. New York, Lippincott Willians and Wilkins, 2007: 108-134.

64. Mutsaers SE. Mesothelial cells: their structure, function and role in serosal repair. Respirology. 2002; 7: 171-191.

65. Antony VB. Immunological mechanisms in pleural disease. Eur Resp J. 2003; 21 : 539-544. 
66. Nasreen N, Mohammed KA, Sanders K, Hardwick J, Van Horn RD, Sriram PS, Ramirez-Icaza C, Hage C, Antony VB. Pleural mesothelial cell (PMC) defense mechanisms against malignancy. Oncol Res. 2003; 14: 155-161.

67. Grove CS, Gary Lee YC. Vascular endothelial growth factor: the key mediator in pleural effusion formation. Curr Opin Pulm Med. 2002; 8: 294301.

68. Hoeben A, Landuyt B, Highley MS, Wildiers H, Van Oosterom AT, de Bruijn EA. Vascular Endothelial Growth Factor and Angiogenesis. Pharmacol Rev. 2004; 56: 549-580.

69. Gale AJ, Gordon SG. Update on Tumor Cell Procoagulant Factors. Acta Haematologica. 2001; 106: 25-32.

70. Hudig D, Bajaj SP. Tissue factor-like activity of the human monocytic tumor cell line U937. Thromb Res. 1982; 27: 321-332.

71. Ruggiero V, Latham K, Baglioni C. Cytostatic and cytotoxic activity of tumor necrosis factor on human cancer cells. J Immunol. 1987; 138: 2711-2717.

72. Williams GM. Antitumor necrosis factor-alpha therapy and potential cancer inhibition. Eur J Cancer Prev. 2008; 17: 169-177.

73. Shimomoto H, Hasegawa Y, Nozaki Y, Takagi N, Shibagaki T, Nakao A, Shimokata K. Expression of tumor necrosis factor receptors in human lung cancer cells and normal lung tissues. Am J Respir Cell Mol Biol. 1995; 13: 271-278.

74. Stathopoulos GT, Sherrill TP, Karabela SP, Goleniewska K, Kalomenidis I, Roussos C, Fingleton B, Yull FE, Peebles RS Jr, Blackwell TS. Host-derived interleukin-5 promotes adenocarcinoma-induced malignant pleural effusion. Am J Respir Crit Care Med. 2010; 182: 1273-1281.

75. Stathopoulos GT, Kollintza A, Moschos C, Psallidas I, Sherrill TP, Pitsinos EN, Vassiliou S, Karatza M, Papiris SA, Graf D, Orphanidou D, Light RW, Roussos C, Blackwell TS, Kalomenidis I. Tumor necrosis factor-a promotes malignant pleural effusion. Cancer Res. 2007; 67: 9825-9834.

76. Stathopoulos GT, Psallidas I, Moschos C, Moustaki A, Kollintza A, Karabela S, Porfyridis I, Vassiliou S, Karatza M, Zhou Z, Joo M, Blackwell TS, Roussos C, Graf D, Kalomenidis I. A central role for tumor-derived monocyte chemoattractant protein-1 in malignant pleural effusion. J Natl Cancer Inst. 2008; 100: 1464-1476.

77. Cui R, Takahashi F, Ohashi R, Yoshioka M, Gu T, Tajima K, Unnoura T, Iwakami S, Hirama M, Ishiwata T, Iwase A, Takahashi K. Osteopontin is involved in the formation of malignant pleural effusion in lung cancer. Lung Cancer. 2009; 63: 368-374.

78. Yeh H-H, Lai W-W, Chen HHW, Liu H-S, Su W-C. Autocrine IL-6-induced Stat 3 activation contributes to the pathogenesis of lung adenocarcinoma and malignant pleural effusion. Oncogene. 2006; 25: 4300-4309.

79. Gary Lee YC, Melkerneker D, Thompson PJ, Light RW, Lane KB. Transforming growth factor beta induces vascular endothelial growth factor 
elaboration from pleural mesothelial cells in vivo and in vitro. Am J Respir Crit Care Med. 2002; 165: 88-94.

80. Fridlender ZG, Sun J, Kim S, Kapoor V, Cheng G, Ling L, Worthen GS, Albelda SM. Polarization of tumor-associated neutrophil phenotype by TGFbeta: "N1" versus "N2" TAN. Cancer Cell. 2009; 16: 183-194.

81. Wu SG, Gow CH, Yu CJ, Chang YL, Yang CH, Hsu YC, Shih JY, Lee YC, Yang PC. Frequent epidermal growth factor receptor gene mutations in malignant pleural effusion of lung adenocarcinoma. Eur Respir J. 2008; 32: 924-930.

82. Han HS, Eom DW, Kim JH, Kim KH, Shin HM, An JY, Lee KM, Choe KH, Lee $\mathrm{KH}$, Kim ST, Koo JH, Lee HC, Lee OJ. EGFR mutation status in primary lung adenocarcinomas and corresponding metastatic lesions: discordance in pleural metastases. Clin Lung Cancer. 2011; 12: 380-386.

83. Vaz MC, Marchi E, Vargas FS. Pleurodesis: technique and indications. $J$ Bras Pneumol. 2006; 32: 347-356.

84. Marchi E, Teixeira LR, Vargas FS. Management of malignancy-associated pleural effusion: current and future treatment strategies. Am J Respir Med. 2003; 2: 261-273.

85. Shaw P, Agarwal R. Pleurodesis for malignant pleural effusions. Cochrane Database Syst Rev. 2004, CD002916.

86. Marchi E, Vargas FS, Acencio MM, Antonangelo L, Teixeira LR, Light RW. Low doses of silver nitrate induce pleurodesis with a limited systemic response. Respirology. 2009; 14: 885-869.

87. Paschoalini MS, Vargas FS, Marchi E, Pereira JR, Jatene FB, Antonangelo L, Light RW. Prospective randomized trial of silver nitrate versus talc slurry in pleurodesis for symptomatic malignant pleural effusions. Chest. 2005; 128: 684-689.

88. Warren WH, Faber LP. Clinical experience with Pleurx catheters for malignant pleural effusions. Chest. 2000; 118 (Supplement): 130S.

89. Teixeira LR, Vargas FS, Puka J, Acencio MMP, Antonangelo L, Terra RM, Damico FM, Pitta FG, Marchi E. Effectiveness and safety of iodopovidone in an experimental pleurodesis model. Clinics. 2013; 68: 557-562.

90. Marchi E, Vargas FS, Takemura RL, Acencio MMP, Antonangelo L, Teixeira LR, Light RW. Monoclonal antibodies anti-TGF beta 1 and anti-VEGF inhibit the experimental pleurodesis induced by silver nitrate. Growth Factors. 2012; 30: 304-309.

91. Teixeira LR, Vargas FS, Acencio MMP, Ribeiro SC, Sales RKB, Antonangelo L, Marchi E. Blockage of vascular endothelial growth factor (VEGF) reduces experimental pleurodesis. Lung Cancer. 2011; 74: 392-395.

92. Ribeiro SC, Vargas FS, Antonangelo L, Marchi E, Genofre EH, Acencio MM, et al. Monoclonal anti-vascular endothelial growth factor antibody reduces fluid volume in an experimental model of inflammatory pleural effusion. Respirology. 2009; 14: 1188-1193. 
93. Teixeira LR, Vargas FS, Acencio MM, Bumlai RU, Antonangelo L, Marchi E. Experimental pleurodesis induced by antibiotics (macrolides or quinolones). Clinics. 2006; 61: 559-564.

94. Marchi E, Vargas FS, Acencio MMP, Antonangelo L, Teixeira LR, Genofre $\mathrm{EH}$, Light RW. Talc and silver nitrate induce systemic inflammatory effects during the acute phase of experimental pleurodesis in rabbits. Chest. 2004; 125: 2268-2277.

95. Vargas FS, Teixeira LR, Antonangelo L, Vaz MA, Carmo AO, Marchi E, Light RW. Experimental pleurodesis in rabbits induced by silver nitrate or talc: 1-year follow-up. Chest. 2001; 119: 1516-1520.

96. Acencio MMP, Puka J, Marchi E, Antonangelo L, Terra RM, Vargas FS, Capelozzi VL, Teixeira LR. A modified experimental model of malignant pleural disease induced by lung Lewis carcinoma (LLC) cells. J Transl Med. 2015; 13: 1-8.

97. Tamiya M, Tamiya A, Yasue T, Nakao K, Omachi N, Shiroyama T, Tani E, Hamaguchi M, Morishita N, Suzuki H, Okamoto N, Okishio K, Kawaguchi T, Atagi S, Hirashima T. Vascular Endothelial Growth Factor in Plasma and Pleural Effusion Is a Biomarker for Outcome After Bevacizumab plus Carboplatin-Paclitaxel Treatment for Non-small Cell Lung Cancer with Malignant Pleural Effusion. Anticancer Res. 2016; 36: 2939-2944.

98. Dvorak HF. Vascular permeability factor/vascular endothelial growth factor: a critical cytokine in tumor angiogenesis and a potential target for diagnosis and therapy. Journ J Clin Oncol. 2002; 20: 4368-4380.

99. Tamiya M, Tamiya A, Yamadori T, Nakao K, Asami K, Yasue T, Otsuka T, Shiroyama T, Morishita N, Suzuki H, Okamoto N, Okishio K, Kawaguchi T, Atagi S, Kawase I and Hirashima T. Phase 2 study of bevacizumab with carboplatin-paclitaxel for non-small cell lung cancer with malignant pleural effusion. Med Oncol. 2013; 30: 676.

100. Johnson BE, Kabbinavar F, Fehrenbacher L, Hainsworth J, Kasubhai S, Kressel B, Lin CY, Marsland T, Patel T, Polikoff J, Rubin M, White L, Yang $\mathrm{JCH}$, Bowden C e Miller V. ATLAS: Randomized, Double-Blind, PlaceboControlled, Phase IIIB Trial Comparing Bevacizumab Therapy With or Without Erlotinib, After Completion of Chemotherapy, With Bevacizumab for First-Line Treatment of Advanced Non-Small-Cell Lung Cancer. J Clin Oncol. 2013; 31: 3926-3934.

101. Larsen JE, Minna JD. Molecular Biology of Lung Cancer: Clinical Implications. Clin Chest Med. 2011; 32: 703-740. 
APÊNDICE 


\title{
Apêndice
}

\section{A modified experimental model of malignant pleural disease induced by lung Lewis carcinoma (LLC) cells}

\author{
Milena Marques Pagliarelli Acencio ${ }^{1}$, Juliana Puka', Evaldo Marchi ${ }^{1,2}$, Leila Antonangelo ${ }^{1,3}$,
} Ricardo Mingarini Terra ${ }^{4}$, Francisco Suso Vargas' ${ }^{1}$, Vera Luiza Capelozzi ${ }^{1}$ and Lisete Ribeiro Teixeira ${ }^{1 *}$

\begin{abstract}
Background: Malignant pleural effusion resulting mainly from pleural metastases of lung adenocarcinoma has clinical relevance, being a sign of poor prognosis and low life expectancy. Experimental models can mimic the human condition, contributing to advances in current understanding of the mechanisms patients' pleural fluid accumulation and possible therapeutic strategies. The objective of this study is to evaluate the role of different concentrations of Lewis lung carcinoma cells (LLC cells) at the time of induction of experimental MPE and the main effects on survival of animals.

Methods: C57BL/6 mice received intrapleural injection of $0.1,0.5$ or $1.5 \times 10^{5} \mathrm{LLC}$ cells and survival curve, biochemical and pathological analyses of pleural fluid and tissue were analyzed.

Results: Evaluation of weight loss, mobility and survival showed that animals that received $0.5 \times 10^{5}$ cells maintained more stable condition up to day 14 and a gain of 6 days survival over mice that received the highest concentration.

Conclusion: This study may allow a better understanding the mechanisms involved in the development of malignant pleural effusion and it may be promising in evaluating therapy to avoid recurrence, as the best time to indicate pleurodesis or target therapies.
\end{abstract}

Keywords: Lewis lung carcinoma, Malignant pleural effusion, Lung cancer

\section{Background}

Malignant pleural effusion (MPE) resulting from pleural metastasis of lung adenocarcinoma is a common clinical problem with severe implications, since it is a debilitating condition associated with high morbidity, poor prognosis and low life expectancy (3-15 months) [1-6]. Approximately $15 \%$ of lung cancer patients present pleural effusion at the time of diagnosis and half of them develop pleural effusion at disease advanced stages [1-5].

Current therapeutic options for MPE are limited to treatment of the primary tumor and pleural cavity drainage with or without pleurodesis, practices that can cause

"Correspondence: lisetepneumo@yahoo.com.br

${ }^{1}$ Pleura Laboratory, Pulmonary Division, Heart Institute (InCor), University

of Sao Paulo Medical School, Rua Dr. Eneas de Carvalho Aguiar, 44,

Cerqueira César, Säo Paulo Zip coder 05403-000, Brazil

Full list of author information is available at the end of the article pain and discomfort, carry risks of adverse effects, and do not benefit a substantial portion of patients [7-14].

For a long time, the pathogenesis of MPE has been poorly understood, but substantial progress has been made over the past few years facilitated by the use of animal models [15-19]. These models can mimic the human condition, contributing to advances in current understanding of the mechanisms patients' pleural fluid accumulation and possible therapeutic strategies [19-27].

The objective of this study is to evaluate the role of different concentrations of Lewis lung carcinoma cells (LLC cells) at the time of induction of experimental MPE and the main effects on survival of animals.

The increase of survival time and delaying systemic effects, a better and more detailed understanding of the mechanisms involved in the development of malignant pleural effusion can be gained. This would facilitate 
future studies making a better assessment of therapeutic response possible.

\section{Methods}

\section{Cell culture}

The Lewis lung carcinoma (LLC) cells were purchased from the American Type Culture Collection (Manassas, VA, USA) and were cultured at $37{ }^{\circ} \mathrm{C}$ in $5 \% \mathrm{CO}_{2}{ }^{-} 95 \%$ air using Dulbecco's modiWed Eagle's medium (DMEM) with $10 \%$ fetal bovine serum.

\section{Animal model}

One hundred and thirty male (6-8 weeks old) C57BL/6 mice (obtained from Laboratory Animal Center of Faculty of Medicine of University of São Paulo) were acclimatized for 1 week. All animal care and experimental procedures were approved by the University Ethics Committee (CEUA/CAPPesq).

Animals were anesthetized using $35 \mathrm{mg} / \mathrm{kg}$ of ketamine hydrochloride (Cristalia, Brazil) and $5 \mathrm{mg} / \mathrm{kg}$ of xylazine hydrochloride (Bayer, Brazil) prior to all procedures. The right chest was cleansed with an alcohol solution (Rioquimica, Sao Paulo, Brazil). The intrapleural injection was performed using a 23-gauge needle attached to a $1-\mathrm{mL}$ syringe containing the solution of cells which was introduced into the chest cavity at $1 \mathrm{~cm}$ lateral to the right parasternal line. The plunger of the syringe was removed and the needle was slowly advanced until it reached the pleural space, where the sub-atmospheric intrapleural pressure allowed the fluid to enter the pleural cavity spontaneously. The mice were monitored after the procedure until they were completely recovered.

Three groups of 40 mice each received concentrations of LLC at $0.1,0.5$ or $1.5 \times 10^{5}$ cells intrapleurally. These animals were subdivided into two groups; the first (30 animals per concentration of cells) were euthanized after 7,14 or 21 days and the second group (10 animals per concentration of cells) were evaluated for survival expectancy. A control group of 10 animals received saline solution intrapleurally.

Mice were killed according to the study calendar; the abdominal wall was opened and the viscera were retracted to visualize the diaphragm. Pleural fluid (PF), when present, was gently aspirated and the volume was measured and placed in tubes for evaluation.

\section{Weight, mobility and survival analysis}

After the procedure all animals were observed until complete recovery and they were evaluated for weight (g) and mobility by a subjective score of $0-3(0=$ normal and $3=$ stillness). We monitored mortality daily for all groups to obtain the survival curve.

\section{Histological assays}

After 7,14 or 21 days the thorax was dissected and removed en bloc. A small amount of $10 \%$ formaldehyde was injected through the trachea to keep the lungs expanded and the entire block plus kidney, liver and spleen were placed in $10 \%$ formaldehyde. After at least $24 \mathrm{~h}$ in formaldehyde, the pleural cavities were opened and exposed through longitudinal chest incisions at the mid-clavicular lines. Tissues were fixed in $10 \%$ neutrally buffered formalin for $24 \mathrm{~h}$ and $70 \%$ ethanol for 3 days. In sequence, they were embedded in paraffin, and $5-\mu \mathrm{m}$ thick slices were cut, mounted on slides and stained with hematoxylin and eosin $(\mathrm{H} \& \mathrm{E})$.

\section{Blochemical assays}

Lactic dehydrogenase (kinetic UV method) and total protein (Biuret method) were quantified in the pleural fluid using commercial kits (Wienner, Argentina) and analyzed in semi-automatic device.

\section{Cytology}

Pleural fluid cells were counted in a Neubauer chamber. After centrifugation, cells cytospin were prepared and the slides were air dried and stained using Leishman staining to determine the cell differential.

\section{Statistics}

The results are presented as mean and standard deviation. Comparisons among the groups were performed using ANOVA followed by the comparison multiple test. For the survival time, Kaplan-Meier curves were established for each group and the times were compared using a $\log$-rank test. A value of $p<0.05$ was considered significant. SigmaStat 3.1 (Systat, CA, USA) was used for the analyses.

\section{Results}

After the intrapleural injection of different concentrations of LLC cells, all animals presented tumor implantation with development of malignant pleural effusion showing differences among them according to the time and stage of disease. Free-floating bilateral pleural effusions and pleural tumor foci were clearly visible through the diaphragm. Interestingly, in the majority of mice that received $0.1 \times 10^{5}$ cells, minimal or absence of pleural fluid and few tumoral implants were observed until the 14th day.

Evaluation of body weight and mobility showed that mice in the group of $1.5 \times 10^{5}$ cells had reduced weight and mobility after 14 days while in the other groups, these differences were noted only after 21 days $(p<0.05$ ).

In the survival analysis, pleural carcinomatosis was lethal in all groups. In the group of highest concentration 
$\left(1.5 \times 10^{5}\right.$ cells) the mortality was $100 \%$ on the 19 th day while the groups of 0.5 and $0.1 \times 10^{5}$ cells showed maximum survival of 25 and 27 days, respectively (Fig. 1).

Pleural fluid volume was measured at 7, 14 and 21 days. The volume was increasing significantly according to the time and LLC cells concentration ( $\mathrm{p}<0.05)$; group $0.1 \times 10^{5}$ cells showed pleural effusion only after 14 days in few animals and for group $1.5 \times 10^{5}$ cells, evaluation was only possible up to the 14th day (all animals died by day 19) (Fig. 2). In the control group (saline intrapleurally), we do not observe pleural fluid accumulation.

The macroscopic aspect of most pleural fluid was hemorrhagic (but did not coagulate). By harvesting mice at serial time points we observed that malignant pleural effusion was formed gradually and that their red blood cell content increased stepwise.

Total cells count was progressively increasing up to 14 day being more evident in highest concentrations ( 0.5 and $1.5 \times 10^{5}$ ) (Fig. 2). MPE differential cells revealed a mixed inflammatory infiltrate interspersed with malignant cells. The inflammatory cell population consisted of mononuclear cells (60\%), lymphocytes (20\%) and neutrophils (10\%). Mesothelial cells accounted for less than $1 \%$ of cells.

Pleural fluid LDH levels were higher proportional to the time $(\mathrm{p}<0.001)$ and concentration $(\mathrm{p}<0.05)$ of injected LLC cells. Protein levels were similar among groups excepted at 7 days in $0.1 \times 10^{5}$ LLC cells group (Fig. 2).

Tumor implants in the pleura were evident earlier in groups that received a larger concentration of LLC cells. The presence of loose tumors in the pleural space was also noted in all study groups at 7 days except in the group with the lowest concentration of LLC cells. Larger pleural tumors formed bridges between the lung parenchyma and the thoracic cage and infiltrated neighboring anatomic structures, including the chest wall, mediastinum, and diaphragm (Fig. 3). In group $1.5 \times 10^{5} \mathrm{LLC}$ cells numerous tumor implants were observed in the visceral and parietal pleura after 7 days of exposure. In group $0.5 \times 10^{5}$ cells LLC we noted few dispersed implants at day 7 with more pronounced implantation after 14 days. In animals receiving lower cells concentration, tumor implants were only observed after 14 days (Fig. 3 ).

Neoplastic infiltration of lung parenchyma was observed only in few animals with no correlation with the dose or exposure time. However, lung parenchymal inflammation was unremarkable in all groups over all check points; there was no inflammatory focus at concentration $0.1 \times 10^{5}$ cells on day 7 .

Histological evaluation of pericardium and heart muscle showed tumor implants in the first 7 days after injection of $1.5 \times 10^{5}$ LLC cells with increased progression over time. In the other concentrations few tumor implants were observed during the study (Fig. 4).

In the liver, micro foci of steatosis were observed after 14 days at concentrations 1.5 and $0.5 \times 10^{5}$ LLC cells. No relevant histological changes were observed in the renal evaluation. Hyperplasia of the white pulp of the spleen was observed at all evaluation time points with greater evidence at concentrations of 1.5 and $0.5 \times 10^{5}$ LLC cells (Fig. 4).

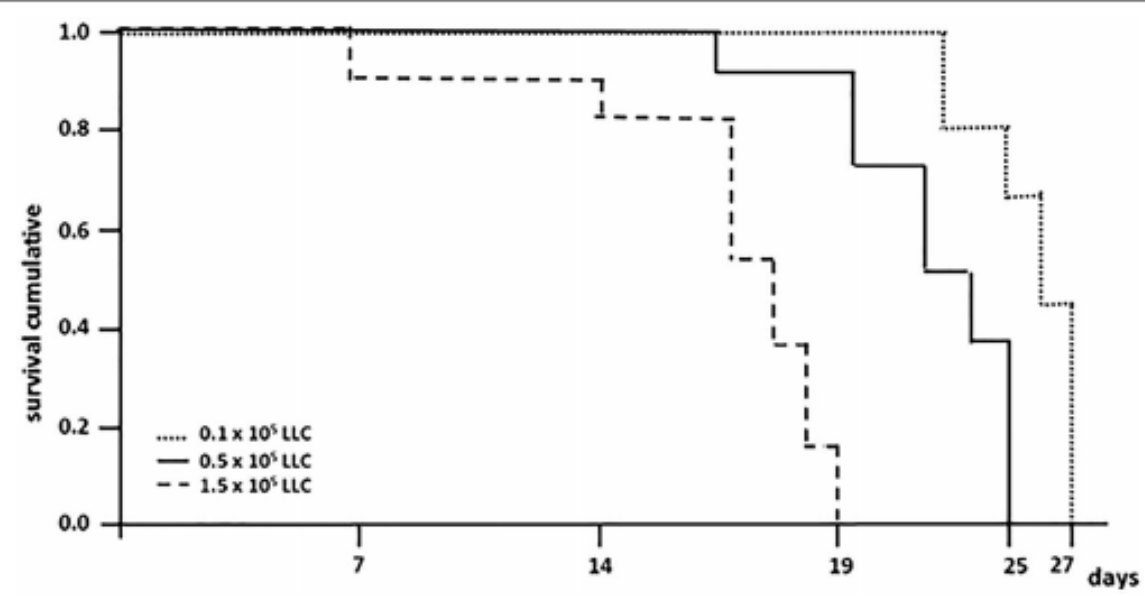

Flg. 1 Mice survival time evaluation with intrapleural injection of $0.1,0.5$ or $1.5 \times 10^{5}$ LLC cells 


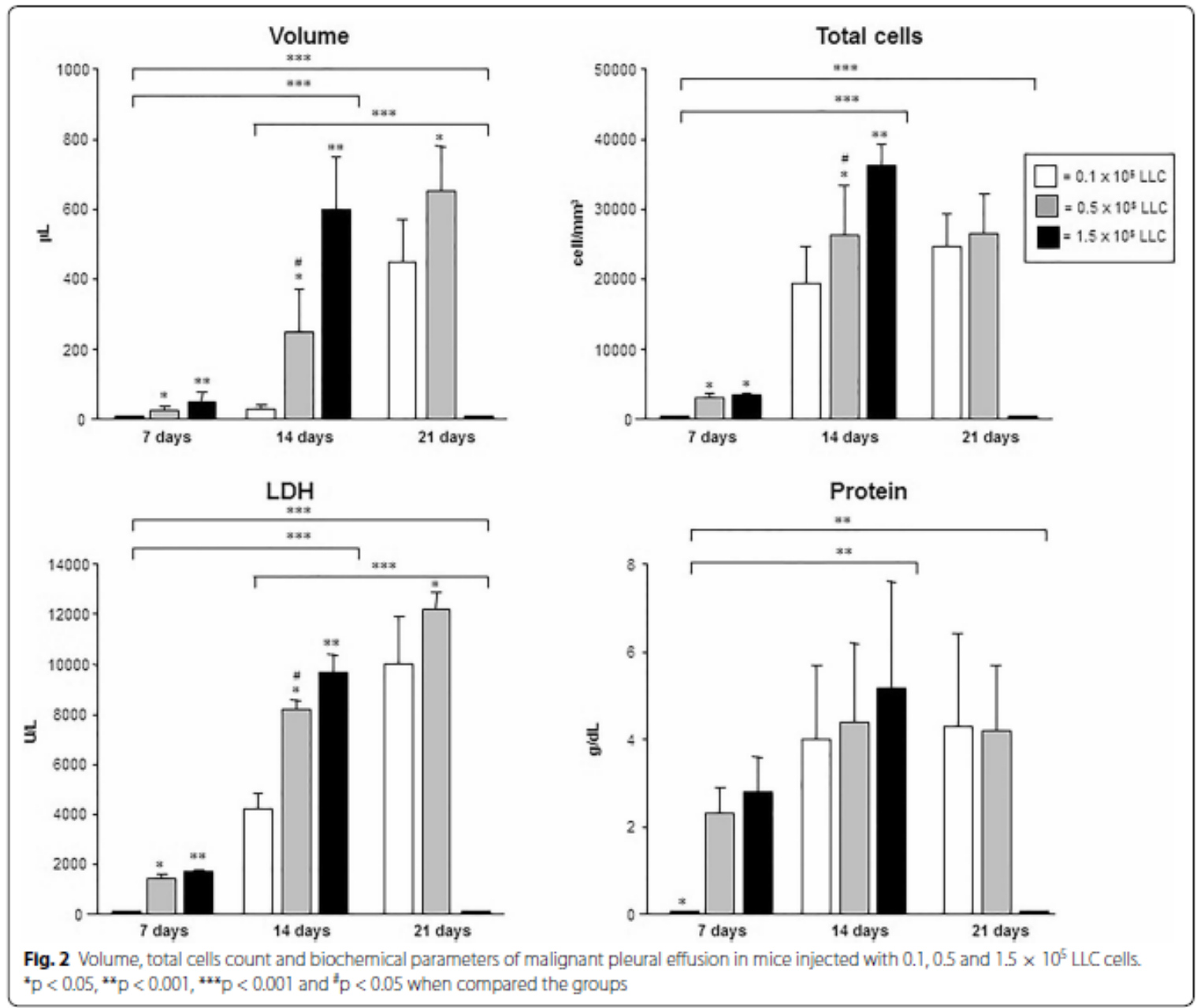

\section{Discussion}

This study evaluated the survival curve, laboratorial and histological aspects in an experimental murine model of MPE using different concentrations of LLC cells. Evaluation of weight loss, mobility and survival at the higher concentrations ( 0.5 and $1.5 \times 10^{5}$ cells) showed that animals that received $0.5 \times 10^{5}$ cells maintained more stable condition up to day 14. The survival curve shows a gain of 6 days survival over mice that received the highest concentration. We found MPE from day 7 and several tumor foci in both the visceral and parietal pleura in the higher concentration groups. However, minimal or no volume of pleural fluid and few implants were observed in the smaller LLC concentration group at day 14.

Lung cancer is the most common cause of worldwide cancer-related mortality, leading to over a million deaths each year and adenocarcinoma is its most common histological type [1-5]. In this scenario, MPE resulting mainly from pleural metastases of lung adenocarcinoma has clinical relevance $[4,14]$. Its emergence is a sign of poor prognosis and low life expectancy, as it indicates that the tumor is incurable by surgery [4]. Dyspnea occurs in more than $50 \%$ of patients, severely compromising their quality of life. In spite of the therapeutic advances since the platinum-based schemes, lung cancer treatment does not significantly impact the disease evolution of most patients [4-14].

New therapeutic strategies are needed to improve local control and the spread of cancer, but this requires greater insight into the pathogenesis of this disease.

Until some time ago, there were a few experimental models for the study of pleural neoplasms, most using 

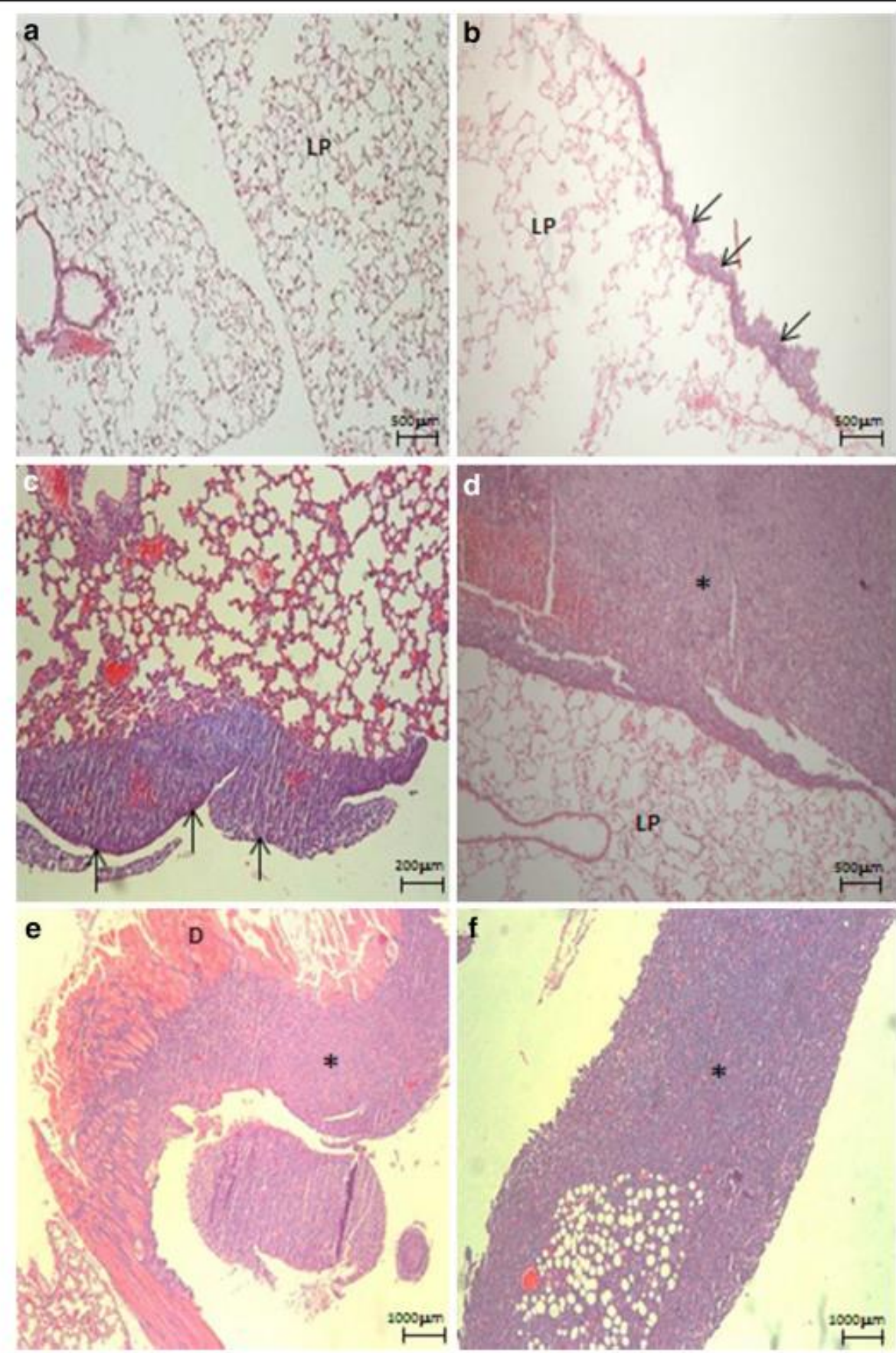

Fig. 3 Histology of pleura, lung parenchyma and diaphragm of mice that received intrapleural injection of LLC cells. a Pleura and lung parenchyma after 7 days of $0.1 \times 10^{5}$ cells; b tumor implantation in visceral pleura after 7 days of $0.5 \times 10^{5}$ cells (arrows); $\mathbf{c}$ tumor implants in visceral pleura after 14 days of $0.5 \times 10^{5}$ cells (arrows); d tumor implants in visceral pleura after 14 days of $1.5 \times 10^{5}$ cells (asterisk); e massive tumor invading diaphragm after 14 days of $1.5 \times 10^{5}$ cells (asterisk); f tumor mass observed after 21 days of LLC cells (asterisk). Hernatoxylin \& easin staining. LP lung parenchyma, asterisk tumor, arrows tumor implants 

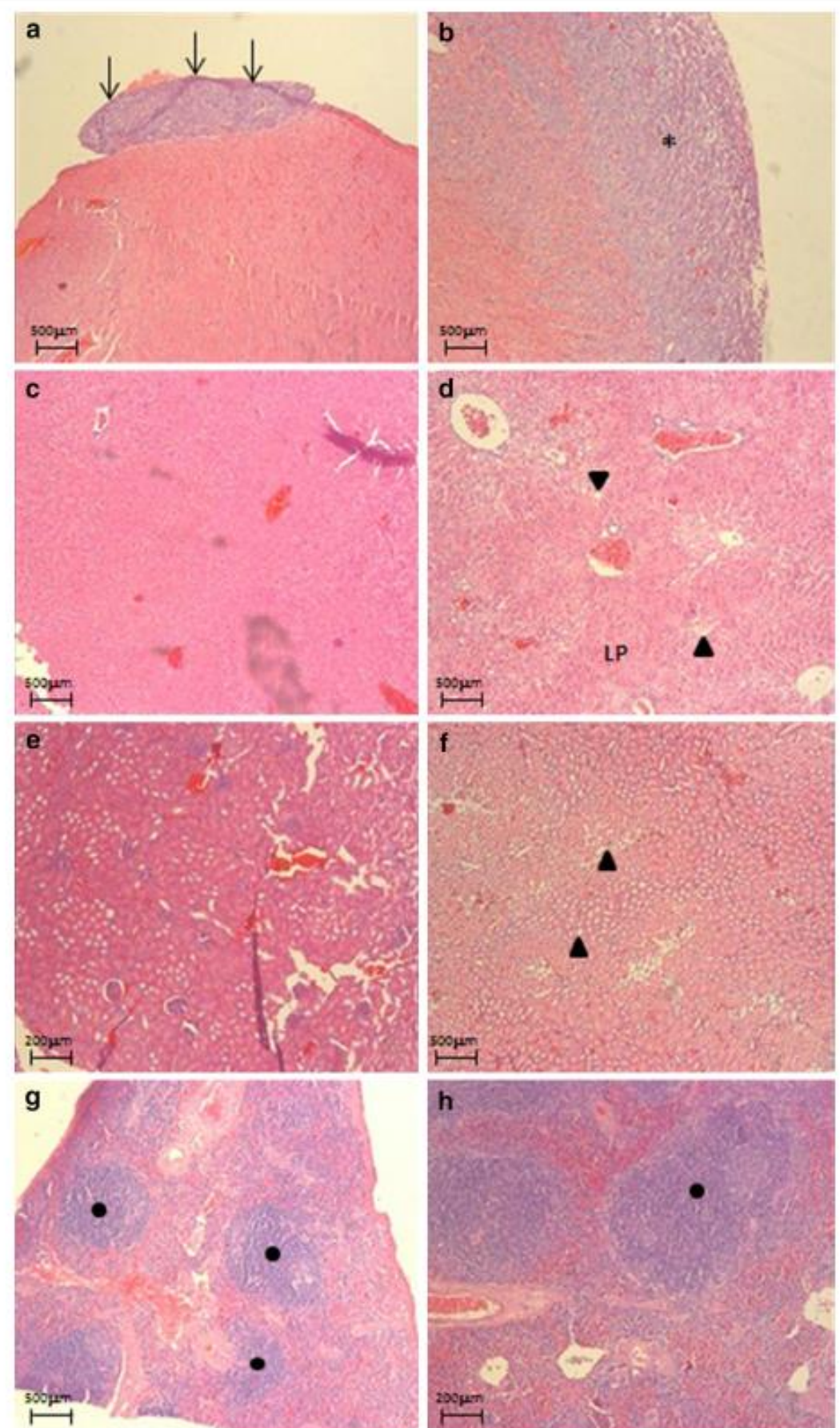

Fig. 4 Histology of organs of mice that received intrapleural injection of UC cells. a Tumor implants in pericardium after 7 days of $1.5 \times 10^{5}$ cells (arrows); b neoplastic cells infiltrating the myocardium (asterisk) after 14 days of $1.5 \times 10^{5}$ cells; c normal liver after 7 days of $0.5 \times 10^{5}$ cells; d liver with steatosis (filled triongle) after 14 days of LC cells; e, f kidney with tubular steatosis (filled triangle) and without neoplastic cells after 7 or 14 days. g. h Reactive spleen (filled circle) without neoplastic cells after 7 and 14 days. Hernatoxylin \& eosin staining 
animals with normal pleura to test palliative therapies such as pleurodesis [24-26]. In the absence of malignant disease assessment of the natural evolution of the cancer, neoplasia-host interactions, or possible immune response is obviously not possible $[25,26]$. Therefore, some researchers have developed novel models of MPE with a more accurate mimicry of the human condition. These models have contributed to significant advances in the understanding of fluid exudation induced by cancer metastasis to the pleura [19]. They have yielded novel insights into the pathogenesis of adenocarcinoma as well as into the mechanisms of intrapleural malignant effusion accumulation, tumor dissemination and possible therapeutic targets to block pleural effusion [19].

In 2006, Stathopoulos et al. developed and characterized a novel mouse model of malignant pleural effusion by injecting $1.5 \times 10^{5}$ Lewis lung carcinoma (LLC) cells directly into the pleural space of immunocompetent C57BL/6 mice [20].

LLC cells are derived from a spontaneously arising lung adenocarcinoma in C57BL/6 mice. These cells are characterized by short doubling times in vitro and in vivo and aggressive biological behavior [19-21]. The cells can be propagated in $\mathrm{C} 57 \mathrm{BL} / 6$ mice, giving rise to lung adenocarcinoma and human-like MPEs producing exudates with high protein and LDH content, as well as high levels of VEGF and monocyte chemoattractant chemokines [19-21].

This LLC-C57BL/6 model is highly reproducible since it uses immunocompetent animals, closely resembles human MPEs and provides reproducible end-points. It can be used to study the influence of specific host and tumor factors on the pathogenesis of MPE and to evaluate new therapeutic strategies. In addition, all of the animals get MPE and intense tumor foci on visceral and parietal pleura in 14 days [20].

Nevertheless, the maximum survival of the animals in the Stathopoulos et al. model was 17 days, an unfavorable point, since survival is an important outcome measure and so few days may not be sufficient to assess outcome $[20,21]$.

Also, in these studies authors observed a correlation between the number of pleural tumor foci and the volume of pleural fluid. They discussed the importance of the host immune response, which is partly responsible for the malignant pleural fluid accumulation [20-23]. These issues are directly relevant in studies to investigate the pathogenesis and treatment of MPEs. The pleural fluid accumulation remains the primary end-point in this model; however, determinations relevant to these bioprocesses may serve as additional end-points in animal models of MPE.
The cellular and biochemical profile of pleural effusion resulting from induced lung adenocarcinoma mimics human MPE, which is high in protein and LDH levels and nucleated cells with neoplastic cells permeating a rich inflammatory infiltrates. Implantation and growth of pleural tumors triggers a host inflammatory response characterized by a mixed inflammatory cell influx into the pleural fluid, angiogenesis, and vascular hyperpermeability, all fundamental steps in MPE pathogenesis [19-21].

We found tumors implants in the visceral and parietal pleura in all groups studied and they were proportional to the concentration and time from instillation of LLC cells. Metastasis to the pericardium was more evident at the highest concentration. Inflammatory lung parenchyma cells and histological changes in the liver, kidneys and spleen were observed in all groups with the highest scores in groups 0.5 and $1.5 \times 10^{5}$ cells.

Furthermore, induction of MPE in animals leads to cachexia, which can serve as a surrogate marker of tumor progression. In our study mice that received $0.5 \times 10^{5}$ LLC cells maintained more stable condition through day 14 compared to mice that received the highest concentration, resulting in a longer survival.

One limitation of our study was related to the assessment of animals at 21 days due to the fact that most died before analysis could be done.

\section{Conclusions}

Our results show that using a dose of $0.5 \times 10^{5}$ cells LLC is possible not only to induce the disease as well as to better evaluate survival time, without prejudice to the model proposed initially by Stathophoulous and colleagues [20]. With this cell concentration we obtained a model that allowed for monitoring longer survival, the study of pleuropulmonary changes and to assess local and distant metastases, opening a fantastic range of study opportunities.

This study may allow a better understanding the mechanisms involved in the development of malignant pleural effusion. In addition, it may be promising in evaluating therapy responses, the best time to indicate pleurodesis, as well as, to consider the response to immunomodulatory therapies, costs and benefits of targeted therapies.

\section{Authors' contributions}

LRT contributed to the conception and design of the study, acquisition of the data, statistical analysis and interpretation of the data, writing and final review of the manuscript. MMPA: responsible to development of methodology and execution of experimental and laboratorial techniques, interpretation of the data and writing the manuscript. EM:contributed to the conception and design of the study, critical revision of the manuscript for important intellectual content. LA: cytological analysis and critical revision of the manuscript for important intellectual content. JP. execution of experimental techniques; revision of manuscript and references. RMT: statistical analysis and revision of manuscript. FSV. critical revision of the manuscript for important intellectual 
content. VC- pathological analysis and critical revision of the manuscript for important intellectual content. All authors read and approved the final manuscript.

\section{Author details}

'Pleura Laboratory, Pulmonary Division, Heart Institute (InCor), University of Sao Paulo Medical School, Rua Dr. Eneas de Carval ho Aguiar, 44, Cerqueira César, São Paulo Zip code: 05403-000, Brazil. ${ }^{2}$ Medical College of Jundiai, São Paulo, Brazil. ${ }^{3}$ Clinical Laboratory and LIM 03, Department of Pathology, Hospital das Cinicas, University of Sao Paulo Medical School, Sāo Paulo, Brazil ${ }^{4}$ Division of Thoracic Surgery, Heart Institute (InCor), University of São Paulo Madical School, Säo Paulo, Brazil

\section{Acknowledgements}

We thank biologists Carlos SR Silva and Vanessa A Alvarenga for their assis tance with animal care and sample preparation and storage. Finarcial support: Research Support Foundation of the State of São Paulo (FAPESP \# 2013/111489) and the National Research Council (CNPq), Brazil.

\section{Compliance with ethical guidelines}

\section{Competing interests}

The authors declare that they have no competing interests.

\section{Received: 21 May 2015 Accepted: 7 September 2015}

Published online: 15 September 2015

\section{References}

1. Alberg A, Samet JM. Epidemiology of lung cancer. Chest. 2003:123:21-49.

2. Sugiura S, Ando Y, Minami H, Ando M, Sakai S, Shimokata K. Prognostic value of pleural effusion in patients with nonsmall cell lung cancer. Clin Cancer Res. 1997;3:47-50.

3. Rodriguez-Panadero F, Borderas Naranjo F, Lopez-Mejias I Pleural meta static tumours and effusions: frequency and pathogenic mechanisms in post-mortern series. Eur Respir J. 1989;2-366-9.

4. Morgensztern D, Waqar S, Subramanian J, Trinkaus K, Govindan R Prognostic impact of malignant pleural effusion at presentation in patients with metastatic non-small-cell lung cancer. J Thorac Oncol. 2012:7:1485-9.

5. Light RW. Pleural diseases. New York: Lippincott Willians and Wilkins; 2007. p. 108-34.

6. Sahn SA. Malignant pleural effusion. Eur Respir Mon. 2002;22:177-88.

7. Antony VB, Loddenkemper R, Astoul P, Boutin C, Goldstraw P, Hott J, Rodriguez-Panadero F, Sahn SA. Management of malignant pleural effusions. Eur Respir J. 2001:18-402-19.

8. Gary-Lee YC, Light RW. Management of malignant pleural effusions Respirology. 2004;9:148-56.

9. Neragi-Miandoab S. Malignant pleural effusion, current and evolving approaches for its diagnosis and management. Lung Cancer. 2006;54:1-9.

10. Heffner JE, Klein JS. Recent advances in the diagnosis and management of malignant pleural effusions. Mayo Clin Proc 2003.83-235-50.
11. Uzbeck MH, Almeida FA, Sarkiss MG, Morice RC, Jimenez CA, Eapen GA Kennedy MP. Management of malignant pleural effusions. Adv Ther. 2010;27:334-47.

12. Roberts ME, Neville E, Berrisford AG, Antunes G, Ali NI Management of a malignant pleural effusion: British Thoracic Society pleural disease guideline 2010. Thorax. 201065-32-40.

13. Musani Al. Treatment options for malignant pleural effusion. Curr Opin Pulm Med 2009,15:380-7.

14. Felip E, Gridelli C, Baas P, Rosell R, Stahel R, Panel Members. Metastatic nonsmall-cell lung cancer: consensus on pathology and molecular tests, first-line, second-line, and third-line therapy. 1st ESMO consensus conference in lung cancer (Lugano 2010). Ann Oncol. 2011;22:1507-19.

15. Jantz MA, Antony VB. Pathophysiology of the pleura. Respiration. 2008:75:121-33.

16. English JC, Leslie KO. Pathology of the pleura. Clin Chest Med. 2006:27:157-80.

17. Antony VB. Immunological mechanisms in pleural disease. Eur Resp 1 2003-21-539-44.

18. Mutsaers SE. Mesothelial cells: their structure, function and role in serosal repair. Respirology. 2002:7:171-91.

19. Stathopoulos GT, Kalomenidis I. Animal models of malignant pleural effusion. Curr Opin Pulm Med. 2009,15:343-52

20. Stathopoulos GT, Zhu Z, Everhart MB, Kalomenidis I, Lawson WE, Bilaceroglu S, Peterson TE, Mitchell D, Yull FE, Light RW, Blackwell TS. Nuclear factor-kappaB affects turnor progression in a mouse model of malignant pleural effusion. Am J Respir Cell Mol Biol. 2006:34:142-50.

21. Psallidas I, Karabela SP, Moschos C, Sherrill TP, Kollintza A, Magkouta S, Theodoropoulou P, Roussos C, Blackwell TS, Kalomenidis I, Stathopoulos GT. Specific effects of bortezomib against experimental malignant pleura effusion: a preclinical study. Mol Cancer. 2010-95:56.

22. Stathopoulos GT. Translational advances in pleural malignancies. Respirology. 2011;16:53-63.

23. Stathopoulos GT, Kalomenidis I. Malignant pleural effusion: tumor-host interactions unleashed. Am J Respir Crit Care Med. 2012;186-487-92.

24. Guo YB, Kalomenidis I, Hawthorne M, Parman KS, Lane KB, Light RW. Pleurodesis is inhibited by anti-vascular endothelial growth factor antibody. Chest. 2005;128:1790-7.

25. Teixeira LR, Vargas FS, Acencio MM, Ribeiro SC, Sales RK, Antonangelo L, Marchi E. Blockage of vascular endothelial growth factor (VEGF) reduces experimental pleurodesis. Lung Cancer. 2011;74:392-5.

26. Ribeiro SCC, Vargas FS, Antonangelo L, Marchi E, Genofre EH, Acencio MMP, Teixeira LR Monoclonal anti-vascular endothelial growth factor antibody reduces fluid volume in an experimental model of inflammatory pleural effusion. Respirology. 2009;14:1 188-93.

27. Wang Y, Yao Y, Liu H, Ma X, Lv T, Yuan D, Xiao X, Yin J, Song Y. Itraconazole can inhibit malignant pleural effusion by suppressing lymphangiogenesis in mice Transl Lung Cancer Res. 2015:4:27-35.

\section{Submit your next manuscript to BioMed Central and take full advantage of}

- Convenient online submission

- Thorough peer review

- No space constraints or color figure charges

- Immediate publication on acceptance

- Inclusion in PubMed, CAS, Scopus and Google Scholar

- Research which is freely available for redistribution

Submit your manuscript at chom 